\title{
On the origin of life in the Zinc world. 2. Validation of the hypothesis on the photosynthesizing zinc sulfide edifices as cradles of life on Earth
}

\author{
Armen Y Mulkidjanian*1,2 and Michael Y Galperin*3
}

Address: ${ }^{1}$ School of Physics, Universität Osnabrück, D-49069 Osnabrück, Germany, ${ }^{2}$ A.N. Belozersky Institute of Physico-Chemical Biology, Moscow State University, Moscow, 119991, Russia and ${ }^{3}$ National Center for Biotechnology Information, National Library of Medicine, National Institutes of Health, Bethesda, MD 20894, USA

Email: Armen Y Mulkidjanian* - amulkid@uos.de; Michael Y Galperin* - galperin@ncbi.nlm.nih.gov

* Corresponding authors

Published: 24 August 2009

Biology Direct 2009, 4:27 doi:10.1186/1745-6/50-4-27
Received: 15 July 2009

Accepted: 24 August 2009

This article is available from: http://www.biology-direct.com/content/4/I/27

(C) 2009 Mulkidjanian and Galperin; licensee BioMed Central Ltd.

This is an Open Access article distributed under the terms of the Creative Commons Attribution License (http://creativecommons.org/licenses/by/2.0), which permits unrestricted use, distribution, and reproduction in any medium, provided the original work is properly cited.

\begin{abstract}
Background: The accompanying article (A.Y. Mulkidjanian, Biology Direct 4:26) puts forward a detailed hypothesis on the role of zinc sulfide (ZnS) in the origin of life on Earth. The hypothesis suggests that life emerged within compartmentalized, photosynthesizing $\mathrm{ZnS}$ formations of hydrothermal origin (the $\mathrm{Zn}$ world), assembled in sub-aerial settings on the surface of the primeval Earth.

Results: If life started within photosynthesizing $\mathrm{ZnS}$ compartments, it should have been able to evolve under the conditions of elevated levels of $\mathrm{Zn}^{2+}$ ions, byproducts of the $\mathrm{ZnS}$-mediated photosynthesis. Therefore, the $\mathrm{Zn}$ world hypothesis leads to a set of testable predictions regarding the specific roles of $\mathrm{Zn}^{2+}$ ions in modern organisms, particularly in RNA and protein structures related to the procession of RNA and the "evolutionarily old" cellular functions. We checked these predictions using publicly available data and obtained evidence suggesting that the development of the primeval life forms up to the stage of the Last Universal Common Ancestor proceeded in zinc-rich settings. Testing of the hypothesis has revealed the possible supportive role of manganese sulfide in the primeval photosynthesis. In addition, we demonstrate the explanatory power of the $\mathrm{Zn}$ world concept by elucidating several points that so far remained without acceptable rationalization. In particular, this concept implies a new scenario for the separation of Bacteria and Archaea and the origin of Eukarya.
\end{abstract}

Conclusion: The ability of the $\mathrm{Zn}$ world hypothesis to generate non-trivial veritable predictions and explain previously obscure items gives credence to its key postulate that the development of the first life forms started within zinc-rich formations of hydrothermal origin and was driven by solar UV irradiation. This concept implies that the geochemical conditions conducive to the origin of life may have persisted only as long as the atmospheric $\mathrm{CO}_{2}$ pressure remained above ca. 10 bar. This work envisions the first Earth biotopes as photosynthesizing and habitable areas of porous $\mathrm{ZnS}$ and $\mathrm{MnS}$ precipitates around primeval hot springs. Further work will be needed to provide details on the life within these communities and to elucidate the primordial (bio)chemical reactions.

Reviewers: This article was reviewed by Arcady Mushegian, Eugene Koonin, and Patrick Forterre. For the full reviews, please go to the Reviewers' reports section. 


\section{Background Energetic aspects of the origin of life}

The problem of origin of life on Earth (abiogenesis) remains one of the central and most intractable problems of modern biology. The current hypotheses cluster either around the "replication first" paradigm or the "metabolism first" concept, see [1-10] for consideration of the controversy between the two concepts. The "replication first" paradigm implies that formation of the first replicating entities preceded the origin of metabolism. This concept has grown from the so-called heterotrophic theory of abiogenesis that can be traced to Oparin, who had suggested that formation of complex proteinaceous complexes could proceed spontaneously under the conditions of reducing primordial atmosphere $[11,12]$. The Oparin's proposal, which was the first detailed scenario of abiogenesis, found an experimental confirmation. It has been shown later that simple building blocks, such as amino acids and carbohydrates, indeed, could build up from inorganic compounds under the conditions imitating the reduced primeval atmosphere, provided that external energy was delivered in the form of electric discharges or UV light [13-16]. The modern successors of Oparin's hypothesis are various RNA World scenarios, where the first RNA-like molecules are seen as capable both of selfreproduction and simple metabolism and thus preceding both proteins and DNA [17-33]. The "replication first" concept has been further supported by isolation and characterization of RNA enzymes (ribozymes) with different catalytic activities (see $[27,29,31,34,35]$ and references therein). In addition, oligonucleotides of up to 30-50 units could be obtained in abiogenic systems from chemically activated monomers (e.g. nucleoside 5'-phosphorimidazolides [36]) when either polynucleotide chains [36-38] or mineral surfaces [39-44] were used as polymerization templates.

Still, the heterotrophic theory of abiogenesis has encountered certain problems. Oparin's initial model implied that primordial atmosphere was reducing, dominated by methane and hydrogen gas $[11,12]$. However, according to the current views, the primordial atmosphere was more oxidized and similar to those of modern Mars and Venus, where $\mathrm{CO}_{2}$ still makes $95 \%$ of the atmosphere with $\mathrm{N}_{2}$ and $\mathrm{H}_{2}$ being present in small amounts [45-53]. In a $\mathrm{CO}_{2}^{-}$ dominated atmosphere, any primordial (bio)chemistry could not start unless $\mathrm{CO}_{2}$ was reduced to organic molecules capable of participating in pre-biological syntheses (see [16] and references therein). Straightforward attempts to achieve abiogenic syntheses of amino acids or nucleobases with $\mathrm{CO}_{2}$-dominated gas mixtures so far proved unsuccessful $[16,54]$.

The alternative "metabolism first" concept implies that emergence of the first replicators was preceded by estab- lishment of self-sustaining cycles of chemical reactions that could produce increasingly complex organic compounds (see $[10,55]$ for recent surveys). Currently, there are two detailed evolutionary scenarios representing the "metabolism first" concept. Wächtershäuser envisioned "two-dimensional" primordial metabolic cycles driven by oxidation of iron monosulfide (FeS) into iron disulfide $\left(\mathrm{FeS}_{2}\right.$, pyrite) and confined to the mineral surfaces at the sea floor [56-61]. Besides the involvement of FeS clusters in a variety of anaerobic enzymes, consideration of FeS/ $\mathrm{FeS}_{2}$ metabolism had an added benefit of accounting for the key role of sulfur in cell metabolism. Russell and coworkers [62-71], in turn, have suggested that the first metabolic cycles started inside porous chimneys of the deepsea alkaline hydrothermal vents. It has been suggested that such compartmentalized structures consisting of FeS could offer three-dimensional reaction space and provide a framework for the emergence of the first cells [64].

From the viewpoint of energetics, any hypothesis of abiogenesis has to indicate explicitly the energy source(s) that could account for the (i) formation of reduced carbon compounds and (ii) primordial polymerization reactions. Therefore, it might be useful to compare the available scenarios of abiogenesis with respect to the underlying energy mechanisms. When considering the field from this point of view, it transpires that the proponents of the "replication first" scenarios, and in particular of the RNA World concept, just do not focus on primordial energetics and leave all options open (see e.g. [16]). Instead, more emphasis is put on understanding the chemistry of the primeval syntheses and the mechanisms of information processing in primordial replicating cycles [17-33].

In contrast, proponents of the "metabolism first" concept explicitly address the energetics problem. Several papers by Wächtershäuser proposed a detailed chemical mechanism where oxidation of $\mathrm{FeS}$ to $\mathrm{FeS}_{2}$ at the sea floor was used to drive the reduction of either $\mathrm{CO}_{2}$ or $\mathrm{CO}$ [56-61]. Indeed, the free energy of the redox transition of $\mathrm{FeS}$ to $\mathrm{FeS}_{2}$, at least under some conditions, is sufficient to drive the reduction of $\mathrm{CO}_{2}$. Unfortunately, so far, all attempts to yield measurable $\mathrm{CO}_{2}$ reduction at the expense of FeS oxidation reaction under simulated "primordial" conditions have failed (see [72] and references therein). The reason for this failure, as discussed in detail by Schoonen and co-workers [72], is that for redox reactions, favorable thermodynamics alone is not sufficient. In addition, the redox potential of the electron donor has to be lower than that of the electron acceptor. To drive $\mathrm{CO}_{2}$ reduction at an appreciable rate, one needs a reducing agent with a redox potential that is lower than the redox potential of the $\mathrm{CO}_{2}$ /formate redox pair, whereas the reducing potential of the $\mathrm{FeS} / \mathrm{FeS}_{2}$ redox pair is higher than that (see Fig. 1). The reduction of $\mathrm{CO}$ by FeS is, in principle, possible and 


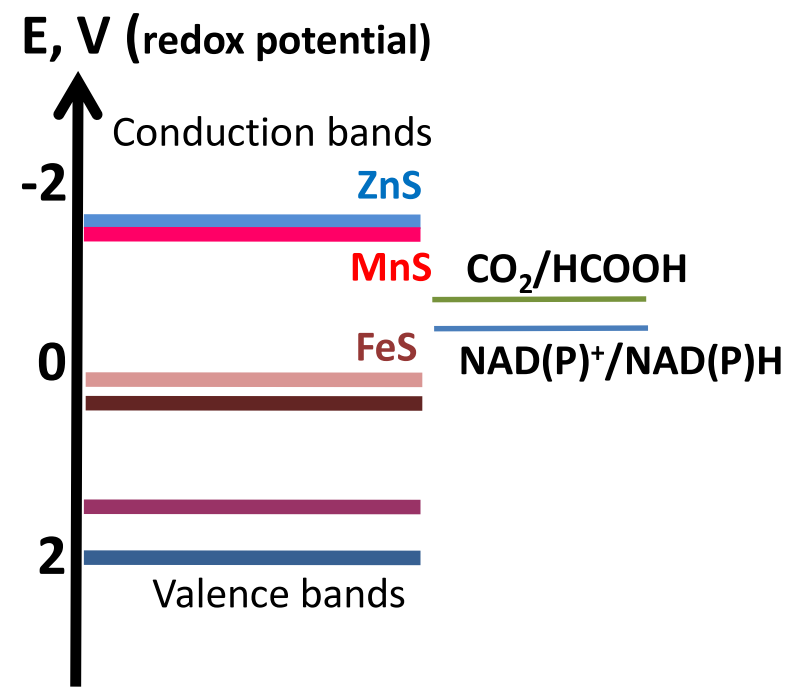

Figure I

Energy diagrams for FeS, ZnS, and MnS as potential donors of photo-excited electrons (left column) and for the biologically relevant electron acceptors (right column). The Highest Occupied Molecular Orbital (HOMO) level in the valence bands of each semiconductor is shown by a darker color than the respective Lowest Unoccupied Molecular Orbital (LUMO) level in the conduction band. The picture is based on data from references $[72,99,122,262,264]$.

has been reported, albeit at unphysiologically high temperatures [59]. However, CO is not a major atmospheric constituent and probably never was one. In the atmospheres of Mars and Venus it is present in trace amounts. Instead, as argued by Schoonen and co-workers, it could arise in primordial settings predominantly via $\mathrm{CO}_{2}$ reduction; the reduction of $\mathrm{CO}_{2}$ to $\mathrm{CO}$ is, however, even less thermodynamically favorable than the reduction of $\mathrm{CO}_{2}$ to formic acid [72]. Regarding the energetics of the primeval polymerization, Wächtershäuser speculated that ionic binding of the primordial building blocks to the FeS surfaces might facilitate their interaction and even make the synthetic reactions thermodynamically favorable [5658].

In the most recent of the scenarios put forward by Russell and co-workers, hydrogen and hydrocarbons were produced below the sea floor in the complex "serpentinization" reactions and then brought to the surface by hydrothermal fluids (see [71] and references therein). Considering the primeval polymerization reactions inside the porous, compartmentalized bodies of hydrothermal vents, these authors suggested that the $\mathrm{pH}$ gradient across the inorganic membranes of these compartments, between the alkaline hydrothermal fluids and the more acidic primordial ocean, could have served as the energy source for primeval syntheses $[70,71]$, by analogy with the transmembrane proton gradients on the membranes of modern bacterial cells. However, coupling of the transmembrane proton gradient to synthetic reactions - even in most primitive bacteria - is performed by a sophisticated enzyme machinery which seems to be evolutionarily recent [73]. Therefore it remains unclear whether and how such coupling could have occurred in the inorganic systems.

\section{The concept of the photosynthetic origin of life in the Zinc world}

A few scholars have invoked the solar radiation as a potential source of energy for the origin of life (see e.g. [74-85]). However, the idea of driving the abiogenesis directly by solar energy has not won much support, despite the Sun being by far the most powerful energy source on this planet $[16,45,86]$. The limited acceptance of this idea is probably due to several factors. First, only short-length UV quanta carry enough energy to drive primeval organic syntheses in the absence of enzymes [75]. These quanta were available on the primordial Earth: in the absence of the ozone shield, the UV component of the solar light was by 2-3 orders of magnitude stronger than now $[87,88]$. However, the same UV quanta would cause photo-dissociation of organic compounds. Therefore, most scholars considered the UV irradiation of the primordial Sun to be a hazard for the first life forms and suggested searching for life origins at the sea floor (see e.g. [87]). Second, as the energy of UV quanta could be utilized for the synthetic reactions in many different ways, there has been no consensus on the particular mechanisms involved. For example, considering the ways of $\mathrm{CO}_{2}$ fixation, Mauzerall and co-workers advocated the idea of $\mathrm{CO}_{2}$ photo-reduction to formaldehyde in the presence of dissolved ferrous hydroxide $[83,89,90]$, while other authors have argued that several naturally occurring minerals possess the properties of broad-band semiconductors and could perform abiogenic photosynthesis [81,91-93]. Further, since there are several minerals with this capacity, different authors advocated participation of different minerals in the primordial (photo)syntheses. Bard and co-workers [92,93], and, more recently, Senanayake and Idriss [94] studied the photosynthesis on the surface of $\mathrm{TiO}_{2}$ (anatase/rutile), Halmann and co-workers tested the $\mathrm{CO}_{2}$ photo-reduction by diverse minerals getting a high outcome with $\mathrm{WO}_{3}$ (wolframite) [81], while Schoonen and co-workers investigated MnS (alabandite [95]) and $\mathrm{ZnS}$ (sphalerite [96]). Last but not least, no detailed - and hence testable - scenario of light-driven abiogenesis has been suggested so far. 
The first such detailed scenario has been put forward in the accompanying article [97]. This scenario centers on the role of zinc sulfide ( $\mathrm{ZnS}$ ) as a compound that uniquely combines several traits that could be decisive for the emergence of life on Earth. Among others, the arguments included $\mathrm{ZnS}$ crystals being, on the one hand, extremely efficient photo-catalysts capable of reducing $\mathrm{CO}_{2}$ and other organic compounds with a quantum yield of up to $80 \%$ [96,98-103] and, on the other hand, common constituents of the hydrothermal vent systems typically coating those that eject fluids with the temperature in the $200-300^{\circ} \mathrm{C}$ range [104-106]. The Zinc world hypothesis suggests that, as long as the atmospheric pressure at the surface of primordial Earth remained above ca. $10 \mathrm{bar}$, porous $\mathrm{ZnS}$ formations could build up in the direct reach of UV-rich sun beams, because the temperature of liquid water in hot springs could remain above $200^{\circ} \mathrm{C}$ even in sub-aerial settings. In this "Zn world", the energy of light could be used (i) for the abiogenic, ZnSmediated photosynthesis of diverse organic compounds, (ii) for the selection of most photochemically stable of them, and (iii) for driving the surface-catalyzed polymerization reactions (see [97] for details). This ZnS-mediated photosynthesis, however, would gradually decline with the drop in atmospheric pressure below $10 \mathrm{bar}$, with the ZnS-coated surfaces persisting only around deep-sea hydrothermal vents, which continue to extrude hot, $\mathrm{Zn}$ rich fluids up to these days. The hypothesis further envisions that after the submergence of the $\mathrm{Zn}$-rich formations, sub-aerial biotopes had to cope with the impact of the generally abundant $\mathrm{Fe}^{2+}$ ions. Iron, unlike zinc, is redox-active, so that the first life forms had to undergo major changes to adjust to the iron-containing, redoxactive environment.

\section{Approaches to validation of evolutionary hypotheses}

Obviously, experimental verification of this (or any other) evolutionary scenario would prove extremely difficult, if not impossible. However, as noted by Wächtershäuser [107], validation of such concepts could be accomplished through rigorous application of Karl Popper's principles of testing scientific theories $[108,109]$. These tests include (i) consideration of the experimental evidence, (ii) the relation of the hypothesis to earlier theories in the field, (iii) falsification tests, and (iv) demonstration of the explanatory power of the hypothesis. Popper described the falsification tests as follows: "The purpose of this last kind of test is to find out how far the new consequences of the theory - whatever may be new in what it asserts - stand up to the demands of practice, whether raised by purely scientific experiments, or by practical technological applications. Here too the procedure of testing turns out to be deductive. With the help of other statements, previously accepted, certain singular statements - which we may call 'predictions' - are deduced from the theory; especially predictions that are easily testable or applica- ble. From among these statements, those are selected which are not derivable from the current theory, and more especially those which the current theory contradicts. Next we seek a decision as regards these (and other) derived statements by comparing them with the results of practical applications and experiments. If this decision is positive, that is, if the singular conclusions turn out to be acceptable, or verified, then the theory has, for the time being, passed its test: we have found no reason to discard it. But if the decision is negative, or in other words, if the conclusions have been falsified, then their falsification also falsifies the theory from which they were logically deduced" (quoted from ref. [109]). As noted by Yarus and colleagues [25], falsification tests are especially important when hypotheses cannot be experimentally proven in principle, as in the case of evolutionary scenarios. Several falsification tests are then required, since multiple confirmed predictions would enhance the plausibility of the initial idea [25].

In the accompanying article [97], the available evidence for the $\mathrm{Zn}$ world hypothesis was considered, the underlying physical and chemical mechanisms were analyzed, and the suggested scenario was compared to other concepts of the origin of life. Here, in continuation of this analysis, we formulate and check a set of predictions that follow from the $\mathrm{Zn}$ world hypothesis. We also address the explanatory power of the hypothesis and discuss how the suggested concept could eventually be experimentally tested.

\section{Results}

\section{Falsification tests of the Zinc world concept}

As noted by Popper, predictions stemming from the tested hypothesis must be logically uncoupled from the premises on which the hypothesis had been based [109]. The $\mathrm{Zn}$ world hypothesis is based on the three key premises, namely (i) the experimentally demonstrated ability of ZnS crystals and nanoparticles to photoreduce $\mathrm{CO}_{2}$ with a high quantum yield $[96,99-103,110]$, (ii) the need of metal-rich hydrothermal settings for the emergence of first organisms $[45,47,62,63,65-67,111-114]$ and the frequent coating of such settings by ZnS [104,115117], and (iii) the unique photostablity of polynucleotides that could imply their emergence in the presence of UV light as a selective factor [33,78,118-121]. Since all these premises are either physico-chemical or geological, it seemed worthwhile to focus here on the biological predictions stemming from this hypothesis. A specific trait of the $\mathrm{Zn}$ world would be the constantly elevated concentrations of $\mathrm{Zn}^{2+}$ ions. Indeed, upon reduction of $\mathrm{CO}_{2}$ by photo-excited electrons, the negative charge of these electrons is compensated by protons coming from the water $[99,122]$, according to the equation:

$$
\mathrm{ZnS} *+\mathrm{CO}_{2}+2 \mathrm{H}^{+} \rightarrow \mathrm{HCOOH}+\mathrm{Zn}^{2+}+\mathrm{S}
$$


where $\mathrm{ZnS}^{*}$ is the photo-excited state of a $\mathrm{ZnS}$ crystal, see Fig. 1 . The resulting accumulation of positive charges in the illuminated $\mathrm{ZnS}$ crystals leads to their disruption and to the release of $\mathrm{Zn}^{2+}$ ions, i.e. photo-corrosion. Photocorrosion cannot be completely prevented even by applying efficient electron donors (so-called hole scavengers, see the accompanying article [97] for details and references). It remains the main obstacle in the practical applications of $\mathrm{ZnS}$ in photoelectric devices, so that the less photo-corrosive $\mathrm{TiO}_{2}$ is routinely used $[122,123]$. A similar photo-corrosion should have taken place within the primeval illuminated ZnS compartments and caused their enrichment in $\mathrm{Zn}^{2+}$ ions. An environment with continuously elevated $\mathrm{Zn}^{2+}$ content is geochemically unusual. Generally, $\mathrm{Zn}^{2+}$ ions form poorly soluble salts with such widespread anions as phosphate, carbonate and sulfide, which is why the concentration of free $\mathrm{Zn}^{2+}$ in modern seawater is less than $2 \mathrm{nM}$ [104]. The concentration of $\mathrm{Zn}^{2+}$ ions in primordial anoxic waters should have been lower than now because of the poor solubility of $\mathrm{ZnS}$, the predominant $\mathrm{Zn}^{2+}$ source in the ancient ocean [124]. The available estimates of $\mathrm{Zn}^{2+}$ content in primordial waters are in the range of $10^{-15}-10^{-12} \mathrm{M}$ [124-126].

Hence, if we could find evidence of the emergence of life in $\mathrm{Zn}^{2+}$-rich habitats, the $\mathrm{Zn}$ world hypothesis could be considered confirmed in its key postulate. Indeed, because the $\mathrm{Zn}^{2+}$ ions should be continuously removed by precipitation, an elevated $\mathrm{Zn}^{2+}$ content would be expected to persist only at the continuously photosynthesizing $\mathrm{ZnS}$ surfaces, i.e. both the $\mathrm{ZnS}$ surfaces and photosynthesis (as a sink for electrons) are required. Thus, any evidence of the origin of life in a primeval $\mathrm{Zn}^{2+}$-rich milieu is, at the same time, evidence of ZnS-mediated abiogenic photosynthesis at the primordial Earth. Such evidence could be obtained by examining properties of modern prokaryotic and eukaryotic cells: those RNA and protein molecules that stem from the $\mathrm{Zn}$ world could retain certain traits from their emergence in $\mathrm{Zn}^{2+}$-rich settings owing to the principle of chemistry conservation. As discussed in more detail elsewhere [8], this principle, which is implicitly acknowledged by natural scientists, entails that the organismal chemistry can retain information about ancient environmental conditions (see e.g. [45]). Apparently, post-modification of metabolic pathways in response to environmental changes is often either not possible or evolutionarily less probable than simply maintaining the "ancient" intrinsic chemical milieu. For example, the cell cytoplasm is highly reduced even in those organisms that inhabit oxygenated environments. The reduced state of the cytoplasm indicates that the first cells have evolved and the principal biochemical pathways have been established - before the atmosphere became oxygenated (which was due to the activity of cyanobacteria at $2-2.5$ Ga [127]). The principle of chemistry conservation can be applied to reconstruction of primordial environmental conditions even in those cases when no reliable geological evidence is available.

The $\mathrm{Zn}$ world concept suggests that the environment that housed the first life forms was enriched in $\mathrm{Zn}^{2+}$ ions. Then the $\mathrm{Zn}^{2+}$ ions, released upon photosynthesis, could interact with the polymers at the $\mathrm{ZnS}$ surface. The latter interaction could be thermodynamically favorable since the polymer molecule could potentially provide several coordinating bonds for a $\mathrm{Zn}^{2+}$ ion (which can form up to 6 of them [128]). However, to use all these bonding modalities, the $\mathrm{Zn}^{2+}$ ion had either to induce folding of the polymer around itself (see [129]) or to bind several polymer molecules together. Those RNA and protein molecules that succeeded in trapping $\mathrm{Zn}^{2+}$ ions, in turn, could get selective advantage either as more stable or as catalytically active ones. These $\mathrm{Zn}$-containing polymers would then be likely preserved in the course of evolution and could show up in the modern cells.

Based on these arguments, we have made a set of specific predictions related to the occurrence of $\mathrm{Zn}$ in modern organisms. In the subsequent sections, we test these predictions one by one. In order to avoid potential biases, we relied, wherever possible, on data extracted from the published literature and the publicly available databases. This testing turned out to be fairly complicated. $\mathrm{Zn}^{2+}$ ions are spectroscopically elusive: unlike other biologically-relevant transition metals, such as $\mathrm{Fe}, \mathrm{Cu}$, and $\mathrm{Mn}$, zinc has no characteristic spectral signatures either in optical (UV-visible) or in EPR spectra (see [130] and references therein). Therefore, analysis of the Zn content of biopolymers cannot rely on spectroscopy, which is, generally, the method of choice in bioinorganic chemistry. Instead, presence of a bound $\mathrm{Zn}^{2+}$ ion in a biopolymer has to be revealed either by methods of analytical chemistry (see e.g. $[131,132])$, or from structural data, or from functional measurements, e.g. of the catalytic activity in the presence of different metal ions (see $[133,134]$ and references therein), or by bioinformatics approaches [135].

We would like to emphasize that the $\mathrm{Zn}$ world concept contrasts a variety of models that center around the role of iron in the emergence of life, either as $\mathrm{Fe}^{2+}$ ions in solution $[77,83,89,90,136]$, or as iron sulfide $[56-58,60$ $64,67,68,71,137,138]$. Therefore, while analyzing the data, we specifically looked at the content of iron and other transition metals that are essential for life (hereafter "essential metals" [128]).

\section{The presence of $\mathrm{Zn}^{2+}$ in modern RNAs}

The $\mathrm{Zn}$ world scenario implies that the first RNA-like oligomers emerged within the illuminated ZnS compartments. Then the $\mathrm{Zn}^{2+}$ ions might be preserved in modern 
RNA molecules either as structural elements or catalytic cofactors.

\section{Occurrence of $\mathrm{Zn}$ the RNA structures}

The idea of modern RNA structures retaining the $\mathrm{Zn}^{2+}$ ions that were trapped by the first RNA molecules emerging in the zinc-rich habitats leads to the prediction no. 1: Known RNA structures should be enriched with $\mathrm{Zn}^{2+}$ as compared to other transition metals. To check this, we have turned to the solved RNA-containing structures, available in the Protein Data Bank (PDB, $[139,140])$ and Nucleic Acid Database [141,142].

A comparison of the transition metal content in the available RNA-containing structures, as listed in the MERNA (Metals in RNA) database $[143,144]$, is presented in Table 1 (these data represent transition metal atoms located at the distance of no more than $6 \AA$ from any atom that is part of the RNA molecule). RNA-containing structures from the PDB include such essential metals as $\mathrm{Zn}, \mathrm{Mn}$ and $\mathrm{Co}$, with $\mathrm{Zn}$ seen in 64 structures, more than any other transition metal. The relatively large number of Co-containing structures is due to the routine use of cobalt (III) hexamine as a standard stabilizing reagent which mimics hydrated magnesium [145]. Manganese atoms are seen in 16 structures, whereas no $\mathrm{Fe}$ atoms in the vicinity of RNA molecules have been reported. Our own further analysis, which used a shorter cut-off of $3 \AA$, has shown that the majority of these metal atoms interact not with RNA proper but with the side chains of various RNA-bound proteins. Still, in some cases we could find transition metal atoms that interacted directly with nucleotides, namely $\mathrm{Zn}$ in the PDB entries 1NLC, 1S03, 1YXP, 1D9F, $\mathrm{Mn}$ in the PDB entries 1EHZ, 1N35, 1Y3O, 2G81, and so on. The certain scarcity of these interactions is due to the poor binding of metal cations to RNA and, accordingly, the poor selectivity of such binding. Therefore transition metal atoms are usually seen in those structures that were crystallized from solutions that contained the respective salts. In the absence of added $\mathrm{Zn}$ or Mn salts, Mg atoms, which are present in standard crystallization media, bind in the respective positions (as could be judged from the comparative analysis of the RNA structures that were crystallized several times, with different divalent cations (see e.g. [146]). Thus, a separate question that, generally, deserves clarification is the nature of the divalent metal atoms that are bound by the RNA-protein complexes in vivo. We have tackled this question while trying to clarify the origin of $\mathrm{Cd}$ atoms in the RNA-containing structures. The presence of $\mathrm{Cd}$ in 42 RNA-containing structures, as reported in the MERNA database (Table 1), was intriguing since $\mathrm{Cd}$ is not an essential metal. We have checked the Cd-containing structures and found out that 41 of them represent different ribosomal structures which were crystallized in the presence of $\mathrm{CdCl}_{2}[147,148] ; \mathrm{CdCl}_{2}$ was apparently used to improve the crystal stability (Dr. Gulnara Yusupova, personal communication). The remaining Cd-containing structure shows a complex of the hammerhead ribozyme with substrate RNA that was crystallized in the presence of $25 \mathrm{mM}$ of $\mathrm{CdSO}_{4}$ [149]. For the 41 structures related to the large ribosomal subunit, we could tentatively infer the nature of the metal ions that were replaced by the added $\mathrm{Cd}^{2+}$ ions. Ramakrishnan and coworkers have recently crystallized the whole bacterial ribosome with bound tRNA and mRNA under physiological conditions, with $\mathrm{Mg}^{2+}$ as the only divalent ion used upon preparation [150]. This structure contains dozens of $\mathrm{Mg}^{2+}$ ions, a few $\mathrm{Zn}^{2+}$ ions, and no $\mathrm{Cd}^{2+}$ ions. Apparently the $\mathrm{Cd}^{2+}$ ions in the 41 ribosomal structures occupied the loci that are normally occupied by either $\mathrm{Mg}^{2+}$ or $\mathrm{Zn}^{2+}$ ions. Since Ramakrishnan and co-workers crystallized the ribosome without adding $\mathrm{Zn}$ salts to the crystallization medium [150], the $\mathrm{Zn}$ atoms seen in that structure should be the retained native ones. These data show that, indeed, $\mathrm{Zn}$ atoms are found in RNA molecules and RNA-protein complexes much more often than any other transition metal atoms.

Table I: Transition metal content in RNA structures.

\begin{tabular}{|c|c|c|c|c|c|c|c|c|c|c|}
\hline Group & $\begin{array}{c}3 \\
\text { (IIIB) }\end{array}$ & $\begin{array}{c}4 \\
\text { (IVB) }\end{array}$ & $\begin{array}{c}5 \\
(\mathrm{VB})\end{array}$ & $\begin{array}{c}6 \\
\text { (VIB) }\end{array}$ & $\begin{array}{c}7 \\
\text { (VIIB) }\end{array}$ & $\begin{array}{c}8 \\
\text { (VIIIB) }\end{array}$ & $\begin{array}{c}9 \\
\text { (VIIIB) }\end{array}$ & $\begin{array}{c}10 \\
\text { (VIIIB) }\end{array}$ & $\begin{array}{l}\text { II } \\
\text { (IB) }\end{array}$ & $\begin{array}{c}12 \\
\text { (IIB) }\end{array}$ \\
\hline Period 4 & $\begin{array}{c}\text { Sc } \\
0\end{array}$ & $\begin{array}{l}\mathrm{Ti} \\
0\end{array}$ & $\begin{array}{l}V \\
2\end{array}$ & $\begin{array}{c}\mathrm{Cr} \\
0\end{array}$ & $\begin{array}{c}M n \\
16\end{array}$ & $\begin{array}{c}\mathrm{Fe} \\
0\end{array}$ & $\begin{array}{l}\text { Co } \\
32\end{array}$ & $\begin{array}{c}\mathrm{Ni} \\
0\end{array}$ & $\begin{array}{c}\mathrm{Cu} \\
0\end{array}$ & $\begin{array}{l}Z n \\
64\end{array}$ \\
\hline Period 5 & $\begin{array}{l}Y \\
0\end{array}$ & $\begin{array}{c}\mathrm{Zr} \\
0\end{array}$ & $\begin{array}{c}\mathrm{Nb} \\
0\end{array}$ & $\begin{array}{c}\text { Mo } \\
0\end{array}$ & $\begin{array}{c}\text { Tc } \\
0\end{array}$ & $\begin{array}{c}\mathrm{Ru} \\
\mathrm{I}\end{array}$ & $\begin{array}{c}\mathrm{Rh} \\
4\end{array}$ & $\begin{array}{c}\mathrm{Pd} \\
0\end{array}$ & $\begin{array}{c}\mathrm{Ag} \\
0\end{array}$ & $\begin{array}{l}C d \\
42\end{array}$ \\
\hline Period 6 & $\begin{array}{c}\mathrm{La} \\
0\end{array}$ & $\begin{array}{c}\mathrm{Hf} \\
0\end{array}$ & $\begin{array}{c}\mathrm{Ta} \\
0\end{array}$ & $\begin{array}{c}W \\
6\end{array}$ & $\begin{array}{c}\mathrm{Re} \\
0\end{array}$ & $\begin{array}{c}\text { Os } \\
3\end{array}$ & $\begin{array}{l}\text { Ir } \\
3\end{array}$ & $\begin{array}{c}\mathrm{Pt} \\
\mathrm{I}\end{array}$ & $\begin{array}{c}\mathrm{Au} \\
0\end{array}$ & $\begin{array}{c}\mathrm{Hg} \\
3\end{array}$ \\
\hline
\end{tabular}

Essential metals are shown in bold font. The data are taken from the February 2007 release of the MERNA database [143, 144], and reflect data from 389 individual RNA-containing structures. Each value represents the number of structures where the indicated transition metal atoms are located within $6 \AA$ from the nearest RNA atom. 


\section{Role of $\mathrm{Zn}$ in the RNA catalysis}

The metal ions that were trapped by primeval RNA polymers could serve as catalytic centers. This consideration leads to the prediction no. 2: There should be ribozymes with Zn-dependent catalytic activities.

The detailed catalytic mechanisms of natural ribozymes have been studied only in few cases (see [35,151-155] for recent comprehensive reviews). RNA molecules are surrounded by a shell of diverse cations that stabilize the negative charges of the backbone phosphate groups. Generally, the metal specificity of ribozymes is low, because of weaker, as compared to proteins, cation binding, so $\mathrm{Mg}^{2+}$ ions, which are always present in large amounts as stabilizers, can seemingly occupy any metalbinding site. Therefore, the exact chemical nature of the catalytically-relevant metal ions is often difficult to determine. In most cases, the catalytic activity of ribozymes could be restored by several divalent cations, e.g. by $\mathrm{Mg}^{2+}$, $\mathrm{Zn}^{2+}, \mathrm{Mn}^{2+}, \mathrm{Cd}^{2+}, \mathrm{Pb}^{2+}$. In some cases, however, only particular ions, e.g. $\mathrm{Zn}^{2+}[156,157]$ or $\mathrm{Mn}^{2+}[158,159]$ were found to be functional. Taking into account that $\mathrm{Cd}$ and $\mathrm{Pb}$ do not belong to the essential metals [128], the available data (see e.g. $[35,151-155,160-167]$ ) indicate that the transition metals that can be relevant for natural RNA catalysis are, in the first line, $\mathrm{Zn}$ and $\mathrm{Mn}$.

Summarizing the RNA-related predictions, it is worth noting that Fe has not been reported either as a structural constituent of RNA molecules or as a metal that is important for the RNA catalysis. The striking absence of iron atoms in the vicinity of natural RNA molecules is likely to be due to the danger of the RNA cleavage by hydroxyl radicals that could be produced in the presence of redox-active $\mathrm{Fe}^{2+} / \mathrm{Fe}^{3+}$ ions [168-170]. Accordingly, it seems reasonable to suggest that early evolution of RNA proceeded in habitats that were enriched in $\mathrm{Mg}$, $\mathrm{Zn}$ and $\mathrm{Mn}$, but not in iron.

Traces of the $\mathrm{Zn}^{2+}$-rich environment in the evolutionarily old proteins Occurrence of $\mathrm{Zn}$ the oldest protein folds

The same logics as used above to suggest the possibility of stabilization of the early RNA folds by photosynthetically released $\mathrm{Zn}^{2+}$ ions is applicable to the first proteins, which, owing to the more versatile chemistry, could bind metal ions even tighter than RNA molecules do [128]. $\mathrm{Zn}^{2+}$-mediated protein folding has indeed been reported, see e.g. $[171,172]$. Hence, it is possible to formulate the prediction no. 3: $\mathrm{Zn}^{2+}$ ions should be associated with the evolutionarily oldest protein folds.

Yang and colleagues recently checked the distribution of fold superfamilies (FSF) among 174 complete genomes [173]. Of 1294 FSFs only 49 were reported to be present in all Archaea, Bacteria and Eukarya with known complete genomes. It seems reasonable to assume that these FSFs are among the evolutionarily oldest ones. Table 2 contains data on metals associated with these 49 FSFs [174]. Because of certain elusiveness of zinc (see above), we have checked the metal content in those representatives of these 49 FSF whose structures could be found in the PDB. Zinc atoms were found in representatives of 37 FSFs. Cadmium atoms were present in the representatives of 21 FSFs. Again, since Cd is not an essential metal [128], Cd atoms most likely occupy the sites where $\mathrm{Mg}^{2+}$ or $\mathrm{Zn}^{2+}$ ions are normally bound (see above and [175]). Iron atoms were associated only with representatives of three FSFs. Manganese has been found in representatives of 19 FSFs, whereas Mg atoms were present in all FSFs except for one. These data support the idea that formation and stabilization of the oldest protein folds have occurred in the settings that were rich in $\mathrm{Mg}$, $\mathrm{Zn}$ and $\mathrm{Mn}$, but not in Fe.

\section{Occurrence of $\mathrm{Zn}$ in the proteins with the oldest functions}

The $\mathrm{Zn}$ world concept, as well as some other evolutionary scenarios (see [28] and references therein) imply that the first enzymes could have emerged to overtake the catalytic functions from ribozymes. An up-to-date list of the known catalytic activities of ribozymes can be found in ref. [29]. In the absence of proteins or organic cofactors, ribozymes, especially the artificial ones, can catalyze breakdown and formation of diverse covalent bonds, as well as group transfer reactions by employing acid-base catalysis which often proceeds in a metal-assisted way (see the discussion above and refs. [29,35,151-155,176]). The first enzymes can be expected to have had similar catalytic activities. If the first enzymes emerged in the Zn-rich environments, one could expect involvement of $\mathrm{Zn}^{2+}$ ions in the oldest enzymes, particularly those that catalyze the formation and breakdown of covalent bonds and the group transfer reactions. This consideration leads to the prediction no. 4: The enzymes with evolutionarily "oldest" functions, including catalysis of formation and breakdown of chemical bonds, should depend on zinc.

Zerkle and co-workers recently analyzed biogeochemical signatures, trying to reconstruct changes in the enzyme metal content in the course of evolution [125]. Their reconstruction showed that $37 \%$ of metalloenzymes that could be timed to the "very early life" were $\mathrm{Zn}$-dependent with their relative fraction dropping to $19 \%$ in modern organisms. The fraction of Mn-dependent enzymes remained almost constant (10\% versus $9 \%$ ), while the fraction of iron-dependent enzymes increased from $18 \%$ to $34 \%$. These data [125] indicate that presumed evolutionarily oldest functions were largely performed by $\mathrm{Zn}$ containing enzymes.

To check the prediction on zinc dependence of the enzymes that catalyze formation and breakdown of chemical bonds, as well as group transfer reactions, we have 
Table 2: Occurrence of metal atoms in the representatives of the $\mathbf{4 9}$ fold superfamilies that are common to Bacteria, Archaea and Eukarya

\begin{tabular}{|c|c|c|c|c|c|c|c|}
\hline Name & $\mathbf{Z n}$ & $\mathbf{F e}$ & Cd & $\mathbf{N i}$ & $\mathrm{Cu}$ & Mn & Mg \\
\hline SI3-like H2TH domain & $3(38)$ & 0 & 0 & 0 & 0 & 0 & $3(18)$ \\
\hline SI5/NSI RNA-binding domain & $\mathrm{I}(\mathrm{I})$ & 0 & 0 & 0 & 0 & 0 & $\mathrm{I}(\mathrm{I7})$ \\
\hline Anticodon-binding domain of a subclass of class I aminoacyl-tRNA synthases & $5(2 I)$ & 0 & 0 & 0 & 0 & 0 & $I(2)$ \\
\hline Ribosomal protein LII, C-terminal domain & 0 & 0 & 0 & 0 & 0 & 0 & I (4) \\
\hline 5 ' to $3^{\prime}$ exonuclease, C-terminal subdomain & $2(3)$ & 0 & 0 & 0 & 0 & $2(2)$ & $2(2)$ \\
\hline Ribosomal protein S7 & I (I8) & 0 & 0 & 0 & 0 & 0 & $\mathrm{I}(15)$ \\
\hline Translation proteins $\mathrm{SH}$-like domain & 0 & 0 & $3\left(57^{a}\right)$ & 0 & 0 & 0 & I (19) \\
\hline Ribosomal protein LI4 & 0 & 0 & $\mathrm{I}\left(19^{\mathrm{a}}\right)$ & 0 & 0 & 0 & I (19) \\
\hline Nucleic acid-binding proteins & $15(59)$ & 0 & $2(1+19 a)$ & $I(1)$ & $I(1)$ & $4(10)$ & $10(50)$ \\
\hline Translation proteins & $I(6)$ & 0 & $\mathrm{I}(19 \mathrm{a})$ & 0 & 0 & 0 & $8(40)$ \\
\hline EF-Tu/eEF-I $\alpha /$ elF2- $\gamma$ C-terminal domain & $I(6)$ & 0 & 0 & 0 & 0 & 0 & $4(18)$ \\
\hline ValRS/lleRS/LeuRS editing domain & $2(7)$ & 0 & 0 & 0 & 0 & 0 & $I(2)$ \\
\hline Metallo-dependent hydrolases & $9(50)$ & $2(9)$ & $2(4)$ & $2(32)$ & I (2) & $2(2)$ & $2(4)$ \\
\hline HAD-like & 1 & 0 & 0 & 1 & 0 & 0 & $14(35)$ \\
\hline Ribosomal proteins LI5p and LI8e & 0 & 0 & $2\left(38^{a}\right)$ & 0 & 0 & 0 & $2(38)$ \\
\hline PIN domain-like & $2(3)$ & 0 & 0 & 0 & 0 & $2(2)$ & $2(2)$ \\
\hline NAD(P)-binding Rossmann-fold domains & $13(89)$ & 0 & $3(7)$ & $2(2)$ & $I(I)$ & $7(14)$ & II (20) \\
\hline Initiation factor IF2/elF5b, domain 3 & 0 & 0 & 0 & 0 & 0 & 0 & $I(1)$ \\
\hline Ribosomal protein S2 & $\mathrm{I}(\mathrm{I})$ & 0 & 0 & 0 & 0 & 0 & $\mathrm{I}(15)$ \\
\hline Class I glutamine amidotransferase-like & $3(4)$ & 0 & I (2) & I (4) & 0 & $\mathrm{I}(10)$ & $5(5)$ \\
\hline Nucleotidylyl transferase & $8(24)$ & 0 & $I(6)$ & 0 & 0 & $2(2)$ & $9(15)$ \\
\hline Adenine nucleotide $\alpha$ hydrolases-like & $8(24)$ & 0 & I (6) & 0 & 0 & $3(3)$ & $13(34)$ \\
\hline FAD/NAD(P)-binding domain & $I(I)$ & 0 & 0 & 0 & 0 & $I(2)$ & $2(3)$ \\
\hline P-loop containing nucleoside triphosphate hydrolases & $18(45)$ & 0 & $3(13)$ & $2(2)$ & 0 & $8(12)$ & $108(455)$ \\
\hline Anticodon-binding domain of Class II aaRS & $2(15)$ & 0 & 0 & 0 & 0 & 0 & I (4) \\
\hline Actin-like ATPase domain & $2(3)$ & 0 & $\mathrm{I}(\mathrm{I})$ & 0 & 0 & $I(I)$ & $7(38)$ \\
\hline Ribonuclease $\mathrm{H}$-like & $8(43)$ & 0 & $3(3+19 a)$ & 0 & 0 & $8(15)$ & $10(76)$ \\
\hline Translational machinery components & I (I8) & 0 & I (19a) & 0 & 0 & 0 & $2(34)$ \\
\hline
\end{tabular}


Table 2: Occurrence of metal atoms in the representatives of the 49 fold superfamilies that are common to Bacteria, Archaea and Eukarya (Continued)

\begin{tabular}{|c|c|c|c|c|c|c|c|}
\hline S-adenosylmethionine-dependent methyltransferases & $\mathrm{I}(\mathrm{I})$ & 0 & $\mathrm{I}(\mathrm{I})$ & $\mathrm{I}(\mathrm{I})$ & 0 & 0 & $\mathrm{~T}(3)$ \\
\hline Class II aaRS and biotin synthetases & $2(15)$ & 0 & 0 & 0 & 0 & $4(4)$ & $5(13)$ \\
\hline ATPase domain of HSP90 chaperone/DNA topoisomerase II/histidine kinase & 0 & 0 & 0 & 0 & 0 & $\mathrm{I}(2)$ & II (25) \\
\hline Creatinase/aminopeptidase & $2(3)$ & 0 & 0 & 0 & 0 & $2(8)$ & 0 \\
\hline DNA clamp & $\mathrm{I}(\mathrm{I})$ & 0 & 0 & 0 & 0 & 0 & $\mathrm{I}(\mathrm{l})$ \\
\hline Ribosomal protein S5 domain 2-like & $4(39)$ & 0 & $2(2)$ & 0 & 0 & 0 & $12(49)$ \\
\hline Ribosomal protein $\mathbf{S 8}$ & I (19) & 0 & 0 & 0 & 0 & 0 & $\mathrm{I}(15)$ \\
\hline Ribosomal protein L6 & 0 & 0 & $\mathrm{I}(19 \mathrm{a})$ & 0 & 0 & 0 & I (19) \\
\hline DNA ligase/mRNA capping enzyme, catalytic domain & $2(3)$ & 0 & 0 & 0 & 0 & $\mathrm{I}(\mathrm{I})$ & $\mathrm{I}(\mathrm{I})$ \\
\hline Metallo-hydrolase/oxidoreductase & $4(33)$ & $\mathrm{I}(\mathrm{I})$ & $2\left(1+2^{b}\right)$ & 0 & 0 & $\mathrm{I}(\mathrm{I})$ & 0 \\
\hline FKBP-like & $4(4)$ & $\mathrm{I}(\mathrm{I})$ & 0 & 0 & 0 & 0 & 0 \\
\hline Ribosomal protein $\mathrm{LIOe}$ & & & $\mathrm{I}(19 \mathrm{a})$ & 0 & 0 & 0 & I (19) \\
\hline dsRNA-binding domain-like & I (18) & 0 & 0 & 0 & 0 & 0 & $\mathrm{I}(15)$ \\
\hline Ribosomal protein L22 & 0 & 0 & $\mathrm{I}(19 \mathrm{a})$ & & 0 & 0 & I (19) \\
\hline EF-G/eEF-2 domains III and V & 0 & 0 & 0 & 0 & 0 & 0 & $2(2)$ \\
\hline$\alpha-L$ RNA-binding motif & I (18) & 0 & 0 & 0 & 0 & 0 & $\mathrm{I}(15)$ \\
\hline Threonyl-tRNA synthetase (ThrRS), second 'additional' domain & I (3) & 0 & 0 & 0 & 0 & 0 & 0 \\
\hline RBPII-like subunits of RNA polymerase & $3(21)$ & 0 & 0 & 0 & 0 & $2(14)$ & $3(7)$ \\
\hline Ribosomal protein L5 & 0 & 0 & $\mathrm{I}(19 \mathrm{a})$ & 0 & 0 & 0 & $\mathrm{I}(20)$ \\
\hline Ribosomal protein LI & 0 & 0 & 0 & 0 & 0 & 0 & $\mathrm{I}(\mathrm{I})$ \\
\hline$\beta$ and $\beta^{\prime}$ subunits of DNA dependent RNA-polymerase & $4(22)$ & 0 & 0 & 0 & 0 & $2(14)$ & $4(10)$ \\
\hline
\end{tabular}

Fold superfamily names are from the SCOP database [174]; metal content is from the Protein Data Bank [140]. The figures show the nonredundant numbers of hits, the figures in parentheses show the total number of hits (see text for details).

a - Proteins of the large ribosomal subunit, whose crystals were soaked in $\mathrm{CdCl}_{2}$ during sample preparation ([147, I48], 19 different PDB entries).

b - Cd-substituted Zn-dependent metallo-beta-lactamase [175].

analyzed the involvement of transition metals as cofactors in different enzyme classes according to the enzyme descriptions in the International Union of Biochemistry and Molecular Biology (IUBMB) Enzyme Nomenclature, as documented, among others, in the ExporEnz database $[177,178]$. Since we needed specific information on metals as catalysts, and not just as structural elements, we searched the MACiE (Mechanism, Annotation and Classification in Enzymes) database $[179,180]$ and its recently described Metal-MACiE supplement, a database of metal- based reaction mechanisms $[181,182]$. Andreini and coworkers [181] compared metal-containing enzymes listed in these databases with metal-containing proteins in the PDB and showed that the relative occurrence of catalytic metals in Metal-MACiE matched well that in the PDB. Table 3 shows the presence of metal cofactors in different groups of enzymes listed in Metal-MACiE database (complemented by information from the MACiE database to distinguish between $\mathrm{Fe}^{2+}$ and $\mathrm{Fe}^{3+}$ ). 
Table 3: Metal dependence of the enzyme catalytic activities.

\begin{tabular}{|c|c|c|c|c|c|c|c|c|}
\hline Enzyme class & $\mathrm{Zn}$ & $M n$ & $\mathrm{Fe}^{2+}$ & $\mathrm{Fe}^{3+}$ & $\mathrm{Cu}$ & Co & $\mathrm{Ni}$ & Mo \\
\hline Oxidoreductases & I & I & 33 & 6 & 6 & I & 1 & 7 \\
\hline Transferases & I & 5 & & & & & & \\
\hline Hydrolases & 17 & 4 & $\mathrm{I}^{\mathrm{a}}$ & I & & & I & \\
\hline Lyases & 6 & 2 & 1 & 1 & & I & & \\
\hline Isomerases & & 2 & & & & 5 & & \\
\hline Ligases & & & & & & & & \\
\hline
\end{tabular}

The numbers of enzymes with particular transition metals as catalytic cofactors are from the MACiE database $[179,180]$, and its recently described Metal-MACiE supplement $[181,182]$, see text for details. a - Peptide deformylase, where the Fe atom is functionally replaceable by $\mathrm{Co}, \mathrm{Ni}$ or $\mathrm{Zn}$ [185].

As follows from Table 3, $\mathrm{Fe}, \mathrm{Cu}$ and Mo are catalytically active in oxidoreductases (which catalyze electron transfer reactions), whereas $\mathrm{Zn}^{2+}$ ions are the predominant metal cofactors in hydrolases (which catalyze breaking of chemical bonds with the involvement of a water molecule) and lyases (which catalyze breaking of various chemical bonds by means other than hydrolysis and oxidation). For transferases (which catalyze transfer of functional groups from one molecule to another), the preferred metal cofactor was Mn. Only few hits were obtained for isomerases, with a preference for Co as a cofactor. As seen in Table 3, no transition metal hits were obtained for ligases (which catalyze joining of two molecules by forming a new chemical bond), although, according to the MACiE database, some ligases depend on $\mathrm{Mg}^{2+}$ ions. Since the number of hits in the Metal-MACiE database was small for transferases, isomerases and ligases, the survey of these enzyme classes was expanded by extracting additional data from BRENDA (BRaunschweig ENzyme DAtabase, [183-185]). BRENDA is manually curated and contains a wealth of information on the properties of various enzymes, including presence of metals and their likely functions $[183,184]$. In the case of transferases, the involvement of $\mathrm{Zn}^{2+}$ ions as cofactors seemed to be less specific than of $\mathrm{Mn}^{2+}$; in the vast majority of cases, both $\mathrm{Zn}^{2+}$ and $\mathrm{Mn}^{2+}$ ions could be functionally replaced by other divalent cations such as $\mathrm{Mg}^{2+}, \mathrm{Ni}^{2+}$ or $\mathrm{Co}^{2+}$. Involvement of $\mathrm{Fe}^{2+}$ ions in the catalysis by transferases appeared to be limited to their ability to replace $\mathrm{Mg}^{2+}, \mathrm{Mn}^{2+}, \mathrm{Zn}^{2+}, \mathrm{Ni}^{2+}$ or $\mathrm{Co}^{2+}$ ions; $\mathrm{Fe}^{2+}$ ions were routinely reported to be the least efficient catalysts in the series. The list of metal-dependent isomerases shows non-specific utilization of several divalent cations such as $\mathrm{Mg}^{2+}, \mathrm{Mn}^{2+}, \mathrm{Co}^{2+}, \mathrm{Zn}^{2+}$, or $\mathrm{Ni}^{2+}$. In many cases, the highest enzyme activity, as compared to other cations, was reported with $\mathrm{Mn}^{2+}$ or $\mathrm{Co}^{2+}$ ions, similarly to the data in Table 3. Specific involvement of iron has been shown only for lysine 2,3-aminomutase, where a FeS redox cluster is involved in electron exchange with the catalytic site [186]. Ligases generally use divalent cations, such as $\mathrm{Mg}^{2+}, \mathrm{Co}^{2+}, \mathrm{Zn}^{2+}$, or $\mathrm{Mn}^{2+}$. No evidence of specific catalytic activity of $\mathrm{Fe}$ in ligases could be obtained from the BRENDA database.

It is noteworthy that only two transition metals, namely $\mathrm{Zn}$ and $\mathrm{Mn}$, are found in the representatives of all six enzyme classes [181]. Zn is by far the most abundant catalytic transition metal in hydrolases and lyases, whereas Mn seems to be involved in transferases and, together with $\mathrm{Co}$, in isomerases. In transferases, isomerases and ligases, the pattern of the transition metal use, with a nonspecific need for a divalent cation as catalyst, resembles the catalytic preferences of ribozymes (see above). The $\mathrm{Fe}^{2+}$ ions, with few exceptions, are not used in catalysis outside the oxidoreductases.

Altogether, data on metal content of proteins are consistent with the notion that the early evolution of enzymes could have proceeded in habitats that were enriched in $\mathrm{Mg}$, Zn, and Mn, but depleted of Fe.

\section{The elevated $\mathrm{Zn}^{2+}$ content inside modern cells}

If life emerged in the environments that had relatively high levels of $\mathrm{Zn}^{2+}$ ions [97], the primordial life forms, which lacked the tools to alter their ionic content [187], should have had high $\mathrm{Zn}^{2+}$ levels as well. In accordance with chemical continuity principle, the ionic content of the primordial environments should be conserved inside modern cells. This leads to the prediction no. 5: The total amount of $\mathrm{Zn}^{2+}$ in the live cell should be elevated as compared to the levels of other essential transition metals.

Early studies on the total $\mathrm{Zn}$ content in several bacteria produced values of $\sim 0.03 \%$ of the dry weight, much higher than for any other transition metal except for $\mathrm{Fe}$ [188]. The content of $\mathrm{Zn}$, as compared to $\mathrm{Fe}$, was somewhat smaller in Escherichia coli, but 2-3 times higher in Micrococcus roseus and Bacillus cereus [188]. The data for E. coli were recently confirmed by inductively coupled plasma mass spectrometry analysis of whole-cell lysates, yielding values of $\sim 200 \mu \mathrm{M}$ for $\mathrm{Zn}$ and $200-300 \mu \mathrm{M}$ for $\mathrm{Fe}$, depending on the growth conditions [189]. The total $\mathrm{Zn}$ content in the human body tissues is, on average, somewhat higher than that of $\mathrm{Fe}, 3-5 \mathrm{mg}$ versus $2.5-5$ $\mathrm{mg} / 100 \mathrm{~g}$ of tissue (the data were obtained from tissue samples that had been washed from blood; the amount of other transition metals was much lower [190]). It is noteworthy that although cells contain comparable total amounts $(100-300 \mu \mathrm{M})$ of $\mathrm{Fe}[191,192]$ and $\mathrm{Zn}$ (see [193] and references therein), the concentrations of free (labile) ions differ dramatically, with the free $\mathrm{Fe}^{2+} / \mathrm{Fe}^{3+}$ 
concentration of $\sim 10 \mu \mathrm{M}[191,192]$ and free $\mathrm{Zn}^{2+}$ present only in picomolar amounts $[130,193]$. These data indicate that intracellular $\mathrm{Zn}$ levels are tightly controlled; they also suggest that modern cells are more limited in $\mathrm{Zn}$ than in $\mathrm{Fe}$.

Modern sea water contains somewhat more iron, (about 5 $\mathrm{nM}$ of mostly $\left.\mathrm{Fe}^{3+}\right)$ than $\mathrm{Zn}^{2+}(<2 \mathrm{nM})$, see [104] and Table 1 in the accompanying article [97]. Hence, compared to the composition of sea water, $\mathrm{Zn}$ appears to be the transition metal that is concentrated to the highest extent in the cell. As noted by Williams and Fraústo da Silva, the primeval anoxic ocean must have contained $\mathrm{Fe}^{2+}$ ions, which are more soluble than $\mathrm{Fe}^{3+}$ ions. The available estimates of $\mathrm{Fe}^{2+}$ content in primordial waters are in the range of $10^{-6}-10^{-5} \mathrm{M}$, compared to the estimate of $10^{-15}-10^{-}$ ${ }^{12} \mathrm{M}$ for $\mathrm{Zn}^{2+}$ ions [124-126]. Hence, the intracellular $\mathrm{Zn}$ concentration of 100-300 $\mu \mathrm{M}$ reflects a very efficient scavenging of $\mathrm{Zn}^{2+}$ ions and is consistent with the idea that the emergence of first life forms indeed occurred in very special, $\mathrm{Zn}^{2+}$-rich environments.

\section{The metallome of the Last Universal Common Ancestor}

While the idea that life originated - and the first RNA and protein molecules evolved - in $\mathrm{Zn}^{2+}$-rich settings appears to be compatible with the available data, it does not explicitly state whether these $\mathrm{Zn}^{2+}$-rich settings played any direct role in the formation of the first cells. Although it is hard to make any specific and verifiable predictions for these matters, in this section we try tracing the possible roles of $\mathrm{Zn}^{2+}$ ions at the times of the Last Universal Common Ancestor of all living cellular organisms (LUCA).

All cellular life forms belong to one of the three main branches of the Tree of Life, Bacteria, Archaea, or Eukarya [194]. The conservation of a set of essential genes between the three domains of life has been considered as evidence in favor of the existence of the LUCA, see [195-197] for reviews. Some researchers view LUCA as a consortium of replicating entities which shared a common gene pool [195]. Alternatively, representatives of the LUCA were suggested to be full-fledged organisms comparable to modern prokaryotes [198,199]. There are also numerous possible variants between these two extreme visions of the LUCA. The infrequency of inter-domain transfer of genes responsible for information processing [200-203] might indicate that these genes, at least at the LUCA stage, already formed constant genetic cores of the first organisms. At the same time, the easily spreading metabolic genes could form a common pool of transferable operational genes [200], such that the organisms, depending on their metabolic requirements, could acquire the necessary tools from a common gene pool. The universal conservation of membrane-embedded subunits of the general protein secretory pathway [204] and the F- and A/V-type ATP synthases [205] has been considered as an indication that the LUCA was already a membrane-encased life form [206]. Its membranes, however, had to be permeable to enable the exchange of genes, proteins and metabolites [73]. The recent modeling by Szathmáry and co-workers showed that "collective" metabolism, with different replicators contributing different metabolites to the common pool, could be a pre-condition for the viability of the whole consortium and its resistance to parasites [207].

Koonin and Martin have argued that the LUCA consortia might have dwelled in networks of iron-sulfur inorganic compartments ("bubbles") of hydrothermal chimneys [138]. As discussed in the accompanying article [97], this model fits nicely into the $\mathrm{Zn}$ world concept, provided that the deep-see chimneys built of FeS are replaced by "spongy" ZnS precipitates encircling the sub-aerial hot springs. Precipitation of $\mathrm{ZnS}$ at the sites of geothermal activity should have led to continuous formation of new, empty compartments, so that the more competitive consortia could overcome others by "moving in" first. As argued elsewhere $[73,138,208]$, such a scheme implies an extensive (gene) exchange between the members of one consortium, but not between dwellers of different, physically discrete inorganic compartments. It therefore resolves a major conundrum between the notion of extensive gene mixing that is considered a major feature of early evolution [195] and the requirement of separately evolving units for the Darwinian selection.

To what extent the conclusions on primordial bioinorganic chemistry that we have drawn from the data on metal content in modern cells could be related to the LUCA? The intracellular $\mathrm{Zn}^{2+}$ concentration of $10^{-3}-10^{-4}$ $M$ is a feature that is shared by representatives of all there domains [188-190,209]. The simplest way to explain this remarkable trait is by assuming that the LUCA still lived in Zn-rich habitats. An alternative explanation would assume that the Zn content of LUCA was low and then independently increased in all three major lineages, responding e.g. to the elevation of environmental $\mathrm{Zn}^{2+}$ level from $10^{-12}-10^{-15} \mathrm{M}$ in the anoxic ocean up to $10^{-9} \mathrm{M}$ after its oxygenation [124-126]. The latter possibility, however, appears unlikely. The high total $\mathrm{Zn}$ content in cells is contributed not by free $\mathrm{Zn}^{2+}$ ions, which are scarce $[130,193]$, but by large number of $\mathrm{Zn}$-binding proteins mostly involved in processing of RNA and DNA. These proteins are widespread in all three domains of life and their Zn-binding motifs (in particular, so called "zinc fingers") are homologous [210]. Therefore it appears unlikely that these Zn-binding motifs could independently develop in different lineages. Since the ligand chemistry of these binding sites is specifically tuned to prefer $\mathrm{Zn}^{2+}$ over other transition metal ions [211,212], it is equally unlikely that they served first to bind some other 
metal, e.g. iron, and only later adapted to binding zinc. It also appears implausible that selective Zn-enrichment of LUCA's interior could be accomplished by powerful ion pumps capable of maintaining the huge $\mathrm{Zn}$ gradient between the LUCA's interior and the surrounding $\mathrm{Zn}$ depleted, anoxic waters. As argued elsewhere, the LUCA should have had primitive membranes [73,138,187,206] that could not hold the required $\mathrm{Zn}$ concentration gradient of $>10^{8}$; even the modern membranes can hardly do that. Thus, the most parsimonious explanation of the high cellular content of $\mathrm{Zn}$ in representatives of all three domains of life is by suggesting that the LUCA thrived in Zn-rich habitats that apparently were in the ionic equilibrium with the LUCA's interior.

It is tempting therefore to make prediction no. 6: The proteins that could be attributed to LUCA should be enriched in $\mathrm{Zn}$. The problem of the LUCA-specific protein set has been addressed by several authors, see [197] for a review. After completion of the first microbial genomes, a "minimal" set of genes shared by these genomes was deduced; it has been speculated that these genes made the genome of the LUCA $[213,214]$. With increasing number of sequenced genomes, the set of genes shared by all genomes kept shrinking; it has become clear that with just 50 such genes it would not be possible to build a full-fledged organism [196,215]. Accordingly, it is now believed that the metabolism of the LUCA was carried out by operational genes that are not necessarily conserved in all genomes [216]. However, a small set of genes that are shared by all known genomes is still believed to form the core of the LUCA's genome $[196,197,215]$. The products of these ubiquitous genes and their metal affinities are listed in Table 4 [217-238] and show a notable preference for $\mathrm{Zn}$ and $\mathrm{Mg}$ as metal cofactors. Iron was found only in some structures of a single protein family (YgjD/Gcp/ QRI7) of obscure function that was originally reported to have O-sialoglycoprotein endopeptidase activity, later identified as an apurinic endonuclease, and recently shown to be essential for genome maintenance in Archaea and Eukarya $[234,239,240]$. These data indicate that proteins likely to be present in the LUCA - and, hence, the LUCA itself - existed in a Zn-rich environment. As discussed above, since the equilibrium $\mathrm{Zn}$ concentration in the primordial oceans must have been extremely low [124-126], a $\mathrm{Zn}$ rich environment could persist only due to some steady geochemical reaction leading to continuous release of $\mathrm{Zn}^{2+}$ ions, such as abiogenic photosynthesis.

Summarizing the preceding part of the Results, Zn-rich habitats appear to have shaped the primeval biochemistry by favoring the emergence of Zn-stabilized protein and RNA folds, as well as $\mathrm{Zn}$-dependent enzymatic reactions. Seemingly, the development of the first life forms proceeded in the $\mathrm{Zn}$-rich settings up to the stage of the LUCA.

\section{Testing the Explanatory Power of the Zn world concept}

The $\mathrm{Zn}$ world concept offers an entirely new look at many aspects of the primeval evolution and biochemistry. Tracking all the facts that could be explained by the $\mathrm{Zn}$ world concept better than by other hypotheses on the origin of life is beyond the scope of this paper. In particular, we anticipate that this concept will provide a framework for many observations related to the biochemistry of zinc. Here we consider only those explanations that clearly separate the suggested concept from other hypotheses of abiogenesis. Besides, we try focusing on the phenomena that until now did not have acceptable explanations.

\section{Energetics of abiogenesis}

The $\mathrm{Zn}$ world concept explains how both the reduction of $\mathrm{CO}_{2}$ and the primeval biosyntheses could be driven by solar energy (see the accompanying article [97] for details). Other hypotheses on the origin of life either do not consider the energetics of abiogenesis explicitly (heterotrophic origin of life/RNA World) or, as the above discussed concepts of Wächtershäuser [56-61] and of Russell and co-workers [62-71], suggest mechanisms that do not seem to be plausible from the physical or (bio)chemical viewpoints (see [72] and the Background section above).

\section{Photostability of polynucleotides}

As discussed in the accompanying article [97], (poly)nucleotides, especially those building WatsonCrick pairs, are uniquely photostable (see also $[33,120,121])$. The $\mathrm{Zn}$ world concept explains this unique photostability by the role of the UV light not only as an energy source, but also as a selective factor during the first evolutionary steps. The unique photostability of (poly)nucleotides finds no explanation in any other hypothesis on the origin of life.

\section{The zinc paradox}

As discussed above, $\mathrm{Zn}^{2+}$ ions are used as cofactors by several groups of enzymes that are mostly involved in the cleavage or formation of chemical bonds (see Section 2.1.2.3). Thereby $\mathrm{Zn}^{2+}$ ions serve as Lewis acids upon catalytic transitions [128]. Generally, the capacity of a transition metal to serve as a Lewis acid is determined by its position in the Irving-Williams series and should increase as: $\mathrm{Mn}<\mathrm{Fe}<\mathrm{Co}<\mathrm{Ni}<\mathrm{Cu}>\mathrm{Zn}$ [241]. Hence $\mathrm{Zn}$, as a Lewis acid, is expected to be better than $\mathrm{Mn}$ or Fe, but worse than $\mathrm{Cu}$. However, as specifically noted by Williams and Fraústo da Silva [128], the difference between the transition metals in this respect is not that great, and deviations from the Irving-Williams series are possible, e.g. owing to the influence of the enzyme ligands. In many experiments, $\mathrm{Zn}$ atoms could be replaced by other transition metal atoms with only minor loss in the enzyme activity (in some cases, even with an increase in activity) $[128,242]$. Therefore, the almost exclusive involvement of 
Table 4: Association of essential divalent metals and the products of ubiquitous genes.

\begin{tabular}{|c|c|c|c|}
\hline Protein function & EC number (if available) & Functional dependence on metals & Metals in at least some structures \\
\hline \multicolumn{4}{|c|}{ Products of ubiquitous genes, according to [196] } \\
\hline \multicolumn{4}{|l|}{ Translation and ribosomal biogenesis } \\
\hline Ribosomal proteins ( 33 in total) & & $\mathrm{Mg}$ & $\mathrm{Mg}, \mathrm{Zn}$ (see main text) \\
\hline Seryl-tRNA synthetase & 6.1.1.11 & $\mathrm{Mg}, \mathrm{Zn}$ & Mn [218], Zn [219] \\
\hline Methionyl tRNA synthetase & 6.1.1.10 & $\mathrm{Mg}, \mathrm{Zn}$ & $\mathrm{Zn}[220]$ \\
\hline Histidyl tRNA synthetase & 6.1.1.21 & $\mathrm{Mg}$ & No metals seen \\
\hline Tryptophanyl- tRNA synthetase & 6.1.1.2 & $\mathrm{Mg}, \mathrm{Zn}$ & $\mathrm{Mg}$ \\
\hline Tyrosyl- tRNA synthetase & 6.1.1.1 & $\mathrm{Mg}$ & No metals seen \\
\hline Phenylalanyl- tRNA synthetase & 6.1 .1 .20 & $\mathrm{Mg}, \mathrm{Zn}$ & $\mathrm{Mg}$ \\
\hline Aspartyl- tRNA synthetase & 6.1.1.12 & $\mathrm{Mg}$ & $\mathrm{Mg}, \mathrm{Mn}[221]$ \\
\hline Valyl-tRNA synthetase & 6.1.1.9 & $\mathrm{Mg}$ & $\mathrm{Zn}[222]$ \\
\hline Isoleucyl-tRNA synthetase & 6.1 .1 .5 & $\mathrm{Mg}, \mathrm{Zn}$ & Zn $[223,224]$ \\
\hline Leucyl-tRNA synthetase & 6.1.1.4 & $\mathrm{Mg}$ & $\mathrm{Zn}[225]$ \\
\hline Threonyl-tRNA synthetase & 6.1.1.2 & $\mathrm{Mg}, \mathrm{Zn}$ & Zn [226] \\
\hline Arginyl-tRNA synthetase & 6.1 .1 .19 & $\mathrm{Mg}$ & No metals seen \\
\hline Prolyl-tRNA synthetase & 6.1.1.15 & $\mathrm{Mg}, \mathrm{Zn}$ & $\mathrm{Mg}, \mathrm{Zn}$ [227], Mn [228] \\
\hline Alanyl-tRNA synthetase & 6.1.1.7 & $\mathrm{Mg}, \mathrm{Zn}$ & $\mathrm{Mg}, \mathrm{Zn}$ [229] \\
\hline Translation elongation factor $\mathrm{G}$ & 3.6.5.3 & $\mathrm{Mg}$ & $\mathrm{Mg}$ \\
\hline $\begin{array}{l}\text { Translation elongation factor } \mathrm{P} / \text { translation } \\
\text { initiatiation factor elF5-a }\end{array}$ & & & $\mathrm{Zn}$ (PDB entry $\underline{2 \mathrm{E}} 9 \mathrm{H})$ \\
\hline Translation initiation factor 2 & & & $\operatorname{Zn}[230]$ \\
\hline Translation initiation factor IF-I & & & No divalent metals \\
\hline Pseudouridylate synthase & 5.4 .99 .12 & $\mathrm{Mg}, \mathrm{Zn}[2 \mid 7]$ & No metals seen \\
\hline Methionine aminopeptidase & 3.4 .11 .18 & $\mathrm{Mn}, \mathrm{Zn}$, or Co & Mn or $\mathrm{Zn}$ or Co \\
\hline
\end{tabular}

\section{Transcription}

Transcription antiterminator NusG

$-$

DNA-directed RNA polymerase, subunits $\alpha, \beta, \quad 2.7 .7 .6$ $\beta^{\prime}$

No metals seen

$\mathrm{Mg}$

$\mathrm{Mg}, \mathrm{Mn}, \mathrm{Zn}[23 \mathrm{I}]$

\section{Replication}


Table 4: Association of essential divalent metals and the products of ubiquitous genes. (Continued)

\begin{tabular}{|c|c|c|c|}
\hline DNA polymerase III, subunit $\beta$ & 2.7.7.7 & $\mathrm{Mg}$ & $\mathrm{Mg}[232]$ \\
\hline $\begin{array}{l}\text { Clamp loader ATPase (DNA polymerase III, } \\
\text { subunit } \gamma \text { and } \tau \text { ) }\end{array}$ & 2.7.7.7. & $\mathrm{Mg}$ & $\mathrm{Mg}, \mathrm{Zn}[233]$ \\
\hline Topoisomerase IA & 5.99.1.2 & $\mathrm{Mg}$ & No metals seen \\
\hline \multicolumn{4}{|l|}{ Repair and Recombination } \\
\hline $\begin{array}{l}\text { 5'-3' exonuclease } \\
\text { (including N-terminal domain of Poll) }\end{array}$ & 3.I.II..$^{\mathrm{a}}$ & $\mathrm{Mg}$ & $\mathrm{Mg}$ \\
\hline $\operatorname{Rec} A / \operatorname{Rad} A$ recombinase & - & - & $\mathrm{Mg}$ \\
\hline \multicolumn{4}{|l|}{ Chaperone function } \\
\hline Chaperonin GroEL & 3.6.4.9 & $\mathrm{Mg}$ & $\mathrm{Mg}$ \\
\hline O-sialoglycoprotease/apurinic endonuclease & 3.4.24.57 & $\mathrm{Zn}$ [239] & $\mathrm{Mg}, \mathrm{Fe}[234]$ \\
\hline
\end{tabular}

\section{Nucleotide and amino acid metabolism metabolism}

\begin{tabular}{llll}
\hline Thymidylate kinase & 2.7 .4 .9 & $\mathrm{Mg}$ & $\mathrm{Mg}$ \\
\hline Thioredoxin reductase & 1.8 .1 .9 & - & No metals seen \\
\hline Thioredoxin & & $\mathrm{Zg}[235]$ & $\mathrm{No}$ entries \\
\hline CDP-diglyceride-synthase & 2.7 .7 .41 & $\mathrm{Mg}$ & $\mathrm{Mg}, \mathrm{Zn}[236]$ \\
\hline Energy conversion & & $\mathrm{Mg}$ & $\mathrm{Mg}$ \\
\hline $\begin{array}{l}\text { Phosphomannomutase } \\
\text { Catalytic subunit of the membrane ATP synthase }\end{array}$ & 3.6 .1 .34 & - & $\mathrm{No}$ metals seen \\
\hline $\begin{array}{l}\text { Proteolipid subunits of the membrane ATP } \\
\text { synthase }\end{array}$ & 3.6 .1 .34 & - & $\mathrm{No}$ metals seen \\
\hline \begin{tabular}{l} 
Triosephosphate isomerase \\
\hline
\end{tabular}
\end{tabular}

\section{Coenzymes}

Glycine hydroxymethyltransferase

2.1.2.1

$\mathrm{Mg}$

No metals seen

\section{Secretion}

Preprotein translocase subunit SecY

Signal recognition particle GTPase FtsY

\section{Miscellanous}

Predicted GTPase

Additional ubiquitous gene products from ref. [215]
2.7.7.-
Zn [238] 
Table 4: Association of essential divalent metals and the products of ubiquitous genes. (Continued)

\begin{tabular}{llll}
\hline $\begin{array}{l}\text { S-adenosylmethionine-6-N', N'-adenosyl (rRNA) } \\
\text { dimethyltransferase (KsgA) }\end{array}$ & 2.I.I.48 & Mg & No metals seen \\
\hline Transcription pausing, L factor (NusA) & - & - & No metals seen \\
\hline
\end{tabular}

The lists of ubiquitous genes were extracted from refs. [196,215]. The data on metal dependence were taken from the BRENDA database [185], the presence of metals was as listed in the Protein Data Bank [140] entries. According to the BRENDA database [185], the enzymatic activity of most $\mathrm{Mg}$-dependent enzymes could be routinely restored by $\mathrm{Mn}$. As concentration of $\mathrm{Mg}^{2+}$ ions in the cell is ca. $10^{-2} \mathrm{M}$, whereas that of $\mathrm{Mn}^{2+}$ ions is ca. $10^{-6} \mathrm{M}$, the data on the functional importance of $\mathrm{Mn}$ were not included in the table.

$\mathrm{Zn}$ as cofactor in all these enzymes has been considered enigmatic, especially taking into account the low levels of $\mathrm{Zn}$ in the seawater $[124,128]$. Moreover, while prevalence of $\mathrm{Zn}$ in certain types of enzymes could be attributed to the catalytic properties of $\mathrm{Zn}^{2+}$ ions, their ubiquitous involvement as structural elements [128,210,243] had no explanation at all. This paradoxical prevalence of $\mathrm{Zn}$ ions can now be explained by the shaping - and folding - of first proteins in Zn-rich habitats.

Summarizing this section, we can conclude that the $\mathrm{Zn}$ world concept offers a single parsimonious explanation for a set of diverse observations that have not been rationalized so far.

\section{Discussion}

In this work, we made six non-trivial biological predictions stemming from the idea of the origin of life in $\mathrm{Zn}$ rich settings. Specifically, we predicted that $\mathrm{Zn}^{2+}$ ions would be preferentially associated with ancient RNA and protein molecules, including ribozymes and those enzymes that catalyze evolutionarily old reactions. These predictions were tested using publicly available data, obtained in studies that had no apparent bias towards $\mathrm{Zn}$. The results of these tests revealed that modern cells contain surprisingly high levels of $\mathrm{Zn}$, which is mostly bound to its constituent molecules, DNA, RNA and proteins. The most parsimonious explanation of these observations seems to be that, indeed, the first life forms evolved in a Zn-rich environment.

In addition, following the Popper's principles, we have tested the $\mathrm{Zn}$ world concept by considering the ability of this concept to provide explanations for obscure facts that other theories either ignore or cannot explain. The fact that the $\mathrm{Zn}$ world concept has successfully passed all these tests makes it a serious contender for the title of a syncretic concept of the origin of life.

\section{Zinc world: No country for old iron?}

Some of the results obtained in the course of this work were rather unexpected, for example, the almost complete absence of the Fe atoms in the evolutionarily oldest protein folds (Table 2) and in putative proteins of the LUCA (Table 4). The apparent absence of correlation between the supposedly primitive traits of life forms and the involvement of iron, which could be seen in a variety of tests (Tables 1, 2, 3, 4), strongly argues against the view that life has emerged in iron-rich environments [56$58,61-71,77,136]$. This iron-centric view is based, among others, on the fact that the iron-sulfur clusters could serve both as protein cofactors (e.g. in ferredoxins) and crystal units of natural minerals (see $[67,244]$ and references therein). The argumentation, however, could be equally well applied to Zn. Zinc atoms and ZnS clusters are prevalent both in hydrothermal settings [104,117] and, as cofactors, in proteins $[128,245-247]$. Furthermore, proteins that coordinate either $\mathrm{Zn}$ atoms or $\mathrm{ZnS}$ clusters seem to be more widespread than iron-sulfur proteins [130,245-251]. Ironically, the first zinc-sulfur protein, metallothionein, had been described by Margoshes and Vallee [252] even before the discovery of the first iron-sulfur protein, ferredoxin [253]. Sequence similarities between proteins that bind FeS and $\mathrm{ZnS}$ clusters were noted e.g. by Williams and Fraústo da Silva [128]. Some metal-binding protein scaffolds can bind either $\mathrm{Fe}$ or $\mathrm{Zn}$, depending on their relative concentrations (see $[254,255]$ and references therein). Remarkably, the iron-sulfur cluster assembly protein IscU is capable of binding $\mathrm{Zn}^{2+}$ ion in its monomeric form [256], whereas three such monomers have to interact to bind a FeS cluster [257]. The Zn-binding mode could well be the evolutionarily older one in this protein. While FeS clusters are involved, to a large extent, in electron transfer reactions (see Table 3), zincsulfur proteins are mostly associated with RNA and DNA, e.g. as zinc fingers $[243,245,246,250]$. In the view of the assumed evolutionary primacy of RNA, one could imagine that, in a Zn-rich environment, zinc-sulfur proteins could have emerged first. In fact, it is extremely unlikely that FeS clusters could have ever been directly involved with RNA since they are efficient cleavage agents for both RNA and DNA (see [258] and references therein), not to mention hazardous hydroxyl radicals that could be produced in the presence of redox-active $\mathrm{Fe}^{2+} / \mathrm{Fe}^{3+}$ ions [168170]. The Fe atoms and FeS clusters could replace $\mathrm{Zn}$ atoms and $\mathrm{ZnS}$ clusters - in some cases - only after the emergence of enzymes and membranes which could protect RNA and DNA from the damaging action of iron and its compounds. The redox-active $\mathrm{Fe}$ and $\mathrm{Cu}$ atoms could be recruited as redox cofactors (in support to the nucle- 
otide-based cofactors such as $\mathrm{NAD}(\mathrm{P}) \mathrm{H}, \mathrm{FMN}, \mathrm{FAD}$, see the accompanying article [97] and references therein) by enzymes of those energy-converting systems that eventually replaced the ZnS-mediated photosynthesis. This time pattern is in agreement with the results of the above discussed analysis of the changes in biogeochemical signatures through time [125], where the relative fraction of Zn-dependent enzymes decreased in the course of evolution, whereas the fractions of the $\mathrm{Fe}$ - and $\mathrm{Cu}$-dependent enzymes have increased. The importance of redox enzymes must have further increased with the oxygenation of Earth habitats, such that the total content of Fe in modern organisms is compatible with that of $\mathrm{Zn}$.

\section{Zinc world: Metals and first biotopes}

Testing the predictions on metal binding by RNA and protein molecules also revealed a notable presence of $\mathrm{Mn}$ atoms in RNA structures and the oldest protein folds. This presence of $\mathrm{Mn}$ might be not accidental. Manganese is unique in at least two respects:

a) $\mathrm{Mn}^{2+}$ ions are typical constituents of hydrothermal fluids $[259,260]$. In experiments that modeled the high-pressure conditions at hydrothermal vents, MnS precipitated at the same rate as $\mathrm{ZnS}$, i.e. much slower than sulfides of $\mathrm{Fe}$ and $\mathrm{Cu}$ [259]. Hence, one can expect that the sulfides of $\mathrm{Zn}$ and $\mathrm{Mn}$ could precipitate at approximately the same distance from the orifices of the primeval sub-aerial hot springs and could form mixed $\mathrm{ZnS} / \mathrm{MnS}$ haloes around them, as found in the ancient volcanogenic metal sulfide (VMS) deposits where the haloes of neighboring vents intersect and join into networks $[105,261]$.

b) MnS is the only other transition metal sulfide besides $\mathrm{ZnS}$ - that can photoreduce $\mathrm{CO}_{2}$ albeit, seemingly, with a lower quantum yield (see Fig. 1 and refs. $[95,262])$. The band gap of MnS is smaller than that of ZnS, about 3-3.5 eV versus 3.2-3.9 eV (see Fig. 1 and [262-264]). Because of the smaller band gap, MnS can photoreduce $\mathrm{CO}_{2}$ by using visible light.

Hence, photoactive formations that contained MnS in addition to $\mathrm{ZnS}$ could use for photosynthesis not only the UV quanta, but also the visible light (up to ca. $450 \mathrm{~nm}$ ), which could increase the productivity of the first photosynthetic communities. In addition, because of its lower scattering, visible light could penetrate deeper into the porous interior of the photosynthetic edifices. We would like to note that the possible supportive role of $\mathrm{Mn}$ in the $\mathrm{Zn}$ world did not follow from the premises of the original hypothesis [97], but transpired during its testing.

The Zinc world concept provides a plausible answer to the question why some transition metals are essential for liv- ing organisms while others are not. The less frequent - as compared to $\mathrm{Zn}$ and $\mathrm{Mn}$ - usage of other transition metals as cofactors can be explained by their scarcity in the settings that hosted the first life forms. Generally, hydrothermal fluids contain not only $\mathrm{Zn}^{2+}, \mathrm{Mn}^{2+}$ and $\mathrm{Fe}^{2+}$ ions, which we have discussed so far, but also notable amounts of $\mathrm{Pb}, \mathrm{Cu}, \mathrm{Ni}$, Co and some other metals, with exact composition varying depending on location [104-106,260]. These metals are also found, in variable amounts, in the ancient VMS deposits (see $[261,265]$ for reviews and the accompanying article [97] for further details and references). However, the only metal sulfides that can photoreduce $\mathrm{CO}_{2}$ are $\mathrm{ZnS}$ and $\mathrm{MnS}$ (see $[95,99,122,262,264]$ ). Other transition metals, if present as substantial impurities in the ZnS/MnS settings, would function as energy traps for the photo-excited electrons (see Fig. 1 and ref. [264]) and decrease the quantum yield of the abiogenic photosynthesis. Hence, the exact metal content of sulfide precipitates, most likely, could vary at different spots of primeval hydrothermal activity depending on (i) the chemical composition of the underlying crust, (ii) the temperature of hydrothermal fluids and (iii) their $\mathrm{pH}$ value (as it varies nowadays, see [104-106,260]). However, only those precipitates made of $\mathrm{ZnS}$ and $\mathrm{MnS}$ could photosynthesize, support the first organisms, and, hence, be inhabited. Accordingly, if we consider a particular transition metal ion, the probability of its recruitment for some primeval biochemical task could be proportional to its concentration at a particular habitat multiplied by the number of potential "recruiters", i.e. the life forms present. As a result, some photosynthetically inert transition metals became involved only occasionally (e.g. Co, see Table 3 and ref. [266]) or upon later evolutionary steps (as $\mathrm{Fe}$, see discussion above), whereas others failed to attain any essential biological function (e.g. Pb).

The suggested concept might also explain why aluminum, although widespread in the Earth crust and soil, has not been recruited for biochemical tasks. The sulfides of aluminum, as well as of titanium, are unstable in water. Therefore aluminum does not precipitate at the spot of hydrothermal activity but becomes dissolved in water and apparently comes down later, far away from the hydrothermal orifices [267]. The absence of aluminum among essential metals, when combined with the importance of sulfur for biochemistry, appears to discount those models of abiogenesis that envision the origin of life in clays (see [268] and references therein) since clays are aluminum silicates that, unlike hydrothermal sulfide precipitates, do not contain sulfur.

Based on available geochemical data, in particular on the architecture of the ancient VMS deposits [105,261,265], one can envision networks of photosynthesizing and habitable bands of precipitated $\mathrm{ZnS}$ and $\mathrm{MnS}$ around prime- 


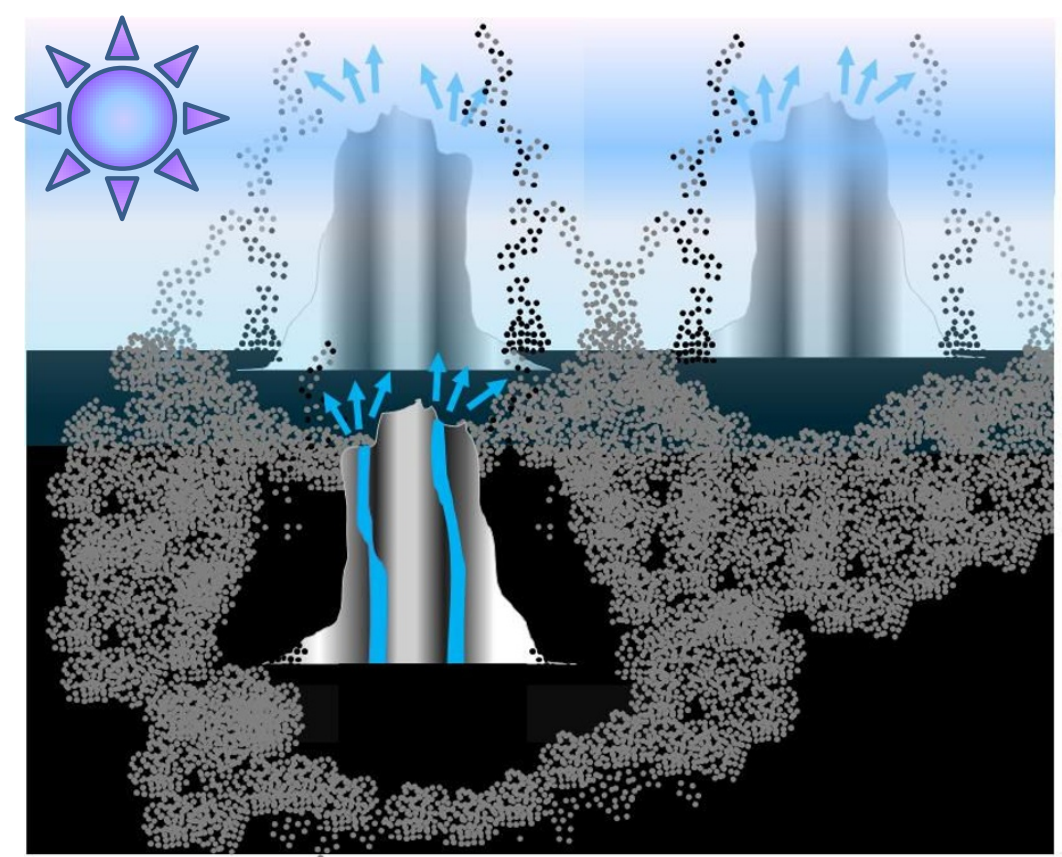

Figure 2

A schematic representation of interweaved haloes made of porous ZnS/MnS (shown as aggregates of grey spheres) around the sub-aerial, hydrothermal hot springs. These networks are proposed to have served as the Earth's first biotopes (see the text and the accompanying article [97]). The picture uses data from refs.[66, I05, II 5, I I 7,260,26I].

val hot springs. These networks of joined rings at the spots of geothermal activity, a kind of primeval "Yellowstone Park" realm, could represent the first Earth biotopes (see Fig. 2).

\section{Decline and fall of the Zinc world}

We can only speculate on the sequence of events that followed the drop in the atmospheric pressure below 10 bar and the gradual decay in the delivery of hot, Zn-rich hydrothermal fluids to the illuminated settings. An obvious consequence of these developments was gradual vanishing of illuminated $\mathrm{ZnS}$ surfaces and cessation of abiogenic photosynthesis.

As suggested in the accompanying article [97], ZnSdependent communities should have been functionally stratified, just as the modern phototrophic communities are (see $[45,269]$ and references therein). If so, the inhabitants of different $\mathrm{ZnS}$ strata would encounter vastly different levels of UV irradiation and evolve under different selective pressures. In particular, those inhabiting upper, light-exposed layers would need some protection from the damaging UV light. Such protection could be provided by UV-absorbing porphyrins and/or chlorins (precursors of chlorophylls). Being attached to proteins, these rings could convert the UV quanta, after absorbing them directly or getting them from nearby aromatic amino acids, into harmless red quanta [270]. In response to the demise of the ZnS-mediated photosynthesis, the life forms in the upper layers could use their chlorin-containing proteins to catalyze light-driven separation of electric charges [270] and thus become capable of reducing such compounds as e.g. $\mathrm{NAD}(\mathrm{P}) \mathrm{H}$, which could then convey the electrons to metabolic chains. Sequence and structural analyses showed that modern photochemical (photosynthetic) reaction centers could have emerged from dimerization of the ancestral simpler chlorin-carrying membrane proteins [270-275], which, in turn, could function as UV-protectors of primordial cells [270]. Halmann and colleagues [81] noted the similarity between physical mechanisms of the chlorophyll-based and semiconductor-based photosyntheses, which both include light-induced charge separation followed by the stabilization of the reduced states, as shown in Fig. 3. This figure also shows that if we focus on the photosynthesis by $\mathrm{ZnS}$ nanoparticles, even the sizes of the abiogenic and biogenic photochemical devices match each other. In addition, the same reaction of sulfide/sulphur oxidation is used to re-fill the photo-generated electron vacancies (holes) in the most primitive, homodimeric photochemical reaction centers of green sulfur bacteria $[276,277]$. The disadvantage of the modern protein-based photoreaction 


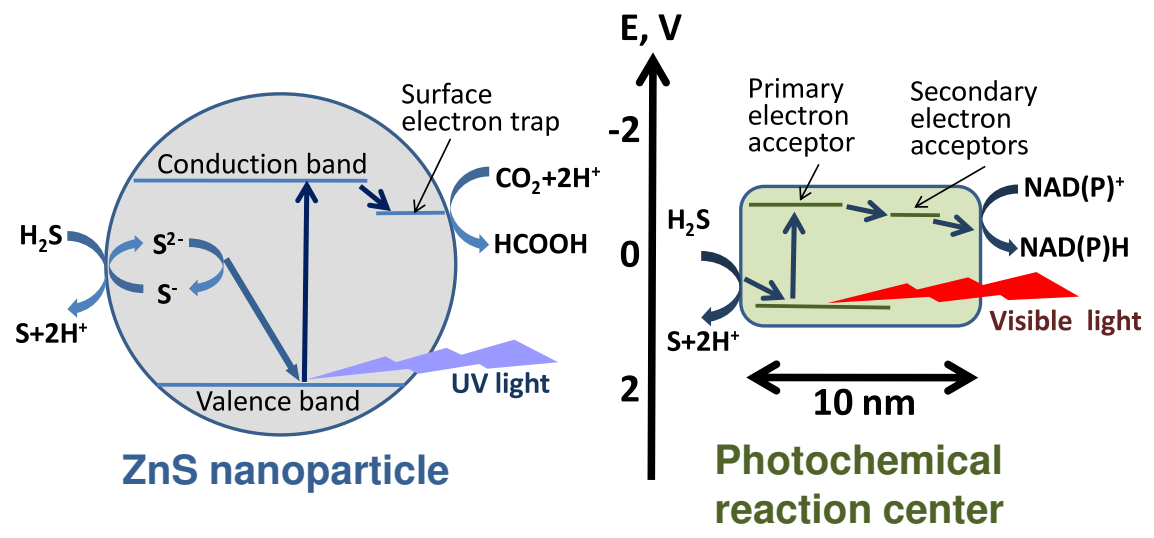

Figure 3

A comparison of energy diagrams for a photosynthesizing ZnS nanoparticle (left panel, the picture is taken from the accompanying article [97] and is based on references $[98,103,122]$ ) and a bacterial photochemical reaction center (right panel, a primitive, sulfide-oxidizing reaction center complex of green sulfur bacteria [276,277] is shown schematically as an example).

centers, as compared to $\mathrm{ZnS}$ crystals, is that they cannot reduce $\mathrm{CO}_{2}$ directly. Therefore a full-fledged proteinbased photosynthesis must include some version of the Calvin cycle to incorporate $\mathrm{CO}_{2}$ into organic molecules at the expense of photoreduced $\mathrm{NAD}(\mathrm{P}) \mathrm{H}$. As argued by Gánti [278], the Calvin cycle could develop directly from the Butlerov's reaction [279-281], since the sugar intermediates of the Calvin cycle essentially overlap with the components of this autocatalytic pathway (see also the accompanying article [97] and references therein). The biogenic photosynthesis could initially complement the gradually diminishing ZnS-mediated photosynthesis; its contribution, however, should have increased with time, as the formation of the $\mathrm{ZnS}$ surfaces in the illuminated, sub-aerial settings came to the end. In this framework, the emergence of biogenic photosynthesis might represent a clear-cut case of functional takeover - with the primeval photochemical reaction centers and primordial Calvin cycle accomplishing together the function that the $\mathrm{ZnS} /$ MnS covered fields could perform alone, namely the utilization of solar energy for fixation of $\mathrm{CO}_{2}$ (see Fig. 3).

Hence, although after the drop in the atmospheric $\mathrm{CO}_{2}$ pressure the photosynthesizing $\mathrm{ZnS}$ edifices could no longer build up in the illuminated settings, the life forms could persist in these habitats by relying on the proteinbased photosynthesis. In the absence of the $\mathrm{ZnS}$ settings, the organisms, however, had to undergo major changes upon adapting to the new environments. This selective pressure should have favored formation of encased, bacteria-like entities that could maintain - in their interior the chemical content similar to that in the $\mathrm{Zn}$ world, i.e. the high Zn level needed for the RNA and DNA processing machinery (see the previous sections). Since the concentration of $\mathrm{Zn}$ ions in the sea water is low, these organisms had to develop active membrane ion pumps to maintain high $\mathrm{Zn}$ levels in their interior, see [282] for reviews.

The Zn world, however, did not vanish completely; fresh, porous $\mathrm{ZnS}$ edifices continued to build up at the sea floor, owing to the high temperature of the deep-sea hydrothermal fluids. These $\mathrm{ZnS}$ habitats could still accommodate life forms, which, however, could no longer rely on abiogenic photosynthesis. One possible metabolic strategy for such organisms would be chemoautotrophy, i.e. obtaining reducing equivalents and energy from oxidation of sulfide or hydrogen, the approach which they could already practice while thriving in the dark, bottom layers of the photosynthesizing ZnS settings and which the prokaryotic inhabitants of hydrothermal vents still use these days. This strategy would impose strict limits on the size of living organisms, as they would have to maintain a high surface-to-volume ratio [283]. These organisms could gradually spread away from the ZnS settings and populate iron-rich settings, provided that they developed the cell envelopes and other tools to keep the intrinsic $\mathrm{Zn}$ level high.

The most conservative survival strategy would be to remain confined to the $\mathrm{ZnS}$ edifices and to retain the ancient heterotrophic way of life, i.e. to consume organic compounds - e.g. by using Zn-dependent hydrolases $[128,284,285]$ - that could come with hydrothermal fluids and/or result from the activity of the chemotrophic 
organisms. From the evolutionary point of view, such heterotrophs remained adherent to the primeval way of life and, hence, could retain some ancient features (e.g. high dependence of their metabolism on $\mathrm{Zn}$ ).

The accompanying paper [97] starts with Darwin's famous notion that emergence of living substance anew is extremely unlikely because "... at the present day such matter would be instantly devoured or absorbed, which would not have been the case before living creatures were formed [286]". Here we argue that the living matter may have emerged on Earth owing to a unique interplay between the solar UV-light and the geochemical conditions that brought into existence the sub-aerial $\mathrm{Zn}$ world. Thus, we dare to suggest that once the photosynthesizing Zn world could not persist anymore - perhaps, partly as a consequence of $\mathrm{CO}_{2}$ consumption by the first life forms there was no force left to power subsequent origins of life on Earth.

\section{Separation of the Main Domains of Life}

The mechanism of separation of LUCA's descendants into three main lineages remains controversial (see $[138,287,288]$ and references therein). Zillig and coworkers have suggested that the split of Bacteria and Archaea resulted from a geographic separation of two populations [289]. Gogarten-Boekels and colleagues proposed a catastrophe, such as a major meteorite impact, with ancestors of Bacteria and Archaea, respectively, as survivors of this catastrophe [290]. Woese suggested a 'genetic annealing' of the common gene pool as a mechanism leading to the three domains of life [195]. Martin and co-workers have suggested that Bacteria and Archaea are descendants of two distinct populations that thrived within an iron-sulfur deep-sea hydrothermal vent [64,138].

Whatever the separation mechanism(s), the modern representatives of the three domains of life are quite different. These differences seem to indicate that they have evolved, after the splitting of the main lineages, under different environmental conditions. Thus, any scenario of the domain separation has to include a tentative explanation of the key differences between the three domains of life. For example, it has to be explained why the (bacterio)chlorophyll-based photosynthesis is found in Bacteria but not in Archaea. Answering this particular question, Nisbet and Fowler hypothesized that (bacterio)chlorophyll-based photosynthesis has developed, among some inhabitants of the deep-sea hydrothermal vents, from heat sensors that could react to infrared radiation. These organisms, after their eventual migration into the sub-aerial habitats, could switch to the photo-autotrophic growth and eventually give rise to future Bacteria [291]. Alternatively, Russell and co-workers hypothesized that after the first life emerged at a deep-sea hydrothermal vent, a geological obduction could bring a portion of the deep-sea biosphere into the photic zone, with (bacterio)chlorophyll-based photosynthesis subsequently emerging in this population $[65,68]$.

The Zinc world scenario, in principle, can explain both the emergence of the main domains of life and the specific traits of the organisms belonging to them. Indeed, as argued above, the LUCA consortia could have inhabited photosynthesizing, porous $\mathrm{ZnS}$ settings. In the previous section, we have discussed the possibility that the inhabitants of different layers of the ZnS-confined communities could respond differently to the gradual decay in the $\mathrm{ZnS}$ deposition in the illuminated settings. The inhabitants of the upper layers would be switching to the (bacterio)chlorophyll-based photosynthesis, whereas the dwellers of the lower, darker layers would either turn to the chemoautotrophy or, alternatively, become highly specialized heterotrophs. It is noteworthy that with gradual migration of the high-temperature hydrothermal systems - and their inhabitants - into the sea depths, the sub-aerial phototrophic communities would eventually separate from the consortia staying with the hydrothermal vents. This separation would then persist at least until the emergence of the swimming mechanisms that enabled movement in the water column. During this time, discrete lineages would evolve independently and attain their specific traits.

The outlined hypothetical scenario implies that the demise of $\mathrm{ZnS}$ mediated photosynthesis triggered a major separation of the first life forms into (i) the sub-aerial communities dependent on (bacterio)chlorophyll-type photosynthesis as source of reducing equivalents (the future Bacteria) and (ii) the communities confined to the $\mathrm{ZnS}$ settings at the sea floor. The dwellers of the sea floor habitats could diversify further. Some of their lineages would evolve by developing new types of metabolism, e.g. chemoautotrophy. Acquisition of cell envelopes would enable their spread into $\mathrm{Zn}$-poor media and give rise to diverse archaeal branches. In contrast, the most conservative lineage would remain adherent both to the ancient $\mathrm{ZnS}$ milieu and to the primeval, heterotrophic way of life. Only after the dwellers of sub-aerial habitats developed swimming machinery they would have been able to detach from the shoreline and populate the ocean photic zones. A certain mixing between lineages would then become possible, enabling a "lateral" gene exchange between them [292]. The flow of organic matter from the surface water layers to the sea floor, owing to the sedimentation processes, had to be more extensive than in the opposite direction. Due to sedimentation, the larger, heterotrophic inhabitants of the ZnS settings, not being constrained by size limitations, could eventually acquire the 
representatives of phototrophic sub-aerial communities as endosymbionts. In particular, a symbiosis with respiring $\alpha$-proteobacteria, the future mitochondria [293], could, perhaps, rescue some of these heterotrophs (hereafter pro-eukaryotes) from oxidation and extinction after the ocean waters became oxygenated [294,295], paving the way to the modern Eukarya (see [287,288,296] and references therein).

The suggested scenario of the domain separation is based on two premises, namely (a) that the demise of the $\mathrm{ZnS}$ mediated photosynthesis would have forced living organisms to search for new sources of energy and (b) that inhabitants of the stratified ZnS habitats could pursue different strategies upon this search. The outlined scenario reproduces the actual differences between the representatives of the major domains and is in agreement with the following observations:

(i) (Bacterio)chlorophyll-based photosynthesis is present in Bacteria but not in Archaea (see [297] and references therein);

(ii) Inhabitants of the primordial microbial community at the Buck Reef Chert (a 250- to 400-m thick rock along the South African coast that was produced by phototrophic microbes $c a$. 3.4 Ga ago), have been defined as partially filamentous phototrophs, which apparently used the Calvin cycle to fix $\mathrm{CO}_{2}[298,299]$. The reported absence of traces of life in the layers that corresponded to the deeper (>200 m) water environments suggests that 3.4 Ga ago microbial communities of the photic zone were physically separated from the communities at the sea floor.

(iii) Archaeal metabolic pathways are very diverse; they include heterotrophy and several different types of chemotrophy [300], in particular, methanogenesis that is specific for Archaea [301]. This diversity suggests that members of the sea floor communities could have used different survival strategies and that their exodus from the deep-sea $\mathrm{Zn}$-rich habitats may have proceeded in several waves. In particular, the strong Ni-dependence of enzymes that are involved in methanogenesis [301] suggests that this type of metabolism emerged within habitats that were particularly enriched in nickel, for example, in the form of NiS (millerite).

(iv) Cell membranes of Archaea are fundamentally different from that of Bacteria (see $[187,302]$ and references therein). As argued elsewhere [73,303], this difference seems to indicate that the formation of modern ion-tight cell envelopes, needed to survive in chemically hostile environments, followed the separation of these two domains of life.

(v) Swimming motility mechanisms in different prokaryotic lineages are fundamentally different and evolutionarily unrelated [304]; this difference suggests that the LUCA could not swim. This deficiency, in turn, could have prevented a major gene exchange between the LUCA's descendants dwelling in different environments until the emergence of the first swimming apparata.

(vi) While Archaea contain many operational genes of supposedly bacterial origin, lateral gene transfer from Archaea to Bacteria was relatively minor and confined to hyper-thermophilic organisms, such as Thermotoga maritima [305,306]. This inequality of the lateral gene flows to and from Bacteria supports the straightforward possibility that the "horisontal" gene transfer between Bacteria and Archaea/Eukarya predominantly proceeded downwards relative to the Earth surface, and could be essentially driven by sedimentation processes.

(vii) No Eukarya-specific autotrophic mechanisms have been reported so far [64]; their absence might indicate that pro-eukaryotes relied on heterotrophy;

(viii) At least $90 \%$ of animal biomass of the modern hydrothermal vents depends on the chemoautotrophic endosymbionts (mostly sulfur- and hydrogen-oxidizing prokaryotes [104,307]). Even singlecelled Protozoa at hydrothermal vents exploit prokaryotic symbionts [308]. These numerous symbioses might reflect a long-lasting cooperation between the larger heterotrophic inhabitants of the vent communities and the smaller prokaryotes capable of che-

Table 5: Distribution of zinc-, non-heme iron- and copperbinding proteins in the three domains of life

\begin{tabular}{lccc}
\hline & $\mathbf{Z n}^{\mathbf{a}}$ & Non-heme $\mathbf{F e}^{\mathbf{b}}$ & $\mathbf{C u}^{\mathbf{c}}$ \\
\hline Bacteria & 4.9 & 3.9 & 0.3 \\
\hline Archaea & 6.0 & 7.1 & 0.4 \\
\hline Eukarya & 8.8 & 1.1 & 0.3 \\
\hline
\end{tabular}

The numbers show the fractions (in \%) of proteins with binding sites for $\mathrm{Zn}$, non-heme $\mathrm{Fe}$ and $\mathrm{Cu}$, respectively, as related to the total protein content, in the representatives of the three domains of life, determined by application of the same bioinformatics approaches [135].

a - Based on the data from [250];

$\mathrm{b}$ - Based on the data from [25I];

c - Based on the data from [3II]; 
moautotrophy; such cooperation may have eventually driven the emergence of eukaryotes $[293,296]$.

(ix) The fraction of Zn-containing enzymes in Eukarya is higher than in Bacteria or Archaea, see Table 5 and refs. $[124,250]$. This observation is consistent with the suggestion that pro-eukaryotes remained adherent to the $\mathrm{ZnS}$ settings for a longer time than the ancestors of other lineages.

Several authors who have noted this prevalence of the Zndependent enzymes in eukaryotes (see e.g. $[124,250]$ ) attributed it to the evolutionarily recent proliferation of Zn-binding motifs (in particular, zinc fingers) among the Eukarya. The abundance of the Zn-dependent enzymes in Eukarya $[124,250,309,310]$, however, is likely to be an ancient feature because it is complemented by the relative deficiency in the Fe-containing enzymes. The Fe deficiency follows from the quantitative estimates (see Table 5 and $[251,311])$, as well as from functional considerations: eukaryotic cells use the mitochondrial assembly systems to insert FeS clusters in the apo-proteins of their cytoplasmically and nuclearly located enzymes [312]. In most cases, an apo-protein is translocated across two mitochondrial membranes into the mitochondrial matrix, the FeS cluster is assembled and inserted, and the folded protein is translocated back into the cytoplasm across the same two membranes; it is still unclear whether and how the internal mitochondrial membrane maintains electric potential of ca. $200 \mathrm{mV}$ while a folded, FeS cluster-containing protein is being translocated across it. The absence of full-fledged cytoplasmic machinery for assembling $\mathrm{FeS}$ clusters in eukaryotes might have several explanations. It is possible that the pro-eukaryote possessed the respective enzymes but they were later replaced by the more efficient machinery of its $\alpha$-proteobacterial endosymbiont. However, it is hard to imagine that the (hypothetical) pro-eukaryotic machinery could be even less efficient than the described, extremely complicated procedure of inserting FeS clusters into the cytoplasmic apo-proteins by the mitochondrial enzymes. In our opinion, it is more probable that the pro-eukaryote just could not deal with FeS clusters because it dwelled in Fe-deficient environments. This certain incompetency of the proeukaryote in dealing with $\mathrm{Fe}$ follows also from the fact that eukaryotes use the heme biosynthesis enzymes that are specific for $\alpha$-proteobacteria and that, most likely, were acquired from the $\alpha$-proteobacterial endosymbiont [313]. Therefore eukaryotes may have colonized Fe-rich habitats later than the representatives of other domains, i.e. only after a pro-eukaryote entered into a symbiosis with a respiring $\alpha$-proteobacterium that provided the host with the Fe-processing enzymes. The emergence of respiring $\alpha$-proteobacteria should, however, follow the oxygenation of the ocean, at 2.0-2.5 Ga [127]. If so, pro- eukaryotes may have thrived and evolved in Zn-rich settings for at least $1 \mathrm{Ga}$, between the separation of the main domains of life and the oxygenation of biosphere $[296,314]$. Thus, not only the LUCA likely dwelled in the Fe-deficient, Zn-rich settings (see above), pro-eukaryotes may have inhabited these environments as well, and for quite a long time.

\section{Outlook: Potentially promising directions of the future research}

Based on the arguments from this paper and the accompanying article [97], we would like to submit that the $\mathrm{Zn}$ world hypothesis has successfully passed the first set of trials and therefore seems to be worth of further testing. We believe that a combination of the "bottom up" and "top down" approaches might be decisive for the further validation of the concept.

\section{Potential "bottom up" trials}

The most straightforward "bottom up" trial is to simulate the events in the primordial $\mathrm{Zn}$ world. The primordial photosynthesis can be simulated by using porous precipitates of $\mathrm{ZnS}$ and MnS (nano)particles covered by a solution that contains phosphite and other relevant ions, is saturated with $\mathrm{H}_{2}$ and $\mathrm{N}_{2} / \mathrm{NH}_{4}+$ in reasonable concentrations, and is set under the $\mathrm{CO}_{2}$ pressure of more than 10 bar. After illumination of this mixture by strong UV light, organic compounds are expected to form at the photosynthesizing surfaces. Upon simulations, it seems reasonable to vary the parameters which might affect the yield of photosynthesis, in particular the relative amounts of $\mathrm{MnS}$, $\mathrm{Mg}^{2+}, \mathrm{K}^{+}, \mathrm{Na}^{+}, \mathrm{N}_{2}$, phosphite, ammonium, and so on. The tricky task would be determining the exact chemical nature of the ZnS-adsorbed reaction products; fortunately, some relevant approaches have been recently developed $[43,94]$, so that this task, hopefully, could be accomplished. The primordial (photo)chemistry at the surface of a photoactive semiconductor might dramatically differ from the textbook biochemistry that describes the interactions of chemically stable compounds. It, however, might be inferred from experimentation. The recent synthesis of activated pyrimidine ribonucleotides from cyanamide, cyanoacetylene, glycolaldehyde, glyceraldehyde and inorganic phosphate in a reaction that bypassed free ribose and the nucleobases serves as a remarkable example of such an approach [33].

Simulations of the $\mathrm{Zn}$ world could also start from other "entry points". Under the above described conditions, (photo)polymerization of pre-formed nucleotides (or nucleosides in the presence of phosphite) could be studied at the $\mathrm{ZnS}$ surfaces. The encouraging results that were obtained upon studying the (photo)polymerization reactions at $\mathrm{TiO}_{2}$ surfaces [94], suggest that nucleotide polym- 
erization at illuminated $\mathrm{ZnS}$ surfaces could proceed with an acceptable quantum yield.

The interactions of pre-formed RNA polymers with ZnS/ MnS nanoparticles (quantum dots, see the accompanying article [97]) and their aggregates also deserve investigation. So far, such studies were mostly focused on the interactions between DNA molecules and CdS nanoparticles (see e.g. [315-318] for reviews and the accompanying article [97] for further references). Studies of the interactions between RNA molecules and $\mathrm{ZnS} / \mathrm{MnS}$ nanoparticles under simulated primeval conditions (see above) could shed light upon the earliest events in the RNA World. In particular, it seems worthy to check the influence of $\mathrm{ZnS}$ surfaces on the activity of ribozymes.

In addition, the stereoselectivity of the ZnS-mediated photocatalysis (see the accompanying article [97] and references therein) can be experimentally tested by applying the already existing approaches [319-323] to the substrates that might be relevant in the context of abiogenesis.

Since structures of key biological molecules and of $\mathrm{ZnS} /$ MnS nanoparticles are all known, it might be worthwhile to perform a computer modeling of the interactions between biopolymers at the $\mathrm{ZnS}$ (MnS) surfaces. The interactions between RNA strands, as well as associations of protein chains and RNA molecules could be modeled at the surface of $\mathrm{ZnS}$ templates; the results of such simulations might be of great interest for understanding the ZnSmediated primeval syntheses.

\section{Potential "top-down" tasks}

A formidable "top-down" task is to reconstruct the tentative biochemistry of the $\mathrm{Zn}$ world using bioinformatics approaches. Comparative genome analysis made it possible, by searching for the common genes in Bacteria, Archaea and Eukarya, to reconstruct the gene repertoire that was responsible for the translation and transcription in the LUCA $[196,197]$. However, this approach did not allow uncovering the metabolism of the LUCA because the metabolic enzymes, owing to the widespread lateral gene transfer [324], rarely could be definitely attributed to a particular lineage (as, for example, the F-type membrane ATPases to Bacteria and, respectively, the A/V-type membrane ATPases to Archaea and Eukarya [205]). The analysis presented here indicates that the initial steps of evolution proceeded in the habitats that were rich in $\mathrm{Zn}$, but deficient in Fe. Hence, Fe-dependent enzymes were unlikely to be involved in primordial metabolism. With the data from Table 2 on the oldest protein folds, it seems feasible to reconstruct the initial biochemistry by identifying the metabolic pathways that (i) predominantly involve $\mathrm{Zn}$ - and Mn-dependent, but not Fe-dependent enzymes and (ii) use proteins with the oldest folds. Leslie Orgel, to whom we would like to dedicate this article, has noted in his brilliant, posthumously published work [9] that the Calvin cycle differs from the reverse citric acid cycle in its preferable usage of $\mathrm{Mg}$ and $\mathrm{Zn}$ as metal cofactors instead of Fe. Orgel wrote: "It is interesting to compare the kind of chemistry involved in the Calvin cycle with that involved in the reverse citric acid cycle. In both cycles, almost all of the molecules involved carry two or more negative charges. In the Calvin cycle, the great majority of these charges are provided by phosphate groups, but in the reverse citric acid cycle, carboxylate groups are the only sources of negative charge. Furthermore, the only reduction that occurs in the Calvin cycle - the conversion of 3-phosphoglyceric acid to glyceraldehyde-3-phosphate - occurs via an acylphosphate intermediate. Reduction in the reverse citric acid cycle never involves a preliminary phosphorylation. Enzymes that use transition metal ions or iron-sulfur clusters play an important role in the reverse citric acid cycle, but are absent from the Calvin cycle, which uses $\mathrm{Mg}^{2+}$ and occasionally $\mathrm{Zn}^{2+}$ cofactors in its enzymes. It seems plausible, therefore, that the enzymes of the reverse citric acid pathway evolved in a region rich in transition metal ions and sulfur, whereas those of the Calvin cycle evolved where phosphate and magnesium were abundant. Presumably, one of these two cycles arose before the other. Is it possible to determine which came first by using information on biosynthetic pathways and genomics data? A decision on this question, though not directly relevant to the origin of life, would be of the greatest importance for understanding the history of protein-based metabolism on the early Earth" (quoted from ref. [9]). In the framework of the $\mathrm{Zn}$ world concept, we can suggest that the Calvin cycle emerged first (see the previous section), while the citric acid cycle would arise later, concomitant with the Fe-containing electron-transfer (respiratory) chains. This suggestion agrees with the accepted fact that the amount of free phosphate in the biosphere has decreased with time (see $[8,97,325]$ and references therein), so that metabolic cycles based on the phosphate usage, such as the Calvin cycle, should be evolutionarily older.

Last but not least, life continues to flourish within the ZnS-coated, deep sea hydrothermal fields, with their inhabitants categorized mostly as Archaea [115,117]. It might be worthwhile to inspect those ZnS-confined communities more closely. Although the ocean waters are saturated by oxygen, the interiors of the chimneys remain anoxic, because of the reduced state of hydrothermal fluids, so that many inhabitants of the vents are obligatory anaerobes [104]. There is a small chance that the descendants of pro-eukaryotes might still thrive in the anoxic, porous $\mathrm{ZnS}$ edifices. 


\section{Conclusion}

In this article we have validated the $\mathrm{Zn}$ world hypothesis by checking the predictions that followed from it. In addition, we have shown that this hypothesis explains several observations which so far remained without acceptable rationalization. Since the hypothesis has passed all these trials, its key suggestion, namely that the development of the first life forms could take place within the photosynthesizing ZnS edifices of hydrothermal origin, appears to have been validated. Further details of the primeval $\mathrm{Zn}$ world, and the exact physics and chemistry of the reactions involved, deserve further clarification.

In the course of this study, we have analyzed the available data on the relative abundance of transition metals in biological systems. We have found that RNA molecules and oldest protein folds are associated with $\mathrm{Zn}$ and $\mathrm{Mn}$, but not with Fe. It seems likely therefore that the early evolution proceeded in several distinct steps, namely (i) the "Zinc Age" with the first replicating entities "grazing" within photosynthesizing $\mathrm{ZnS}$ compartments and evolving into the first proto-cells, (ii) the "Iron Age", during which the organisms, after cessation of the ZnS-mediated photosynthesis, adapted to using abundant, but redoxactive iron atoms in their energy-converting devices, and (iii) the "Oxygen Age" when the increase in the atmospheric oxygen content has driven the major evolutionary changes aimed at prevention of the oxidative damage to aerobic organisms. The transitions between these "ages" probably represent major evolutionary bottlenecks.

While the transition from the anoxic to oxygenated biosphere has been long recognized as a key evolutionary event (see e.g. [295,297,326,327]), the transition from the Zinc Age to the Iron Age, as well as the very existence of the primeval $\mathrm{Zn}$ world remained unnoticed until now. It seems likely that the "Lost $\mathrm{Zn}$ World" has not been uncovered earlier because the spectroscopic elusiveness of $\mathrm{Zn}$ hindered the experimental studies of $\mathrm{Zn}$-containing systems. As a result, the importance of $\mathrm{Zn}$ for cell biology has been by and large underestimated (as a notable exception we would like to acknowledge the contribution of Vallee and co-workers who focused on Zn-containing enzymes for several decades $[248,328])$. Only in recent years, Zn-dependent systems have drawn more attention and the fundamental role of $\mathrm{Zn}$ started to get recognized (see $[124,245,246]$ and references therein). We hope that this article could contribute to a shift from the Fe-centric inorganic biochemistry to the Zn-centric one that would better reflect the key role of $\mathrm{Zn}$ in the living nature and its evolution.

The $\mathrm{Zn}$ world scenario, by implying that the $\mathrm{Zn}$ - and Mndependent enzymes preceded the Fe-dependent ones, offers a new tool - a biochemical time arrow - for the analyses of the earliest evolutionary events. Up till now, there was no clear way to arrange cellular systems in the order of their evolutionary emergence (with the notable exception of the few oxygen-dependent enzymes that have seemingly replaced the oxygen-independent ones after oxygenation of the atmosphere, see [327] and references therein). Although some features of the lost $\mathrm{Zn}$ world are reconstructed in this and the accompanying articles, a lot of further work would be needed to understand the earliest steps of life on the Earth.

Finally, this work suggests that origin of life was not a onetime historical accident but a natural and, perhaps, potentially inevitable consequence of an interplay between the solar UV-light and the geochemical conditions that existed once on the ancient Earth.

\section{Competing interests}

The authors declare that they have no competing interests.

\section{Authors' contributions}

Both authors analyzed the data, wrote and revised the paper.

\section{Reviewers' reports \\ Reviewer I \\ Arcady R. Mushegian, Stowers Institute for Medical Research, Kansas City, MO, USA}

This is the second of two thought-provoking manuscripts that discuss the hypothesis of the "Zn world" in which Life on Earth may have emerged. This manuscript is largely devoted to devising the ways of testing the traces of the $\mathrm{Zn}$ world in the present-day world of RNA and proteins. The computational experiments outlined in the manuscript are, in my opinion, the preliminary thoughts, which are unfortunately not set in a robust quantitative framework. More specifically:

Prediction 1. The elevated $\mathrm{Zn}^{2+}$ content of the primordial environments should be conserved inside modern cells

-- Please elaborate which content should be conserved - is it total concentration or free ion concentration? The latter is very low - is it because $\mathrm{Zn}^{2+}$ ion is nowadays toxic and needs to be sequestered? When in evolution did it become so?

Authors' response. In the revised version of the paper we have changed the order of predictions, this particular prediction has been moved to no. 5. We now explicitly indicate that it is the total concentration of $Z n$ that should be conserved. Actually, zinc is relatively non-toxic, at least for humans who can tolerate it in fairly large amounts [329]. We believe that the low levels of free $\mathrm{Zn}$ in the cells reflect certain $\mathrm{Zn}$ limitation of modern 
organisms and, perhaps, justify the currently popular inclusion of $Z n$-containing complexes into the vitamin sets.

\section{Reviewer I}

Prediction 2. There should be ribozymes with Zn-dependent catalytic activities.

-- I think that an honest conclusion would be that direct evidence of this is weak, though synthetic ribozymes that can use $\mathrm{Zn}^{2+}$ ions are known.

Authors' response. Generally, we agree with the referee's comment. In more detail we consider this topic in our response to Koonin.

\section{Reviewer I}

Prediction 1. RNA structures should be enriched in $\mathrm{Zn}^{2+}$ ions.

-- The way I understand the data, the presence of in the $\mathrm{Zn}^{2+}$ ions in known RNA structures in a form directly bound to RNA is not much different from $\mathrm{Mn}$ and is much less common than Mg. Computing the enrichment statistics here and everywhere else in the study may help, though I appreciate the difficult issues that have to do with the sampling.

Authors' response. In this work, to avoid a "self-serving" bias, we based on the data available either from the literature or from the publicly-accessible databases. We would like to emphasize that an accurate checking of each prediction is a task that would have required writing a separate article.

\section{Reviewer I}

Prediction 3. $\mathrm{Zn}^{2+}$ ions should be associated with the evolutionarily oldest protein folds;

-- This again should be a quantitative argument, but I am not sure what it actually is: associated with the oldest folds more than with the younger ones? Associated more than other divalent cations? More than what should be expected by chance? More specifically: the particular set of ubiquitous folds that are taken as a (most likely, reasonable) proxy for the oldest folds are clearly rich in divalent cation-binding proteins. Many families of dinucleotidebinding Rossmanoids, nucleotidyltransferases and polymerases of different classes - all of them use $\mathrm{Mg}^{2+}$ in preference to everything else, and if there is no $\mathrm{Mg}^{2+}$ in the crystal growth media, occasional $\mathrm{Zn}^{2+}$ will substitute. In these classes, there is no such thing as "Zn or Mg".

Authors' response: We agree that a more systematic study of metal occurrence in the "oldest" and "youngest" folds would be highly desirable. Here we just counted metal ions that are present in the crystal structures. Thereby we did not check whether $\mathrm{Mg}^{2+}$ was present in the crystal growth media or not (usually it was). The fact that $\mathrm{Zn}^{2+}$ ions were seen in many structures in spite of the presence of $\mathrm{Mg}^{2+}$ ions in crystallization media might indicate that in certain cases (e.g. in zinc fingers) $\mathrm{Mg}^{2+}$ ions could not substitute for $\mathrm{Zn}^{2+}$ ions.

\section{Reviewer I}

Prediction 4. Enzymes with evolutionarily "old" functions should depend on $\mathrm{Zn}^{2+}$;

-- I suggest either obtaining Zerkle data and examining them more closely, or not discussing them at all.

Authors' response: We decided to retain the data of Zerkle and co-workers as unbiased evidence, but merged this prediction with the one on the function takeover from ribozymes by first enzymes. In the original version of the manuscript, while discussing the data of the data of Zerkle and co-workers, we have argued that they may have overestimated the fraction of ironcontaining enzymes at the stage of the "very early life" (see also below for a related point made by Forterre). For example, we believe that iron-rich respiratory enzymes - assumed to be present from the very beginning by Zerkle and co-workers [125] - were not needed before the oxygenation of the atmosphere. In the revised manuscript we have dropped this discussion for the sake of brevity. These points deserve be considered in a separate publication.

\section{Reviewer I}

Prediction $4 \mathrm{a}$. The enzymes that emerged to take over the catalytic functions from ribozymes should be dependent on $\mathrm{Zn}^{2+}$

-- Why this would be the case? Transition from the RNA World to the Protein World may have occurred later than the $\mathrm{Zn}$ world, and other metals, like $\mathrm{Mg}^{2+}$, may have taken over the catalytic roles already. This seems to be better compatible with the evidence, does it not?

Authors' response: In the revised manuscript we argue, in response also to the comments of Koonin, that the Last Universal Common Ancestor still dwelled in Zn-rich habitats. Then the transition from the RNA World to the RNA/Protein World would also have proceeded in Zn-enriched environments. The amount of $\mathrm{Mg}^{2+}$ in the sea water is high and apparently always has been high. However, since $\mathrm{Mg}^{2+}$ is a poor Lewis acid, certain catalytic tasks require transition metals. Accordingly, we argue that many catalytic activities that are common for enzymes and ribozymes are catalysed by zinc-dependent enzymes.

\section{Reviewer I}

Manuscript as a whole: There is no discussion of the effect of various concentrations of the $\mathrm{Zn}^{2+}$ ion on the stability 
of the phosphoester bond. There is related discussion of $\mathrm{Fe}^{2+}$ ions on pg 17, but not of $\mathrm{Zn}^{2+}$ ions.

Authors' response:The important topic of the Zn-catalyzed cleavage of phosphoester bonds (see also the comment by Forterre) is now included in the accompanying article [97] and is additionally discussed in the author's response to reviewers of that article.

\section{Reviewer I}

pp. 26-31 are quite redundant with the first manuscript consider shortening?

Authors' response: The redundant parts have been streamlined.

\section{Reviewer I}

p. 34 - items (iv) and (v) sound very reasonable to me, but I do not see how they relate to $\mathrm{Zn}$ world. The same for items (vii) and (viii) on p. 35.

\section{Authors' response:}

Item (iv): The fundamental difference between the membranes of Bacteria and Archaea indicates that modern membranes developed separately in the two domains. Then the Last Universal Common Ancestor (LUCA) must have had primitive (if any) membranes that could not be particularly ion-tight and should have enabled ionic equilibration with surrounding media $[73,138,187,206]$. In the revised manuscript, we argue that the high $\mathrm{Zn}$ content of modern cells could be traced to the ionic equilibrium between the interior of the LUCA and its $\mathrm{Zn}$ rich environment.

Item (v): We suggest that the separation of the major domains was driven by the drift of the ZnS-confined seafloor communities away from the continental phototrophic ones. If the LUCA had swimming gadgets, these communities could continuously mix and exchange genes, preventing the development of Bacteria- and Archaea-specific traits.

Items (vii) and (viii): Item (viii) became (ix) in the revised manuscript. The absence of eukaryote-specific, iron-processing machinery even in modern Eukarya strongly indicates that proeukarya could not rely upon iron-dependent redox metabolism. The only metabolic alternative would have been heterotrophy of some kind relying on the $\mathrm{Zn}$-dependent hydrolases.

\section{Reviewer's response in a second review}

The distance that a swimming LUCA can cover: how does it compare with the velocity of continental drift?

Authors' response: The continental drift was unlikely to take place in Hadean. It is believed that at that time, cooling of the
Earth, the main cause of contemporary continental drift, was mediated by numerous "hot spots" resembling modern Iceland [49]. However, the importance of swimming for the gene exchange between the major domains could be evaluated by estimating the rate of "sinking" of the Zn-rich habitats. Using estimates of the atmospheric pressure of ca. 100 bar after condensation of the ocean at $4.4 \mathrm{Ga}[52,53]$ and 2-6 bar at 3.3 $\mathrm{Ga}[50]$ and assuming a linear decrease of pressure with time, it is possible to calculate that the pressure may have decreased, on average, by 1 bar in 10 million years. When the pressure falls below certain threshold value (ca. 10 bar), the highest temperature of hydrothermal fluids drops below $\sim 200^{\circ} \mathrm{C}$ and they become depleted of $\mathrm{Zn}$. Therefore, after the atmospheric $\mathrm{CO}_{2}$ pressure dropped below 10 bar, the $\mathrm{Zn}$-rich hot springs could function only at a certain depth, where the total pressure - of the atmosphere and the water column - remained above 10 bar. A 10-meter water column produces pressure of ca. 1 bar. Therefore the submersion of the Zn-rich hydrothermal systems should have proceeded with a rate of ca. 10 meters in 10 million years, or ca. 1 micron per year, slow enough to be overcome by any kind of swimming motility. Therefore, if LUCA and its immediate descendants could swim, the phototrophic, swimming organisms could occupy the surface water layer (the photic zone) just above the sea-floor communities. The sedimentation of these organisms would promote sharing of genes and would have prevented crystallization of the domain-specific traits. In contrast, non-swimming organisms would have stayed confined to their habitats, so that the sub-aerial phototrophic communities could not, at least initially, exchange genes with the see-floor, ZnS-confined communities.

\section{Reviewer I}

p. 36 line 19: I do not see why these explanations are parsimonious or why this would necessarily be a good thing.

Authors' response:Parsimony is a good thing. If one finds an explanation that simultaneously covers several unresolved items, the probability that this hypothesis captures some actual features of a natural phenomenon is higher than when one has to come up with a separate explanation for each unsolved item.

Reviewer's response in a second review: You explained why you think parsimony is good but not why you think these explanations are parsimonious.

Authors' response: The Zn world concept may be considered a parsimonious explanation of the three items listed in section on testing the explanatory power of the $\mathrm{Zn}$ world concept. because it explains them all. Alternatively, one could suggest separate explanation(s) for each item. For example, the prevalence of $\mathrm{Zn}$ in modern enzymes ( $Z n$ paradox) might be explained by the emergence of life within Zn-rich hydrothermal settings of sea floor. Then, however, the unique photochemical traits of nucleic acids would still remain unexplained. These unique traits, separately, were suggested to reflect the emergence of life in some 
illuminated settings $[78,119,120]$. If we now try to find a parsimonious explanation for the $\mathrm{Zn}$ paradox and the unique photochemistry of nucleic acids, the seemingly unique solution is the emergence of first life forms in some illuminated, $\mathrm{Zn}$-rich settings. However, Zn could be present on primeval Earth only as $\mathrm{ZnS}$, which, when illuminated, can reduce $\mathrm{CO}_{2}$. Hence a parsimonious explanation just for two items "bore" a solution to the problem of abiogenic $\mathrm{CO}_{2}$ reduction as well.

\section{Reviewer 2}

Eugene V. Koonin, National Center for Biotechnology Information, National Library of Medicine, National Institutes of Health, Bethesda, MD, USA

This paper strives to test the hypothesis that is put forward in the accompanying paper by Mulkidjanian, namely that life originated in a photosynthetic "Zn world" where Zn sulfide catalyzed a variety of synthetic reaction fuelled by the energy of UV radiation [97]. The idea of the pivotal role of $\mathrm{Zn}$ ions (and $\mathrm{ZnS}$ in particular) in the earliest stages of the evolution of life is highly attractive and generally plausible. However, in this manuscript, Mulkidjanian and Galperin put the plank very high by formulating several predictions that they claim to serve as Popperian tests of the "Zn world" hypothesis. In principle, the intention to test the hypothesis in a formal Popperian setting is indeed commendable. In practice, it is well known that it is hard to strictly adhere to Popperian criteria, and this paper is no exception. Unfortunately, as I see it, all the formulated predictions are weak, not unique to the " $\mathrm{Zn}$ World" hypothesis, and the nature of the evidence cited as being compatible with the predictions is such that one is prompted to ask "so what?" on most occasions. I briefly address the predictions and their purported tests one by one (the numbering of the predictions is mine - I think the authors should try to be more consistent to facilitate reading).

\section{Authors' response:}

In relation to the popular view on the importance of iron for the primeval metabolism, our article gives a following answer to the "so what?" question: "the early life, most likely, developed in Zn-rich settings, its emergence in Fe-rich settings is unlikely. Free $\mathrm{Zn}^{2+}$ ions, however, because of their poor solubility in primordial seawater, could have become available only if some process led to their continuous release - e.g. primordial abiogenic photosynthesis, as we suggest".

The rationale beyond our decision to formulate a set of testable predictions was simple (see also ref. [25]): if several predictions prove to be correct, then the tested hypothesis could be fairly countered only by an alternative hypothesis that would explain all those predicted observations. Hence the number of different predictions has a value of its own.
The following paragraphs respond to the specific comments of the referee that are related to particular predictions; the more general comment is addressed at the end of our response.

\section{Reviewer 2}

1. High content of $\mathrm{Zn}$ in modern cells - predicted on the basis of the "chemical conservation" principle. The principle is extremely general and might not be of huge heuristic value but suppose we accept it. The problem with this prediction is that it is not specific at all. Yes, of course, there are many Zn-dependent enzymes in all cells, and $\mathrm{Zn}$ is concentrated compared to any environment. Is it relatively more abundant than other divalent cations? There is no answer in the paper. But, even if it was, does this link $\mathrm{Zn}$ to primordial stages of evolution? Or, if it was not, would that falsify the $\mathrm{Zn}$ world hypothesis? I doubt that either of these propositions holds. The prediction just is not specific enough.

\section{Authors' response:}

1) In the revised manuscript we state explicitly that zinc is indeed relatively more abundant in cells than other divalent transition metals - if compared to the chemical composition of sea water - see Table 1 in the accompanying article.

2) We added a new section devoted to the metallome of the Last Universal Common Ancestor. where we link the content of $\mathrm{Zn}$ in modern cells to primordial stages of evolution.

3) If this particular prediction would not prove to be correct, the hypothesis would not be falsified yet, but strongly weakened; the final outcome would then depend on the tests of other predictions. If they all would fail, the hypothesis would be falsified indeed. Fortunately for us, this is not the case.

\section{Reviewer 2}

2. There should be ribozymes with Zn-dependent activity. Provided the RNA world hypothesis is accepted, there could be a more serious prediction here. However, I think the authors are too permissive in their formulation. A strong prediction would be that ribozymes are, mostly, Zn-dependent or that certain classes of ribozymes that are most relevant to the origin of cells, such as polymerases and ligases, should be $\mathrm{Zn}$-dependent. The way it stands, the prediction is too vague, whereas the data are very uncertain as the authors admit, even as they check this prediction in their favor.

Authors' response: We admit that the test of this prediction has led to the least conclusive results. This has several reasons. (a) The metal specificity of ribozymes is low, such that $\mathrm{Mg}^{2+}$ ions can occupy almost any divalent metal binding site; (b) the incu- 
bation media that are used by RNA scientists usually contain no other divalent cations besides the large amounts of $\mathrm{Mg}^{2+}(\mathrm{G}$. Yusupova, personal communication); and (c) there are only few types of natural ribozymes discovered so far, although, as we discuss in the manuscript, some their representatives show Zn-specific activity.

Among the native ribozymes, only the type I and type II introns can operate as ligases. Their activity requires divalent metals, but seems to be Mg-specific [330]. Generally, the activity of the known natural ribozymes is limited to the cleavage and formation of phosphoester bonds. The enzymes with this kind of activity are also $\mathrm{Mg}$-dependent.

There are no natural ribozymes with polymerase activity. The artificially selected ones were shown to be $\mathrm{Mg}$-dependent since they were selected in a medium that contained $\mathrm{Mg}^{2+}$ as the only divalent cation [331]. We are not aware about attempts to select ribozyme with a polymerase activity by using mixed $\mathrm{Zn} / \mathrm{Mg}$ media. Such an approach proved to be successful when a ribozyme for aldol reaction - which is chemically more demanding than polymerization of nucleotides - was selected. In a selection medium that contained $5 \mathrm{mM} \mathrm{MgCl} 2$ and 0.3 $m \mathrm{M} \mathrm{ZnSO}_{4}$ a $\mathrm{Zn}$-dependent ribozyme was readily obtained [176]. The $\mathrm{Zn}^{2+}$ ions were added to the selection medium since protein aldolases are $\mathrm{Zn}$-dependent. As long as protein polymerases are $\mathrm{Zn}$-dependent as well, we dare to predict that a selection of a Zn-dependent ribozyme polymerase is just a matter of a worthwhile trial. Generally, the hypothetical ribozymes of the RNA World should have been able to catalyze various chemical transformations; the example of enzymes shows that $\mathrm{Zn}^{2+}$ ions may have been involved as catalysts in many of them.

\section{Reviewer 2}

RNA structures should be enriched in $\mathrm{Zn}$ compared to other transition metals. Again, this might make sense in the context of the RNA World. However, there are few RNA structures containing any transitional metals including $\mathrm{Zn}$. The authors present a variety of post hoc considerations to explain the paucity of these ions - all this might be true but as a result, the argument does not seem to be convincing. An interesting observation in this section is the absence of Fe in any RNA structures, and the authors' interpretation that iron is likely to catalyze RNA cleavage makes sense. However, the data that are cited in support of this idea, on ribozyme activation by iron (ref. 179), logically suggest the opposite of their argument, namely, that iron is tolerated by RNA molecules, at least molecules like ribozymes that seem to be most relevant for the RNA World.

Authors' response: This is a very important point, so we have revisited the experimental protocols in ref. [332] (no. 179 in the original manuscript). In these experiments, it was checked whether diverse metals could activate a particular ribozyme, which was pre-selected for the ability to be activated by $\mathrm{Mn}^{2+}$, $\mathrm{Co}^{2+}, \mathrm{Ni}^{2+}, \mathrm{Zn}^{2+}$ and $\mathrm{Cd}^{2+}$. Thirty eight diverse metal chlorides were added at $100 \mu \mathrm{M}$ to the samples that contained precursor RNA and a ribozyme, the reaction was terminated after $5 \mathrm{~min}$ incubation at $23^{\circ} \mathrm{C}$ by the addition of a buffer supplemented with EDTA to the final concentration of $40 \mathrm{mM}$. The reaction products were then electrophoretically separated and the extent of the precursor RNA cleavage was checked. Of the 38 metals tested, only $\mathrm{Fe}^{2+}$ ions were able to induce cleavage of the precursor RNA. However, this procedure seems to be inappropriate for $\mathrm{Fe}^{2+}$ ions. In such a set-up there is no way to discriminate whether the precursor RNA had been cleaved by the $\mathrm{Fe}^{2+}$-activated ribozyme during the $5 \mathrm{~min}$ incubation or by the $\mathrm{Fe}^{2+}$ EDTA complexes after the anticipated reaction termination. In fact, $\mathrm{Fe}^{2+}{ }^{2+E D T A}$ complexes are widely used as cleavage agents for RNA [168]. Because of this uncertainty, we have decided to drop the discussion of the work of Zivartis et al. [332].

\section{Reviewer 2}

3. Zn ions should be present in oldest protein folds. I will refrain from the criticism of the work of Bourne's group - let us assume that the inference of the oldest folds there is reasonable. $\mathrm{Zn}$ is found in a rather small minority of representative structures, albeit from many folds. This is hardly surprising given that, oldest or not, these are indeed very common folds. Perhaps, a comparison with "less ancient" folds would help (it is unclear why such a comparison is not included) but then, again, I am rather skeptical as there can be many reasons why some protein structures contain a particular metal whereas others do not. There is just not bridge from here to the "Zn World".

Authors' response: We agree that checking of the metal content of the "less ancient" folds is a worthwhile task. This task, however, is beyond our current capabilities since the total number of fold superfamilies is about 1300. We, however, would be happy if somebody carried out this work. As already noted, we have added a new section on the metallome of the LUCA where we tried to build a bridge from the traits of modern proteins to the primeval Zn world.

\section{Reviewer 2}

4. Occurrence of $\mathrm{Zn}$ in enzymes with the oldest functions. I find this line of argument more interesting than the preceding 4 lines. It is therefore somewhat unfortunate that the authors do not perform any analysis of their own but rather limit themselves to the citation of [125] where the exact list of "primordial enzymes" is not given. This lack of concreteness seriously weakens this potentially relevant argument.

Authors' response: In this work we deliberately relied on the data sets obtained by others, to avoid a potential bias. Whatever mistakes could have been made by the authors of those data 
sets, neither of them had any intention to provide supporting evidence for the $\mathrm{Zn}$ world concept.

\section{Reviewer 2}

5. Presence of $\mathrm{Zn}$ ions in enzymes that could have taken over ribozyme activities. The argument here is long and convoluted, and I am afraid I cannot conclude that there is any strong data presented.

Authors' response: We shortened this section and merged it with the section on the Zn-dependence of evolutionarily old functions.

\section{Reviewer 2}

In the beginning of the next section, it is claimed that the Zn World hypothesis "has successfully passed all six falsification tests". I am afraid that I cannot condone this statement. To me, there is only one serious falsification test here, \#4. Indeed, if there were no $\mathrm{Zn}$-dependent enzymes among the ones assumed to be primordial, that could be construed to falsify the $\mathrm{Zn}$ World hypothesis. Unfortunately, as noticed above, the analysis of this prediction in the paper is not the strongest. The rest of the predictions, to me, either do not follow from the Zn World hypothesis or are too weak and vague - self-serving, within the framework of the Popperian paradigm - to provide any argument in support of the hypothesis (this is not quite Popperian language but, at the end of the day, when a hypothesis passes several falsification tests, this result constitutes support, and I think this is how the authors see the situation).

Authors' response: In response to reviewers' comments, we have added a new section on the metallome of the LUCA, which discusses the link between the relatively high $\mathrm{Zn}$ levels in modern cells, enzymes, and RNA structures and the primordial stages of evolution. We argue that the $\mathrm{Zn}$ enrichment of modern cells/RNA structures/enzymes is evolutionarily relevant and supports the $\mathrm{Zn}$ world hypothesis. In addition, we now analyze the metal content of the proteins that supposedly were present in the LUCA. To minimize the authors' bias, we have used the data set that was obtained by the Reviewer himself [196]. We show that proteins that supposedly were present in the LUCA predominantly contain $\mathrm{Mg}^{2+}$ and two transition metals, $\mathrm{Zn}$ and $\mathrm{Mn}$.

Our predictions are not "self serving" in the Popperian senseto our knowledge he has never used such a term in relation to the falsification tests. The tests can be either tautological or not - we cared to make predictions that are not related to the premises on which the hypothesis is built.

Our predictions, however, are obviously "self-serving" in the common sense of word - we try to gather support for own hypothesis. Of course, we would be happy to see this hypothesis scrutinized by others.

\section{Reviewer 2}

I must note that I am generally sympathetic with the $\mathrm{Zn}$ World hypothesis and agree with the authors that substituting ZnS for FeS in the model of early evolution within networks of inorganic compartments is a promising idea. Moreover, I think the paper does include an argument that is not only compatible with this hypothesis but can be considered supportive. This is the so-called " $\mathrm{Zn}$ paradox" discussed in section 2.4.3. Indeed, properties of transition metals do not seem to explain why $\mathrm{Zn}$ is a cofactor for a disproportional number of diverse enzymes, and this is a provocative observation. Indeed, if a biological pattern does not have a functional or mechanistic explanation, one starts suspecting that it could be explained by the legacy of early stages of evolution - in this case, the $\mathrm{Zn}$ World. Perhaps, this argument could be addressed in somewhat greater detail.

Authors' response: The respective section has been expanded. We additionally note that while prevalence of $\mathrm{Zn}$ in certain types of enzymes could be attributed to the catalytic properties of $\mathrm{Zn}^{2+}$ ions, their ubiquitous involvement as structural elements [128,210,243] had no known explanation until now. The $\mathrm{Zn}$ world concept explains the paradoxical prevalence of $\mathrm{Zn}$ ions both as catalysts and as structural elements by the shaping - and folding - of first proteins in Zn-rich habitats.

\section{Reviewer 2}

I am rather frustrated with the discussion of the purported implications of the $\mathrm{Zn}$ World hypothesis for the divergence of the domains of life and subsequent evolution. I am not inclined to discuss these in much detail but I think the majority are far-fetched and some just do not seem to be serious like conclusions based on the higher content of Zn-dependent enzymes in eukaryotes compared to archaea and bacteria or the conclusions on symbiosis etc. [(ix) and (vii) in section 2.4.5, respectively] etc. In my opinion, it is highly desirable to simply drop this section.

Authors' response: We have decided to retain some of this discussion; the respective part of the article has been, however, shortened and rewritten for the sake of clarity.

\section{Reviewer 2}

To summarize, I think the accompanying paper by Mulkidjanian together with this paper present a new, interesting, chemically plausible and overall promising hypothesis on the settings of primordial evolution. However, I think the authors do a disservice to their own good idea by heavily overloading the hypothesis with (at best) tangentially relevant arguments that they counter-productively attempt to present in a formal Popperian setting (I 
suppose, at least, in part, this approach is borrowed from Wächtershäuser but here it is taken to much greater and entirely unnecessary lengths). The paper is also full of implications that do not seem to really follow from the hypothesis but are discussed at great lengths. I would note that this paper (and I think the accompanying one as well) are heavily "overspecified", to the extent that there is a danger to completely drawn an interesting idea in a muddy waters of weak argumentation and excessive discussion. In my opinion, both papers could be reduced to a single, perhaps, 10 pages long article on the hypothesis that would discuss the relevant photochemistry and photophysics along with the interesting "Zn paradox". In that form, it would be a valuable contribution to the origin of life literature.

Authors' response: Regular scientific papers are usually addressed to a handful of experts in a narrow research field. The potential audience of a paper on the origin of a life might be much broader and could include readers with different backgrounds, from mathematics to geology. Accordingly, their understanding of which arguments are convincing and which are only tangentially relevant might differ as well. In the view of this broad and unevenly trained potential audience, we have chosen a presentation style that, while being more diffuse as compared to routine scientific papers, might reach more readers.

\section{Reviewer 2}

A specific and relatively minor comment on horizontal gene transfer:

"The rigorous vertical inheritance of the genes responsible for information processing, in particular of the ribosome machinery [200], might indicate that these genes, at least at the LUCA stage, already formed the non-shared genetic cores of the first organisms"

The vertical inheritance of ribosomal protein genes let alone other components of information processing systems is by no account "rigorous", horizontal transfer of these genes is common enough [201,202] even if less common than horizontal transfer of genes for metabolic enzymes, although even that trend has been questioned [203].

Authors' response: These references are now cited.

\section{Reviewer 3}

Patrick Forterre, Institut Pasteur, Département de Microbiologie, Unité de Biologie Moléculaire du Gène chez les Extrêmophiles, Paris, and Université Paris-Sud, Institut de Génétique et Microbiologie, Orsay, France
The origin of life remains a major unsolved problem in science, and no consensus exists in the community of people who try to tackle this problem, despite the great number of theories that have already been proposed. In an accompanying paper, Mulkidjanian proposed a new theory in which the first organisms were photosynthetizers, that used zinc sulfide ( $\mathrm{ZnS}$ ) formed in sub-aerial setting to capture solar energy for abiotic reduction of $\mathrm{CO} 2$. In this paper, Mulkidjanian and Galperin look in modern cells for support of this theory. By extensively reviewing the literature, they made six observations that could be viewed as supporting the idea that Zinc has indeed played a major role in early life evolution. In particular, they conclude from their survey of the experimental literature that ribozymes can work using Zinc as cofactor instead of magnesium, and that zinc is enriched in proteins with "old folds" or "old functions". This part of the paper is very interesting and can push the biochemists to look more carefully at the real metal dependency of the protein they are studying. These observations convince me that somehow Zinc should have played an important role in early biological evolution. An interesting observation is that the fraction of Zn-containing enzymes is higher in Eukarya than in Bacteria or Archaea. If the hypothesis of the author is correct, this supports heretical ideas according to which the proto-eukaryotic lineage might be more ancient than streamlined lineages of Archaea and Bacteria [333]. The authors call the ancestor of Archaea and Eukarya, a protoarchaeon or a pro-eukaryotic archaeon. This is based on the idea that evolution always goes from simple to complex and that streamlining in the archaeal domain has been much less important than complexification in the eukaryotic domain, something not so clear at the molecular level. Considering that Archaea are probably monophyletic [288], I think that the authors should avoid these confusing terms (proto-archaeon or a pro-eukaryotic archaeon) and only refer to the pro-eukaryotic ancestor.

Authors' response: Throughout the manuscript, the proeukaryotic archaeon has been renamed pro-eukaryote.

\section{Reviewer 3}

More importantly considering the objective of this paper, I have a fundamental problem with the idea of an early Zinc world. Indeed, from my own lab experience, it is clear that Zinc has the ability to strongly induce cleavage of DNA, especially at high temperature [334]. Zinc has even a stronger deleterious effect on RNA. The cleavage of polyribonucleotide by Zinc has been extensively studies by Butzow and Eichhorn in the last century. These authors have shown in particular that RNA is especially prone to Zinc-induced degradation and even argued that the higher resistance of DNA to metal-induce degradation explains why DNA replaced RNA as cellular genetic material in the course of evolution [335]. The high sensitivity of RNA to 
Zinc should have created a great problem for early RNAbased systems (before the invention of proteins that could protect RNA against Zinc-induced hydrolysis). In any case, if the Zinc world really occurred it should have done so at low temperature. The Zinc world hypothesis therefore strongly supports the idea of a cold origin of life. It raises the possibility that life could have only invades high temperature environment after the emergence of DNA and modern complex proteins. In any case, this paper is important because it should stimulate investigators to resume the study the effect of Zinc on RNA stability in the presence of minerals, lipids and/or peptides, and to analyze the activity of various ribozymes in the presence of this metal at different temperatures.

Authors' response: The possibility of the Zn-catalyzed cleavage, which was also addressed in the comment by Mushegian, is indeed a very important topic. We now consider this point in detail in the accompanying paper [97] and in the response to the Mushegian's comment to that paper. We argue that the ability of proteins to bind to the 2'-OH group of ribose could protect RNA molecules from $\mathrm{Zn}$-catalyzed cleavage and may have driven the emergence of the first proteins. We are grateful to the Reviewer for pointing out the very useful reference to the work by Butzow and Eichhorn.

\section{Reviewer 3}

Although I found this paper really interesting, I think that the authors were misguided in connecting their Zinc world hypothesis to the Martin and co-workers hydrothermal vent scenario for the origin of life, in which, as described by Mulkidjanian and Galperin: "Bacteria and Archaea are descendents of two distinct populations that thrive around hydrothermal vents". The plural of vents in that description is misleading. Indeed, in that scenario, life should have originated and evolved up to modern cells in a single chimney, since life forms were trapped in mineral cages until the advent of Bacteria and Archaea. If the conditions were favourable to the development of a Zincworld in cold hydrothermal settings, many independent primitive Zinc worlds should have emerged more or less simultaneously at many places at the earth surface. In the one chimney scenario, this means that all hydrothermal vents at the earth surface should have produce living organisms, but that Archaea and Bacteria originated from the same chimney (out of millions) and wiped out all other cells that were produced by other chimneys!! This seems ridiculous. Even if all ancestral chimneys were connected into a single giant chimney all around the globe, living organisms could not have moved and competed from one part of this giant chimney to another since they were trapped in mineralized cages ( $\mathrm{ZnS}$ compartments), so LUCA and its descendents should have originated from the same region of this giant chimney, against wiping out cells that were produced by other parts of this chimney. In general, I don't think that one can trace the origin of the three domains to the evolution of the vent systems and I don't buy the geochemical scenario proposed by the authors for the origin of the three cellular domains. To explain the formation of the three domains, one should understand why three types of molecular biology (for instance three versions of the ribosomes) originated from LUCA, and this cannot be related simply to considerations based on various metabolisms.

Authors' response: The expression "around hydrothermal vents" has been replaced by "within a deep sea hydrothermal vent".

In contrast to Martin and co-workers, we think about the first biotopes as rings of precipitated $\mathrm{ZnS} / \mathrm{MnS}$ particles around chimneys of continental hot springs. Based on the typical structure of ancient volcanogenic massive sulfide deposits [261], we can envision that these rings intersected and formed a continuous net of photosynthesizing and inhabited settings, most likely occupying the bottom lands of primeval hydrothermal fields. The life in these biotopes was confined to the illuminated $\mathrm{ZnS}$ surface, so the first life forms could be moved within these biotopes by water. Moreover, the illuminated ZnS compartments should have been fragile and break continuously because of photocorrosion.

Further, we speculate that upon the separation of the main lineages not the organisms themselves, but the geologic settings that they inhabited started to move away from each other. With the decrease in the $\mathrm{CO}_{2}$ atmospheric pressure, inhabited $\mathrm{ZnS}$ rich settings at hydrothermal vents would move deeper and deeper into the ocean, away from the continental phototrophic communities. As we believe, exactly the initial lack of swimming motility of the first organisms enabled their separate evolution and crystallization of the domain-specific features in the phototrophic communities (future Bacteria), on the one hand, and chemotrophic/heterotrophic communities on the sea floor (future Archaea/Eukarya), on the other hand.

\section{Reviewer 3}

Generally speaking I think that the authors, as many other scientists working in the origin of life fields, tend to underestimate the various evolutionary steps that were required to go from the first proto-cells to LUCA and later on to modern cells (Archaea, Bacteria and Eucarya). This is clear when the authors speak of proteins that have been "attributed to the very early life", including in that category DNA repair and replication proteins. For me these proteins do not testify for the very early life because they could have only appeared after the evolution of very sophisticated ribosomes, at a very late period of early life evolution. If the first life forms indeed originated in $\mathrm{ZnS}$ compartments of an hydrothermal vent, I would suggest that the cells that emerged from these vents were primitive 
cells that started to compete with each others as free living cells in ancestral water ponds and/or in shallow waters of the ancestral oceans. They might have been pre-RNA cells or cells that found a way to protect their RNA against Zincinduced degradation. This does not dismiss the possibility that the first proteins that replaced ribozymes after the invention of ribosomes mainly inherited zinc ions from the catalytic centers of these ribozymes, or that cells of that time (second age of the RNA world) were still thriving in a rich zinc world.

Authors' response. We agree that attribution of DNA repair and replication proteins to the very early life, as done by Zerkle et al. [125], is controversial. In the revised manuscript we still present their data but do not discuss them (see also our response to the respective comment of Mushegian). We fully agree with the Reviewer that acquisition of $\mathrm{Zn}^{2+}$ ions may have preceded the emergence of DNA repair proteins. In the revised version we added a new section on the metallome of the LUCA, where we argue that the first organisms could have thrived in the $\mathrm{Zn}$-rich environments up to the stage of the LUCA.

\section{Acknowledgements}

Valuable discussions with Drs. V.V. Aleshin, J.F. Allen, A.V. Bogachev, D.A. Cherepanov, W.F. Doolittle, M. Eigen, R.B. Gennis, E.V. Koonin, K.S. Makarova, W. Martin, W. Nitschke, A.W. Rutherford, M.J. Russell, V.P. Skulachev, R. Thauer, N.E. Voskoboynikova, R.J.P. Williams, Y.I. Wolf, and G.Z. Yusupova are greatly appreciated. This study was supported by grants to AYM from the Deutsche Forschungsgemeinschaft and the Volkswagen Foundation and by the Intramural Research Program of the National Library of Medicine at the National Institutes of Health (MYG). This manuscript is dedicated to the memory of Leslie E. Orgel.

\section{References}

I. Danchin A: Homeotopic transformation and the origin of translation. Prog Biophys Mol Biol I989, 54(I):8I-86.

2. De Duve C, Miller SL: Two-dimensional life? Proc Natl Acad Sci USA 199|, 88(22): $10014-10017$

3. Trevors JT: Early assembly of cellular life. Prog Biophys Mol Biol 2003, 81 (3):201-217.

4. Pross A: Causation and the origin of life. Metabolism or replication first? Orig Life Evol Biosph 2004, 34(3):307-32I.

5. Pascal R, Boiteau L, Forterre P, Gargaud M, Lazcano A, Lopez-Garcia P, Moreira D, Maurel MC, Pereto J, Prieur D, et al.: Prebiotic chemistry - Biochemistry - Emergence of life (4.4-2 Ga). Earth Moon and Planets 2006, 98(I-4): I53-203.

6. Bada JL, Fegley B Jr, Miller SL, Lazcano A, Cleaves HJ, Hazen RM, Chalmers J: Debating evidence for the origin of life on Earth. Science 2007, 3| 5(58|4):937-939.

7. Copley SD, Smith E, Morowitz HJ: The origin of the RNA world: Co-evolution of genes and metabolism. Bioorg Chem 2007, 35(6):430-443.

8. Mulkidjanian AY, Galperin MY: Physico-chemical and evolutionary constraints for the formation and selection of first biopolymers: Towards the consensus paradigm of the abiogenic origin of life. Chem Biodivers 2007, 4(9):2003-20I5.

9. Orgel LE: The implausibility of metabolic cycles on the prebiotic Earth. PLoS Biol 2008, 6(I):5-13.

10. Trefil J, Morowitz HJ, Smith E: The Origin of Life. A case is made for the descent of electrons. Am Sci 2009, 97(3):206-2I3.

II. Oparin Al: The Origin of Life. Moscow: Moskowskiy rabochiy; 1924.

12. Oparin Al: The Origin of Life. New York: Macmillan; 1938.

13. Miller SL: A production of amino acids under possible primitive Earth conditions. Science 1953, I I 7(3046):528-529.
14. Miller SL, Urey HC: Origin of life. Science 1959 , 130(3389): 1622-1624.

15. Ponnamperuma C: Primordial organic chemistry and the origin of life. $Q$ Rev Biophys 1971, 4(2):77-106.

16. Miller SL, Cleaves HJ: Prebiotic chemistry on the primitive Earth. In Systems Biology, Genomics Volume I. Edited by: Rigoutsos I, Stephanopoulos G. Oxford: Oxford University Press; 2006:4-56.

17. Belozersky AN: On the species specificity of the nucleic acids of bacteria. In The Origin of Life on the Earth Edited by: Oparin Al, Pasynskii AG, Braunshtein AE, Pavlovskaya TE, Clark F, Synge RLM. London: Pergamon Publishers; 1959:322-33I.

18. Woese CR: The Genetic Code. New York: Harper and Row; 1967.

19. Crick FH: The origin of the genetic code. J Mol Biol 1968, 38(3):367-379.

20. Orgel LE: Evolution of the genetic apparatus. J Mol Biol I968, 38(3):38I-393.

21. Eigen M: Selforganization of matter and the evolution of biological macromolecules. Naturwissenschaften 1971, 58(I0):465-523.

22. Gilbert W: The RNA world. Nature 1986, 319:618.

23. Spirin AS: Omnipotent RNA. FEBS Lett 2002, 530(I-3):4-8.

24. Orgel LE: Prebiotic chemistry and the origin of the RNA world. Crit Rev Biochem Mol Biol 2004, 39(2):99-123.

25. Yarus M, Caporaso JG, Knight R: Origins of the genetic code: The escaped triplet theory. Annu Rev Biochem 2005, 74:179-198.

26. Szathmáry E: The origin of replicators and reproducers. Philos Trans R Soc Lond B Biol Sci 2006, 36 I (1474): I76I-I776.

27. Joyce GF: Forty years of in vitro evolution. Angew Chem Int Ed Engl 2007, 46(34):6420-6436.

28. Wolf $\mathrm{YI}, \mathrm{Koonin} \mathrm{EV}$ : On the origin of the translation system and the genetic code in the RNA world by means of natural selection, exaptation, and subfunctionalization. Biol Direct 2007, 2:14.

29. Chen X, Li N, Ellington AD: Ribozyme catalysis of metabolism in the RNA world. Chem Biodivers 2007, 4(4):633-655.

30. Schuster P, Stadler PF: Early replicons: origin and evolution. In Origin and Evolution of Viruses 2nd edition. Edited by: Domingo E, Parrish CR, Holland JJ. Academic Press; 2008: I-4I.

31. Lincoln TA, Joyce GF: Self-sustained replication of an RNA enzyme. Science 2009, 323(59 |8): 1229-1232.

32. Bokov K, Steinberg SV: A hierarchical model for evolution of 23S ribosomal RNA. Nature 2009, 457(7232):977-980.

33. Powner MW, Gerland B, Sutherland JD: Synthesis of activated pyrimidine ribonucleotides in prebiotically plausible conditions. Nature 2009, 459(7244):239-242.

34. Curtis EA, Bartel DP: New catalytic structures from an existing ribozyme. Nat Struct Mol Biol 2005, I 2(II):994-1000.

35. Scott WG: Ribozymes. Curr Opin Struct Biol 2007, 17(3):280-286.

36. Van Roode JHG, Orgel LE: Template-directed synthesis of oligoguanylates in the presence of metal-ions. J Mol Biol 1980, 144(4):579-585.

37. Lohrmann R, Bridson PK, Bridson PK, Orgel LE: Efficient metal-ion catalyzed template-directed oligonucleotide synthesis. Science 1980, 208(445 I): |464-I 465.

38. Bridson PK, Orgel LE: Catalysis of accurate poly(C)-directed synthesis of 3'-5'-linked oligoguanylates by $\mathbf{Z n}^{2+}$. J Mol Biol 1980, I44(4):567-577.

39. Ferris JP: Montmorillonite catalysis of 30-50 mer oligonucleotides: Laboratory demonstration of potential steps in the origin of the RNA world. Orig Life Evol Biosph 2002, 32(4):3II-332.

40. Ferris JP, Hill AR Jr, Liu R, Orgel LE: Synthesis of long prebiotic oligomers on mineral surfaces. Nature 1996, 38 I (6577):59-6I.

4I. Joshi PC, Pitsch S, Ferris JP: Selectivity of montmorillonite catalyzed prebiotic reactions of D, L-nucleotides. Orig Life Evol Biosph 2007, 37(I):3-26.

42. Miyakawa S, Joshi PC, Gaffey MJ, Gonzalez-Toril E, Hyland C, Ross T, Rybij K, Ferris JP: Studies in the mineral and salt-catalyzed formation of RNA oligomers. Orig Life Evol Biosph 2006, 36(4):343-36I.

43. Zagorevskii DV, Aldersley MF, Ferris JP: MALDI analysis of oligonucleotides directly from montmorillonite. J Am Soc Mass Spectrom 2006, I7(9): 1265-1270. 
44. Ferris JP: Montmorillonite-catalysed formation of RNA oligomers: the possible role of catalysis in the origins of life. Philos Trans R Soc Lond B Biol Sci 2006, 36 I (1474): I777-1786.

45. Nisbet EG: Living Earth: A Short History of Life and its Home. London: HarperCollins Academic; 1991.

46. Martin H, Claeys P, Gargaud M, Pinti DL, Selsis F: Environmental context. Earth Moon and Planets 2006, 98(I-4):205-245.

47. Nisbet E, Fowler CMR: The early history of life. In Biogeochemistry Volume 8 . Edited by: Schelsinger WH. Oxford.: Elsevier-Pergamon; 2003:1-39.

48. Nisbet E, Zahnle K, Gerasimov MV, Helbert J, Jaumann R, Hofmann BA, Benzerara K, Westall F: Creating habitable zones, at all scales, from planets to mud micro-habitats, on earth and on mars. Space Sci Rev 2007, I 29(1-3):79-121.

49. Nisbet EG, Sleep NH: The habitat and nature of early life. Nature 200I, 409(6823): 1083-1091.

50. Kasting JF, Howard MT: Atmospheric composition and climate on the early Earth. Philos Trans R Soc Lond B Biol Sci 2006 36I(1474): I733-174I.

5I. Kasting JF, Ono S: Palaeoclimates: the first two billion years. Philos Trans R Soc Lond B Biol Sci 2006, 36 I ( 1470):917-929.

52. Sleep NH, Zahnle K, Neuhoff PS: Initiation of clement surface conditions on the earliest Earth. Proc Natl Acad Sci USA 200I, 98(7):3666-3672.

53. Zahnle K, Arndt N, Cockell C, Halliday A, Nisbet E, Selsis F, Sleep $\mathrm{NH}$ : Emergence of a habitable planet. Space Sci Rev 2007, I 29(I-3):35-78

54. Miller $\mathrm{S}$ : The endogenous synthesis of organic compounds. In The Molecular Origins of Life: Assembling the Pieces of the Puzzle Edited by: Brack A. Cambridge: Cambridge University Press; 1998:59-85.

55. Kauffman S: Origin of life and the living state. Orig Life Evol Biosph 2007, 37(4-5):315-322

56. Wächtershäuser G: Before enzymes and templates: theory of surface metabolism. Microbiol Rev 1988, 52(4):452-484.

57. Wächtershäuser G: Evolution of the first metabolic cycles. Proc Natl Acad Sci USA 1990, 87(I):200-204.

58. Wächtershäuser G: Groundworks for an evolutionary biochemistry: the iron-sulphur world. Prog Biophys Mol Biol 1992, 58(2):85-20I.

59. Huber C, Wächtershäuser G: Activated acetic acid by carbon fixation on (Fe, Ni)S under primordial conditions. Science 1997, 276(53 I0):245-247.

60. Wächtershäuser G: From volcanic origins of chemoautotrophic life to Bacteria, Archaea and Eukarya. Philos Trans $R$ Soc Lond B Biol Sci 2006, 36 I (1474): 1787-I808.

6I. Wächtershäuser G: On the chemistry and evolution of the pioneer organism. Chem Biodivers 2007, 4(4):584-602.

62. Russell M], Hall AJ, Cairns-Smith AG, Braterman PS: Submarine hot springs and the origin of life. Nature 1988, 336(6 I95): I I7-II7.

63. Russell MJ, Hall AJ: The emergence of life from iron monosulphide bubbles at a submarine hydrothermal redox and $\mathrm{pH}$ front. J Geol Soc London 1997, 154(3):377-402.

64. Martin W, Russell MJ: On the origins of cells: a hypothesis for the evolutionary transitions from abiotic geochemistry to chemoautotrophic prokaryotes, and from prokaryotes to nucleated cells. Philos Trans $R$ Soc Lond B Biol Sci 2003, 358( ( 1429):59-83.

65. Russell MJ, Arndt NT: Geodynamic and metabolic cycles in the Hadean. Biogeosciences 2005, 2(I):97-III.

66. Russell M: First Life. Am Sci 2006, 94(I):32-39.

67. Russell M, Hall A): The onset and early evolution of life. Evolution of Early Earth's Atmosphere, Hydrosphere, and Biosphere - Constraints from Ore Deposits: Geological Society of America Memoir 198 2006: I-32.

68. Russell M, Allen J, Milner-White E: Inorganic complexes in the onset of life and oxygenic photosynthesis. Photosynth Res 2007, 9I (2-3):269.

69. Russell MJ: The alkaline solution to the emergence of life: Energy, entropy and early evolution. Acta Biotheoretica 2007, 55(2): 133-179.

70. Martin W, Russell MJ: On the origin of biochemistry at an alkaline hydrothermal vent. Philos Trans $R$ Soc Lond B Biol Sci 2007, 362(I 486): I 887-I 925

7I. Martin W, Baross J, Kelley D, Russell MJ: Hydrothermal vents and the origin of life. Nat Rev Microbiol 2008, 6(I I):805-8I4.

72. Schoonen MAA, $\mathrm{Xu} Y$, Bebie $\mathrm{J}$ : Energetics and kinetics of the prebiotic synthesis of simple organic acids and amino acids with the FeS- $\mathrm{H}_{2} \mathrm{~S} / \mathrm{FeS}$, redox couple as reductant. Orig Life Evol Biosph 1999, 29(I):5-32.

73. Mulkidjanian AY, Galperin MY, Koonin EV: Co-evolution of primordial membranes and membrane proteins. Trends Biochem Sci 2009, 34:206-2I5.

74. Darwin E: The Temple of Nature; or, The Origin of Society. London: J. Johnson; 1806.

75. Moore B, Webster TA: Synthesis by sunlight in relationship to the origin of life. Synthesis of formaldehyde from carbon dioxide and water by inorganic colloids acting as transformers of light energy. Proc $R$ Soc Lond B Biol Sci 1913, 87:163-176.

76. Haldane JBS: The Origin of Life. The Rationalist Annual 1929:3-10.

77. Granick S: Speculations on the origins and evolution of photosynthesis. Ann N Y Acad Sci 1957, 69(2):292-308.

78. Skulachev VP: Accumulation of Energy in the Cell. Moscow: Nauka; 1969.

79. Hartman H: Speculations on origin and evolution of metabolism. J Mol Evol 1975, 4(4):359-370.

80. Krasnovsky AA: Chemical evolution of photosynthesis. Orig Life 1976, 7(2): I33-|43.

8I. Halmann M, Aurian-Blajeni B, Bloch S: Photoassisted carbon dioxide reduction and formation of two and three-carbon compounds. In Third ISSOL Meeting and Sixth ICOL Meeting: 1980, Jerusalem, Israel D. Reidel Publishing Co., Dordrecht; 1980:143-I50.

82. Hartman H: Photosynthesis and the origin of life. Orig Life Evol Biosph 1998, 28(4-6):5I5-521.

83. Mauzerall D: Light, iron, Sam Granik and the origin of life. Photosynth Res 1992, 33(2): 163-170.

84. Skulachev VP: Bioenergetics - the evolution of molecular mechanisms and the development of bioenergetic concepts. Antonie van Leeuwenhoek 1994, 65(4):27|-284.

85. Skulachev VP: Evolution of convertible energy currencies of the living cell: From ATP to $\mathrm{DmH}^{+}$and $\mathrm{DmNa}^{+}$. In Origin and Evolution of Biological Energy Conversion Edited by: Baltscheffsky H. New York: VCH Publishers; 1996:II-35.

86. Calvin M: Chemical Evolution. Oxford: Clarendon Press; 1969.

87. Sagan C: Ultraviolet selection pressure on earliest organisms. J Theor Biol 1973, 39(I): 195-200.

88. Vazquez M, Hanslmeier A: Ultraviolet Radiation in the Solar System. Dordrecht: Springer; 2006.

89. Borowska ZK, Mauzerall DC: Efficient near ultraviolet light induced formation of hydrogen by ferrous hydroxide. Orig Life Evol Biosph 1987, I 7:25I-259.

90. Borowska Z, Mauzerall D: Photoreduction of carbon dioxide by aqueous ferrous ion: An alternative to the strongly reducing atmosphere for the chemical origin of life. Proc Natl Acad Sci USA 1988, 85(18):6577-6580.

91. Halmann M, Ulman M, Aurian-Blajeni B, Zafrir M: Photoassisted carbon dioxide reduction on semiconductor materials. J Photochem 198I, I7(I-2): 156 .

92. Reiche $\mathrm{H}, \mathrm{Bard} \mathrm{A}$ ): Heterogeneous photosynthetic production of amino-acids from methane-ammonia-water at $\mathrm{Pt}-\mathrm{TiO}_{2}$. Implications in chemical evolution. I Am Chem Soc 1979 , I0I(II):3 I 27-3 I 28.

93. Dunn WW, Aikawa Y, Bard AJ: Heterogeneous photosynthetic production of amino-acids at $\mathrm{Pt}-\mathrm{TiO}_{2}$ suspensions by near ultraviolet-light. J Am Chem Soc 198I, I 03(23):6893-6897.

94. Senanayake SD, Idriss $\mathrm{H}$ : Photocatalysis and the origin of life: Synthesis of nucleoside bases from formamide on $\mathrm{TiO}_{2}(\mathrm{OOI})$ single surfaces. Proc Natl Acad Sci USA 2006, I 03(5): I I 94- I I 98.

95. Zhang XV, Martin ST, Friend CM, Schoonen MAA, Holland HD: Mineral-assisted pathways in prebiotic synthesis: Photoelectrochemical reduction of carbon(+IV) by manganese sulfide. J Am Chem Soc 2004, I 26(36): I I247-I I 253

96. Zhang XV, Ellery SP, Friend CM, Holland HD, Michel FM, Schoonen MAA, Martin ST: Photodriven reduction and oxidation reactions on colloidal semiconductor particles: Implications for prebiotic synthesis. J Photochem Photobiol A Chem 2007, I85(23):30I-3II.

97. Mulkidjanian AY: Origin of life in the Zinc World: I. Photosynthetic, porous edifices built of hydrothermally precipitated zinc sulfide $(\mathrm{ZnS})$ as cradles of life on Earth. Biol Direct 2009, 4:26.

98. Henglein A, Gutierrez M, Fischer CH: Photochemistry of colloidal metal sulfides. 6. Kinetics of interfacial reactions at $\mathrm{ZnS}$ par- 
ticles. Berichte Der Bunsen-Gesellschaft-Physical Chemistry Chemical Physics 1984, 88(2): 170-175.

99. Henglein A: Catalysis of photochemical reactions by colloidal semiconductors. Pure Appl Chem 1984, 56(9): I2I 5 - 1224

100. Inoue H, Torimoto T, Sakata T, Mori H, Yoneyama H: Effects of size quantization of zinc-sulfide microcrystallites on photocatalytic reduction of carbon-dioxide. Chem Lett 1990:1483-1486.

10I. Kanemoto M, Shiragami T, Pac CJ, Yanagida S: Semiconductor photocatalysis - effective photoreduction of carbon-dioxide catalyzed by ZnS quantum crystallites with low-density of surface-defects. JPhys Chem 1992, 96(8):352I-3526.

102. Eggins BR, Robertson PKJ, Stewart JH, Woods E: Photoreduction of carbon dioxide on zinc sulfide to give four-carbon and twocarbon acids. J Chem Soc Chem Commun 1993:349-350.

103. Yoneyama $\mathrm{H}$ : Photoreduction of carbon dioxide on quantized semiconductor nanoparticles in solution. Catalysis Today 1997, 39(3): 169-175.

104. Kelley DS, Baross JA, Delaney JR: Volcanoes, fluids, and life at mid-ocean ridge spreading centers. Annu Rev Earth Planet Sci 2002, 30:385-491.

105. Tivey MK: Generation of seafloor hydrothermal vent fluids and associated mineral deposits. Oceanography 2007 20(I):50-65

106. Rona PA: The changing vision of marine minerals. Ore Geology Reviews 2008, 33(3-4):618-666.

107. Wächtershäuser G: The origin of life and its methodological challenge. J Theor Biol 1997, 187(4):483-494.

108. Popper KR: Logik der Forschung. Wien: Verlag Julius Springer; 1935.

109. Popper KR: The Logic of Scientific Discovery. London: Hutchinson; 1959.

I I0. Eggins BR, Robertson PKJ, Murphy EP, Woods E, Irvine JTS: Factors affecting the photoelectrochemical fixation of carbon dioxide with semiconductor colloids. J Photochem Photobiol A Chem 1998, I I 8(I):31-40.

III. Corliss JB: On the evolution of primitive cells in archean submarine hot-spring environments: The emergence of Archaebacteria, Eubacteria and Eukaryotes. Orig Life Evol Biosph 1986, 16(3-4):256-257.

I12. Corliss JB, Baross JA, Hoffman SE: A hypothesis concerning the relationship between submarine hot springs and the origin of life on Earth. 26th International Geology Congress, Geology of Oceans Symposium, Proceedings, Oceanology Acta Special Issue 1981:59-69.

113. Nisbet EG: RNA and hot-water springs. Nature 1986, 322(6076):206-206

II4. Shock EL: Hydrothermal systems as environments for the emergence of life. Evolution of Hydrothermal Ecosystems on Earth (and Mars?) 1996, 202:40-60.

115. Kormas KA, Tivey MK, Von Damm K, Teske A: Bacterial and archaeal phylotypes associated with distinct mineralogica layers of a white smoker spire from a deep-sea hydrothermal vent site $\left(9^{\circ} \mathbf{N}\right.$, East Pacific Rise). Environ Microbiol 2006, 8(5):909-920.

I I6. Petersen S, Herzig PM, Kuhn T, Franz L, Hannington MD, Monecke T, Gemmell JB: Shallow drilling of seafloor hydrothermal systems using the BGS rockdrill: Conical seamount (New Ireland fore-arc) and PACMANUS (Eastern Manus Basin), Papua New Guinea. Marine Georesources \& Geotechnology 2005 23(3): $175-193$.

II7. Takai K, Komatsu T, Inagaki F, Horikoshi K: Distribution of archaea in a black smoker chimney structure. Appl Environ Microbiol 200I, 67(8):3618-3629.

1 18. Cadet J, Vigny P: The photochemistry of nucleic acids. In Bioorganic Photochemistry: Photochemistry and the Nucleic Acids Edited by: Morrison H. New York: John Wiley \& Sons; 1990: I-273.

119. Mulkidjanian AY, Cherepanov DA, Galperin MY: Survival of the fittest before the beginning of life: selection of the first oligonucleotide-like polymers by UV light. BMC Evol Biol 2003, 3:12.

120. Sobolewski AL, Domcke W: The chemical physics of the photostability of life. Europhysics News 2006, 37:20-23.

121. Serrano-Andres L, Merchan M: Are the five natural DNA/RNA base monomers a good choice from natural selection? A photochemical perspective. I Photochem Photobiol C Photochem $\operatorname{Rev} 2009,10(1): 21-32$.
122. Kisch $H$, Künneth $R$ : Photocatalysis by semiconductor powders: Preparative and mechanistic aspects. In Photochemistry and Photophysics Edited by: Rabek J. CRC Press Inc; 1991:131-175.

123. Gratzel M, ed: Energy Resources through Photochemistry and Catalysis. New York: Academic Press; 1983.

124. Williams RJP, Frausto da Silva JJR: The Chemistry of Evolution: The Development of our Ecosystem. Amsterdam: Elsevier; 2006.

125. Zerkle AL, House CH, Brantley SL: Biogeochemical signatures through time as inferred from whole microbial genomes. American Journal of Science 2005, 305(6-8):467-502.

126. Dupont CL, Yang S, Palenik B, Bourne PE: Modern proteomes contain putative imprints of ancient shifts in trace metal geochemistry. Proc Natl Acad Sci USA 2006, I03(47): I 7822-17827.

127. Bekker A, Holland HD, Wang PL, Rumble D, Stein HJ, Hannah JL, Coetzee LL, Beukes NJ: Dating the rise of atmospheric oxygen. Nature 2004, 427(6970): I I7-I 20.

128. Williams RJP, Frausto da Silva JJR: The Biological Chemistry of the Elements. Oxford: Clarendon Press; 1991.

129. Kim HK, Liu J, Li J, Nagraj N, Li M, Pavot CM, Lu Y: Metal-dependent global folding and activity of the 8-17 DNAzyme studied by fluorescence resonance energy transfer. J Am Chem Soc 2007, 129(2I):6896-6902.

130. Thompson RB: Studying zinc biology with fluorescence: ain't we got fun? Curr Opin Chem Biol 2005, 9(5):526-532.

13I. Vallee BL, Galdes A: The metallobiochemistry of zinc enzymes. Adv Enzymol Relat Areas Mol Biol 1 984, 56:283-430.

132. Belozersky MA, Dunaevsky YE, Voskoboynikova NE: Isolation and properties of a metalloproteinase from buckwheat (Fagopyrum esculentum) seeds. Biochem J 1990, 272(3):677-682.

133. Falchuk KH, Hilt KL, Vallee BL: Determination of zinc in biological samples by atomic-absorption spectrometry. Meth Enzy$\mathrm{mol}$ 1988, 1 58:422-434

134. Wesenberg D, Bleuel C, Krauss G-J: A glossary of microanalytic tools to assess the metallome. In Molecular Microbiology of Heavy Metals Edited by: Nies DH, Silver S. Berlin: Springer-Verlag; 2007:159-186.

135. Bertini I, Rosato A: From genes to metalloproteins: A bioinformatic approach. European Journal of Inorganic Chemistry 2007, 2007( ( 8):2546-2555

136. De Duve C: Blueprint for a Cell: The Nature and Origin of Life. Burlington: Neil Patterson Publishers; |991.

137. Hall DO, Cammack R, Rao KK: Role for ferredoxins in the origin of life and biological evolution. Nature 1971, 233(53 | 5): $136-138$

138. Koonin EV, Martin W: On the origin of genomes and cells within inorganic compartments. Trends Genet 2005, 2I( I 2):647-654.

139. Henrick K, Feng Z, Bluhm WF, Dimitropoulos D, Doreleijers JF, Dutta S, Flippen-Anderson JL, lonides J, Kamada C, Krissinel E, et al.: Remediation of the Protein Data Bank archive. Nucleic Acids Res 2008, 36(Database):D426-D433.

140. Protein Data Bank [http://www.rcsb.org/pdb/]

14I. Nucleic Acid Database [http://ndbserver.rutgers.edu/]

142. Berman HM, Olson WK, Beveridge DL, Westbrook J, Gelbin A, Demeny T, Hsieh SH, Srinivasan AR, Schneider B: The Nucleic Acid Database. A comprehensive relational database of threedimensional structures of nucleic acids. Biophys J 1992, 63(3):75I-759.

143. Stefan LR, Zhang R, Levitan AG, Hendrix DK, Brenner SE, Holbrook SR: MeRNA: a database of metal ion binding sites in RNA structures. Nucleic Acids Res 2006, 34:DI3I-DI 34

144. Stefan L, Zhang R, Levitan A, Dhar A, Holbrook SR: MERNA database. [http://merna.lbl.gov/].

145. Cowan JA: Metallobiochemistry of RNA. $\mathbf{C o}\left(\mathrm{NH}_{3}\right)_{6}{ }^{3+}$ as a probe for $\mathrm{Mg}^{2+}(\mathrm{aq})$ binding sites. J Inorg Biochem 1993, 49(3): $|7|-\mid 75$.

146. Ennifar E, Walter P, Dumas P: A crystallographic study of the binding of 13 metal ions to two related RNA duplexes. Nucleic Acids Res 2003, 3 I ( I 0):267|-2682.

147. Ban N, Nissen P, Hansen J, Moore PB, Steitz TA: The complete atomic structure of the large ribosomal subunit at $2.4 \AA$ resolution. Science 2000, 289(548I):905-920.

148. Fedorov R, Meshcheryakov V, Gongadze G, Fomenkova N, Nevskaya N, Selmer M, Laurberg M, Kristensen O, Al-Karadaghi S, Liljas A, et al.: Structure of ribosomal protein TL5 complexed with RNA 
provides new insights into the CTC family of stress proteins. Acta Crystallogr D Biol Crystallogr 200 I, 57:968-976.

149. Murray JB, Szoke H, Szoke A, Scott WG: Capture and visualization of a catalytic RNA enzyme-product complex using crystal lattice trapping and $\mathbf{X}$-ray holographic reconstruction. Mol Cell 2000, 5(2):279-287.

150. Selmer M, Dunham CM, Murphy FV, Weixlbaumer A, Petry S, Kelley AC, Weir JR, Ramakrishnan V: Structure of the 705 ribosome complexed with mRNA and tRNA. Science 2006, 313(5795): 1935-1942.

15I. Lilley DMJ: The origins of RNA catalysis in ribozymes. Trends Biochem Sci 2003, 28(9):495-50I.

152. Fedor MJ, Williamson JR: The catalytic diversity of RNAs. Nat Rev Mol Cell Biol 2005, 6(5):399-4I2.

153. Doudna JA, Lorsch JR: Ribozyme catalysis: not different, just worse. Nat Struct Mol Biol 2005, I 2(5):395-402

154. Walter NG: Ribozyme catalysis revisited: Is water involved? Mol Cell 2007, 28(6):923-929.

155. Sigel RKO, Pyle AM: Alternative roles for metal ions in enzyme catalysis and the implications for ribozyme chemistry. Chem Rev 2007, I07(I):97-II3.

156. Ciesiolka J, Yarus M: Small RNA-divalent domains. RNA 1996 , 2(8):785-793.

157. Borda EJ, Markley JC, Sigurdsson ST: Zinc-dependent cleavage in the catalytic core of the hammerhead ribozyme: evidence for a pH-dependent conformational change. Nucleic Acids Res 2003, 3 I ( I 0):2595-2600.

158. Dange V, Van Atta RB, Hecht SM: A Mn ${ }^{2+}$-dependent ribozyme. Science 1990, 248(4955):585-588.

159. Kolev NG, Hartland El, Huber PW: A manganese-dependent ribozyme in the 3'-untranslated region of Xenopus $\mathbf{V g I}$ mRNA. Nucleic Acids Res 2008, 36(I7):5530-5539.

160. Christian EL, Yarus M: Metal coordination sites that contribute to structure and catalysis in the group I intron from Tetrahymena. Biochemistry 1993, 32(17):4475-4480.

161. Piccirilli JA, Vyle JS, Caruthers MH, Cech TR: Metal ion catalysis in the Tetrahymena ribozyme reaction. Nature 1993 , 36 I (6407):85-88

162. Basu S, Strobel SA: Thiophilic metal ion rescue of phosphorothioate interference within the Tetrahymena ribozyme $\mathbf{P 4}$ P6 domain. RNA 1999, 5(I I): I399-I407.

163. Shan S, Kravchuk AV, Piccirilli JA, Herschlag D: Defining the catalytic metal ion interactions in the Tetrahymena ribozyme reaction. Biochemistry 200I, 40(17):5161-5I7I.

164. Shan S, Yoshida A, Sun S, Piccirilli JA, Herschlag D: Three metal ions at the active site of the Tetrahymena group I ribozyme. Proc Natl Acad Sci USA 1999, 96(22): $12299-12304$.

165. Weinstein LB, Jones BC, Cosstick R, Cech TR: A second catalytic metal ion in group I ribozyme. Nature 1997 388(6644):805-808.

166. Yoshida A, Sun S, Piccirilli JA: A new metal ion interaction in the Tetrahymena ribozyme reaction revealed by double sulfur substitution. Nat Struct Biol I999, 6(4):3 I8-32I.

167. DeRose VJ: Metal ion binding to catalytic RNA molecules. Curr Opin Struct Biol 2003, I3(3):3 I7-324.

168. Meares CF, Datwyler SA, Schmidt BD, Owens J, Ishihama A: Principles and methods of affinity cleavage in studying transcription. Meth Enzymol 2003, 371:82-106.

169. Cohn CA, Borda MJ, Schoonen MA: RNA decomposition by pyrite-induced radicals and possible role of lipids during the emergence of life. Earth Planet Sci Lett 2004, 225(3-4):27I-278.

170. Cohn CA, Mueller S, Wimmer E, Leifer N, Greenbaum S, Strongin DR, Schoonen MA: Pyrite-induced hydroxyl radical formation and its effect on nucleic acids. Geochem Trans 2006, 7:3.

17I. Lee MS, Palmer AG, Wright PE: Relationship between $\mathrm{H}^{\prime}$ and $\mathrm{C}^{13}$ NMR chemical shifts and the secondary and tertiary structure of a zinc finger peptide. I Biomolec NMR I992, 2(4):307-322

172. Bombarda E, Grell E, Roques BP, Mely Y: Molecular mechanism of the $\mathrm{Zn}^{2+}$-induced folding of the distal CCHC finger motif of the HIV-I nucleocapsid protein. Biophys / 2007, 93(I):208-2 I7.

173. Yang S, Doolittle RF, Bourne PE: Phylogeny determined by protein domain content. Proc Natl Acad Sci USA 2005, 102(2):373-378.

174. Andreeva A, Howorth D, Chandonia JM, Brenner SE, Hubbard TJ, Chothia C, Murzin AG: Data growth and its impact on the
SCOP database: new developments. Nucleic Acids Res 2008, 36(Database):D419-D425.

175. Concha NO, Rasmussen BA, Bush K, Herzberg O: Crystal structures of the cadmium- and mercury-substituted metallobeta-lactamase from Bacteroides fragilis. Protein Sci 1997, 6( I 2):267|-2676

176. Fusz S, Eisenfuhr A, Srivatsan SG, Heckel A, Famulok M: A ribozyme for the aldol reaction. Chem Biol 2005, I 2(8):94I-950.

177. McDonald AG, Boyce S, Tipton KF: ExplorEnz: the primary source of the IUBMB enzyme list. Nucleic Acids Res 2009 , 37(Database):D593-D597.

178. ExplorEnz database [http://www.enzyme-database.org]

179. Holliday GL, Almonacid DE, Bartlett GJ, O'Boyle NM, Torrance JW, Murray-Rust P, Mitchell JB, Thornton JM: MACiE (Mechanism, Annotation and Classification in Enzymes): novel tools for searching catalytic mechanisms. Nucleic Acids Res 2007, 35(Database):D515-520.

180. MACiE database [http://www.ebi.ac.uk/thornton-srv/databases/ $\mathrm{MACiE} /]$

18I. Andreini C, Bertini I, Cavallaro G, Holliday GL, Thornton JM: Metal ions in biological catalysis: from enzyme databases to general principles. J Biol Inorg Chem 2008, 13(8): 1205-1218.

182. Metal-MACiE database [http://www.ebi.ac.uk/thornton-srv/data bases/Metal MACiE/home.html]

183. Barthelmes J, Ebeling C, Chang A, Schomburg I, Schomburg D: BRENDA, AMENDA and FRENDA: the enzyme information system in 2007. Nucleic Acids Res 2007, 35(Database):D5II-D5|4.

184. Chang A, Scheer M, Grote A, Schomburg I, Schomburg D: BRENDA, AMENDA and FRENDA the enzyme information system: new content and tools in 2009. Nucleic Acids Res 2009, 37(Database):D588-D592.

185. BRENDA database [http://www.brenda-enzymes.org/]

186. Lieder KW, Booker S, Ruzicka FJ, Beinert H, Reed GH, Frey PA: SAdenosylmethionine-dependent reduction of lysine 2,3-aminomutase and observation of the catalytically functional iron-sulfur centers by electron paramagnetic resonance. Biochemistry 1998, 37(8):2578-2585.

187. Pereto J, Lopez-Garcia P, Moreira D: Ancestral lipid biosynthesis and early membrane evolution. Trends Biochem Sci 2004, 29(9):469-477.

188. Rouf MA: Spectrochemical analysis of inorganic elements in Bacteria. J Bacteriol 1964, 88(6): 1545.

189. Outten CE, O'Halloran TV: Femtomolar sensitivity of metalloregulatory proteins controlling zinc homeostasis. Science 200I, 292(5526):2488-2492

190. Timm F: Zur Histochemie des Zinks. Deutsche Zeitschrift für gerichtliche Medizin I958, 47:428-431.

191. Yamamoto Y, Fukui K, Koujin N, Ohya H, Kimura K, Kamio Y: Regulation of the intracellular free iron pool by Dpr provides oxygen tolerance to Streptococcus mutans. J Bacteriol 2004, 186(18):5997-6002.

192. Kakhlon O, Cabantchik Zl: The labile iron pool: Characterization, measurement, and participation in cellular processes. Free Radical Biology and Medicine 2002, 33(8): 1037-1046.

193. Maret W: Crosstalk of the group Ila and Ilb metals calcium and zinc in cellular signaling. Proc Natl Acad Sci USA 200I, 98(22): I $2325-12327$

194. Woese CR, Kandler O, Wheelis ML: Towards a natural system of organisms: Proposal for the domains Archaea, Bacteria, and Eucarya. Proc Natl Acad Sci USA 1990, 87( I 2):4576-4579.

195. Woese C: The universal ancestor. Proc Natl Acad Sci USA 1998 95(12):6854-6859

196. Koonin EV: Comparative genomics, minimal gene-sets and the last universal common ancestor. Nat Rev Microbiol 2003, I(2): $127-136$

197. Mushegian A: Gene content of LUCA, the last universal common ancestor. Front Biosci 2008, 13:4657-4666.

198. Cavalier-Smith T: Rooting the tree of life by transition analyses. Biol Direct 2006, I:19.

199. Glansdorff N, Xu Y, Labedan B: The Last Universal Common Ancestor: emergence, constitution and genetic legacy of an elusive forerunner. Biol Direct 2008, 3:29.

200. Rivera MC, Jain R, Moore JE, Lake JA: Genomic evidence for two functionally distinct gene classes. Proc Natl Acad Sci USA 1998, 95(I I):6239-6244. 
20I. Brochier C, Philippe H, Moreira D: The evolutionary history of ribosomal protein RpSI4: horizontal gene transfer at the heart of the ribosome. Trends Genet 2000, I 6( I 2):529-533.

202. Makarova KS, Ponomarev VA, Koonin EV: Two C or not two C: recurrent disruption of Zn-ribbons, gene duplication, lineage-specific gene loss, and horizontal gene transfer in evolution of bacterial ribosomal proteins. Genome Biol 200I, 2(9RESEARCH 0033 [http://genomebiology.com/2001/2/9/research/ 0033].

203. Kanhere A, Vingron M: Horizontal gene transfers in prokaryotes show differential preferences for metabolic and translational genes. BMC Evol Biol 2009, 9:9.

204. Cao TB, Saier MH Jr: The general protein secretory pathway: phylogenetic analyses leading to evolutionary conclusions. Biochim Biophys Acta 2003, I 609(I): I I 5- I 25.

205. Hilario E, Gogarten JP: The prokaryote-to-eukaryote transition reflected in the evolution of the V/F/A-ATPase catalytic and proteolipid subunits. J Mol Evol I998, 46(6):703-7/5.

206. Jekely G: Did the last common ancestor have a biological membrane? Biol Direct 2006, I:35.

207. Könnyü B, Czárán T, Szathmáry E: Prebiotic replicase evolution in a surface-bound metabolic system: parasites as a source of adaptive evolution. BMC Evol Biol 2008, 8:

208. Koonin EV: On the origin of cells and viruses: A comparativegenomic perspective. Isr J Ecol Evol 2006, 52(3-4):299-3 I8.

209. Zhang YS, Zhang ZY, Suzuki K, Maekawa T: Uptake and mass balance of trace metals for methane producing bacteria. Biomass and Bioenergy 2003, 25(4):427-433.

210. luchi S, Kudell N, eds: Zinc Finger Proteins: From Atomic Contact to Cellular Function. New York: Kluwer Academic/Plenum Publishers; 2007.

21 I. Lachenmann MJ, Ladbury JE, Dong J, Huang K, Carey P, Weiss MA: Why zinc fingers prefer zinc: ligand-field symmetry and the hidden thermodynamics of metal ion selectivity. Biochemistry 2004, 43(44): I 3910-13925.

212. Hanas JS, Larabee JL, Hocker JR: Zinc finger interactions with metals and other small molecules. In Zinc Finger Proteins: From Atomic Contact to Cellular Function Edited by: luchi S, Kudell N. New York: Kluwer Academic/Plenum Publishers; 2007:39-46.

213. Mushegian AR, Koonin EV: A minimal gene set for cellular life derived by comparison of complete bacterial genomes. Proc Natl Acad Sci USA 1996, 93(19): 10268-10273.

214. Koonin EV: How many genes can make a cell: the minimalgene-set concept. Annu Rev Genomics Hum Genet 2000, I:99-I I 6.

215. Charlebois RL, Doolittle WF: Computing prokaryotic gene ubiq uity: rescuing the core from extinction. Genome Res 2004 I 4( I 2):2469-2477.

216. Danchin A, Fang G, Noria S: The extant core bacterial proteorne is an archive of the origin of life. Proteomics 2007, 7(6):875-889.

217. Arluison V, Hountondji C, Robert B, Grosjean H: Transfer RNApseudouridine synthetase Pus I of Saccharomyces cerevisiae contains one atom of zinc essential for its native conformation and tRNA recognition. Biochemistry 1998 , 37(20):7268-7276.

218. Belrhali $H$, Yaremchuk A, Tukalo $M$, Berthet-Colominas $C$, Rasmus sen $B$, Bosecke $P$, Diat $O$, Cusack $S$ : The structural basis for seryladenylate and Ap4A synthesis by seryl-tRNA synthetase. Structure 1995, 3(4):341-352.

219. Bilokapic S, Maier T, Ahel D, Gruic-Sovulj I, Soll D, Weygand-Durasevic I, Ban N: Structure of the unusual seryl-tRNA synthetase reveals a distinct zinc-dependent mode of substrate recognition. EMBO J 2006, 25(I I):2498-2509.

220. Crepin T, Schmitt E, Blanquet S, Mechulam Y: Three-dimensiona structure of methionyl-tRNA synthetase from Pyrococcus abyssi. Biochemistry 2004, 43(9):2635-2644.

221. Schmitt E, Moulinier L, Fujiwara S, Imanaka T, Thierry IC, Moras D: Crystal structure of aspartyl-tRNA synthetase from Pyrococcus kodakaraensis KOD: archaeon specificity and catalytic mechanism of adenylate formation. EMBO J 1998 I 7( I 7):5227-5237.

222. Fukai S, Nureki O, Sekine S, Shimada A, Tao J, Vassylyev DG, Yokoyama S: Structural basis for double-sieve discrimination of L-valine from L-isoleucine and L-threonine by the complex of tRNAVal and valyl-tRNA synthetase. Cell 2000, I 03(5):793-803
223. Landro JA, Schmidt E, Schimmel P, Tierney DL, Penner-Hahn JE: Thiol ligation of two zinc atoms to a class I tRNA synthetase: evidence for unshared thiols and role in amino acid binding and utilization. Biochemistry 1994, 33(47): |4213-|4220.

224. Nakama T, Nureki O, Yokoyama S: Structural basis for the recognition of isoleucyl-adenylate and an antibiotic, mupirocin, by isoleucyl-tRNA synthetase. J Biol Chem 200I, 276(50):47387-47393.

225. Cusack S, Yaremchuk A, Tukalo M: The 2 A crystal structure of leucyl-tRNA synthetase and its complex with a leucyl-adenylate analogue. EMBO J 2000, I9(I 0):235I-236I

226. Sankaranarayanan R, Dock-Bregeon AC, Rees B, Bovee M, Caillet J Romby $P$, Francklyn CS, Moras D: Zinc ion mediated amino acid discrimination by threonyl-tRNA synthetase. Nat Struct Biol 2000, 7(6):46I-465.

227. Kamtekar S, Kennedy WD, Wang J, Stathopoulos C, Soll D, Steitz TA: The structural basis of cysteine aminoacylation of tRNAPro by prolyl-tRNA synthetases. Proc Natl Acad Sci USA 2003. I00(4): I673-1678

228. Crepin T, Yaremchuk A, Tukalo M, Cusack S: Structures of two bacterial prolyl-tRNA synthetases with and without a cisediting domain. Structure 2006, |4( I 0): I5I|-| 525

229. Ishijima J, Uchida Y, Kuroishi C, Tuzuki C, Takahashi N, Okazaki N, Yutani K, Miyano M: Crystal structure of alanyl-tRNA synthetase editing-domain homolog (PH0574) from a hyperthermophile, Pyrococcus horikoshii OT3 at I.45 A resolution. Proteins 2006, 62(4): I |33-I| 37.

230. Cho S, Hoffman DW: Structure of the beta subunit of translation initiation factor 2 from the archaeon Methanococcus jannaschii : a representative of the elF2beta/elF5 family of proteins. Biochemistry 2002, 4 I ( I 8):5730-5742.

23I. Minakhin L, Bhagat S, Brunning A, Campbell EA, Darst SA, Ebright RH, Severinov K: Bacterial RNA polymerase subunit omega and eukaryotic RNA polymerase subunit RPB6 are sequence, structural, and functional homologs and promote RNA polymerase assembly. Proc Natl Acad Sci USA 2001, 98(3):892-897.

232. Batra VK, Beard WA, Shock DD, Pedersen LC, Wilson SH: Structures of DNA polymerase beta with active-site mismatches suggest a transient abasic site intermediate during misincorporation. Mol Cell 2008, 30(3):3 I 5-324.

233. Podobnik M, Weitze TF, O'Donnell M, Kuriyan J: Nucleotideinduced conformational changes in an isolated Escherichia coli DNA polymerase III clamp loader subunit. Structure 2003, I I(3):253-263.

234. Hecker A, Leulliot N, Gadelle D, Graille M, Justome A, Dorlet P, Brochier C, Quevillon-Cheruel S, Le Cam E, van Tilbeurgh H, et al.: An archaeal orthologue of the universal protein Kael is an iron metalloprotein which exhibits atypical DNA-binding properties and apurinic-endonuclease activity in vitro. Nucleic Acids Res 2007, 35( I 8):6042-605I.

235. Bartolucci S, De Simone G, Galdiero S, Improta R, Menchise V, Pedone C, Pedone E, Saviano M: An integrated structural and computational study of the thermostability of two thioredoxin mutants from Alicyclobacillus acidocaldarius. J Bacterio 2003, 185(14):4285-4289.

236. Regni C, Naught L, Tipton PA, Beamer LJ: Structural basis of diverse substrate recognition by the enzyme PMM/PGM from $\boldsymbol{P}$. aeruginosa. Structure 2004, I 2(I):55-63.

237. Tsukazaki T, Mori H, Fukai S, Ishitani R, Mori T, Dohmae N, Perederina A, Sugita Y, Vassylyev DG, Ito K, et al:: Conformational transition of Sec machinery inferred from bacterial SecYE structures. Nature 2008, 455(72 I 5):988-99।

238. Corn JE, Pease PJ, Hura GL, Berger JM: Crosstalk between primase subunits can act to regulate primer synthesis in trans. Mol Cell 2005, 20(3):39l-40I

239. Abdullah KM, Lo RY, Mellors A: Cloning, nucleotide sequence, and expression of the Pasteurella haemolytica Al glycoprotease gene. J Bacteriol I99I, I 73( I 8):5597-5603.

240. Hecker A, Graille M, Madec E, Gadelle D, Le Cam E, van Tilbergh H, Forterre $P$ : The universal Kael protein and the associated Bud32 kinase (PRPK), a mysterious protein couple probably essential for genome maintenance in Archaea and Eukarya. Biochem Soc Trans 2009, 37(I):29-35

24I. Irving H, Williams RJP: Order of stability of metal complexes. Nature 1948, I 62(4 I 23):746-747. 
242. Griffin PJ, Fogarty WM: Physicochemical properties of native, zinc-prepared and manganese-prepared metalloprotease of Bacillus polymyxa. Appl Microbiol 1973, 26(2): I9|-195.

243. Vallee BL, Coleman JE, Auld DS: Zinc fingers, zinc clusters, and zinc twists in DNA-binding protein domains. Proc Natl Acad Sci USA 1991, 88(3):999-1003.

244. Cody GD: Transition metal sulfides and the origins of metabolism. Annual Review of Earth and Planetary Sciences 2004, 32:569-599.

245. Maret W: Zinc and sulfur: A critical biological partnership. Biochemistry 2004, 43( I 2):330 I-3309.

246. Maret W: Exploring the zinc proteome. I Analyt Atom Spectrom 2004, I9(I): I5-19.

247. Vallee BL, Falchuk $\mathrm{KH}$ : The biochemical basis of zinc physiology. Physiol Rev 1993, 73( (I):79-I I8.

248. Vallee BL, Auld DS: Zinc: biological functions and coordination motifs. Acc Chem Res 1993, 26( I 0):543-55I.

249. Blindauer CA, Sadler PJ: How to hide zinc in a small protein. Acc Chem Res 2005, 38(I):62-69.

250. Andreini C, Banci L, Bertini I, Rosato A: Zinc through the three domains of life. J Proteome Res 2006, 5(I I):3I73-3I78.

25I. Andreini C, Banci L, Bertini I, Elmi S, Rosato A: Non-heme iron through the three domains of life. Proteins 2007, 67(2):317-324.

252. Margoshes $M$, Vallee BL: A cadmium protein from equine kidney cortex. J Am Chem Soc 1957, 79(17):4813-4814.

253. San Pietro A, Lang HM: Photosynthetic pyridine nucleotide reductase. I. Partial purification and properties of the enzyme from spinach. J Biol Chem 1958, 23 I (I):2I I-229.

254. Iwasaki T, Kounosu A, Tao Y, Li Z, Shokes JE, Cosper NJ, Imai T, Urushiyama A, Scott RA: Rational design of a mononuclear metal site into the archaeal Rieske-type protein scaffold. Biol Chem 2005, 280(1 0):9129-9I34.

255. Meyer J: Iron-sulfur protein folds, iron-sulfur chemistry, and evolution. I Biol Inorg Chem 2008, I3(2): I57-I70.

256. Ramelot TA, Cort JR, Goldsmith-Fischman S, Kornhaber GJ, Xiao R, Shastry R, Acton TB, Honig B, Montelione GT, Kennedy MA: Solution NMR structure of the iron-sulfur cluster assembly protein $\mathbf{U}$ (IscU) with zinc bound at the active site. J Mol Biol 2004, 344(2):567-583.

257. Shimomura $Y$, Wada K, Fukuyama $K$, Takahashi $Y$ : The asymmetric trimeric architecture of [2Fe-2S] IscU: Implications for its scaffolding during iron-sulfur cluster biosynthesis. J Mol Biol 2008, 383(I): I33-143

258. Luther GW, Rickard DT: Metal sulfide cluster complexes and their biogeochemical importance in the environment. Journal of Nanoparticle Research 2005, 7(4-5):389-407.

259. Seewald JS, Seyfried WE: The effect of temperature on metal mobility in subseafloor hydrothermal systems: constraints from basalt alteration experiments. Earth and Planetary Science Letters 1990, I0I(2-4):388-403.

260. Tivey MK: How to build a black smoker chimney. Oceanus 1998 , $4 I(2): 22-26$

26I. Galley AG, Hannington MD, Jonasson IR: Volcanogenic massive sulphide deposits. Mineral Deposits of Canada: A Synthesis of Major Deposit-Types, District Metallogeny, the Evolution of Geological Provinces, and Exploration Methods: Geological Association of Canada, Mineral Deposits Division, Special Publication No 5 2007:141-16I.

262. $\mathrm{Xu} Y$, Schoonen MAA: The absolute energy positions of conduction and valence bands of selected semiconducting $\mathrm{min}$ erals. Am Mineral 2000, 85(3-4):543-556.

263. Furdyna JK: Diluted magnetic semiconductors. J Appl Phys 1988 64(4):R29-R64

264. Schoonen M, Smirnov A, Cohn C: A perspective on the role of minerals in prebiotic synthesis. Ambio 2004, 33(8):539-55।.

265. Franklin JM, Lydon JW, Sangster DF: Volcanic-associated massive sulfide deposits. Economic Geology, 75th Anniversary Volume 1981:485-627

266. Kobayashi M, Shimizu S: Cobalt proteins. Eur J Biochem 1999, 26 I(I): I-9.

267. Lunel T, Rudnicki M, Elderfield $H$, Hydes $D$ : Aluminum as a depthsensitive tracer of entrainment in submarine hydrothermal plumes. Nature 1990, 344(6262): |37-139.

268. Cairns-Smith AG: Chemistry and the missing era of evolution. Chemistry 2008, I4(13):3830-3839.

269. Westall F, de Ronde CEJ, Southam G, Grassineau N, Colas M, Cockell C, Lammer $\mathrm{H}$ : Implications of a 3.472-3.333 Gyr-old subaerial microbial mat from the Barberton greenstone belt, South Africa for the UV environmental conditions on the early Earth. Philos Trans R Soc Lond B Biol Sci 2006, 36 I ( I 474): I 857- I875.

270. Mulkidjanian AY, Junge $W$ : On the origin of photosynthesis as inferred from sequence analysis. A primordial UV-protector as common ancestor of reaction centers and antenna proteins. Photosynthesis Research 1997, 5 I (I):27-42.

27I. Vermaas WF: Evolution of heliobacteria: implications for photosynthetic reaction center complexes. Photosynth Res 1994 , 4 I:285-294.

272. Meyer TE: Evolution of photosynthetic reaction centers and light-harvesting chlorophyll proteins. Biosystems 1994, 33(3): $167-175$

273. Olson JM: 'Evolution of Photosynthesis' (1970), re-examined thirty years later. Photosynth Res 200I, 68(2):95-II 2

274. Olson JM, Blankenship RE: Thinking about the evolution of photosynthesis. Photosynth Res 2004, 80(I-3):373-386.

275. Mix LJ, Haig D, Cavanaugh CM: Phylogenetic analyses of the core antenna domain: Investigating the origin of photosystem I. J Mol Evol 2005, 60(2): I53-163.

276. Frigaard NU, Bryant D: Seeing green bacteria in a new light: genomics-enabled studies of the photosynthetic apparatus in green sulfur bacteria and filamentous anoxygenic phototrophic bacteria. Arch Microbiol 2004, I 82(4):265-276.

277. Jagannathan B, Golbeck JH: Unifying principles in homodimeric type I photosynthetic reaction centers: Properties of PscB and the F-A, F-B and F-X iron-sulfur clusters in green sulfur bacteria. Biochim Biophys Acta 2008, I 777( I 2): I535-I544.

278. Gánti T: The Principles of Life. Oxford: Oxford University Press; 2003

279. Butlerov AM: Formation synthétique d'une substance sucreé. CR Acad Sci I86I, 53:145-147.

280. Müller D, Pitsch S, Kittaka A, Wagner E, Wintner CE, Eschenmoser A: Aldomerisierung von Glycolaldehyd-phosphat zu racemischen Hexose-2,4,6-triphosphaten und (in Gegenwart von Formaldehyd) racemischen Pentose-2,4-diphosphaten: racAllose-2,4,6-triphosphat und rac-Ribose-2,4-diphosphat sind die Reaktionshauptprodukte. Helvetica Chimica Acta 1990, 73(5): | $410-1468$.

28I. Pestunova O, Simonov A, Snytnikov V, Stoyanovsky V, Parmon V: Putative mechanism of the sugar formation on prebiotic Earth initiated by UV-radiation. Advances in Space Research 2005, 36(2):214-219.

282. Nies DH, Silver S, eds: Molecular Microbiology of Heavy Metals. Berlin: Springer-Verlag; 2007

283. Koch AL: What size should a bacterium be? A question of scale. Annu Rev Microbiol 1996, 50:317-348.

284. Dominski Z: Nucleases of the metallo-beta-lactamase family and their role in DNA and RNA metabolism. Crit Rev Biochem Mol Biol 2007, 42(2):67-93.

285. Schaeffer D, Tsanova B, Barbas A, Reis FP, Dastidar EG, Sanchez Rotunno M, Arraiano CM, van Hoof $A$ : The exosome contains domains with specific endoribonuclease, exoribonuclease and cytoplasmic mRNA decay activities. Nat Struct Mol Biol 2009, I 6(I):56-62

286. Darwin C. The life and letters of Charles Darwin, including an autobiographical chapter. Volume 3. London: John Murray; I887.

287. Poole AM, Penny D: Evaluating hypotheses for the origin of eukaryotes. BioEssays 2007, 29(I):74-84.

288. Yutin N, Makarova KS, Mekhedov SL, Wolf YI, Koonin EV: The deep archaeal roots of eukaryotes. Mol Biol Evol 2008 25(8): $1619-1630$.

289. Zillig W, Palm P, Klenk H-P: A model of the early evolution of organisms: the arisal of the three domains of life from the common ancestor. In The Origin and Evolution of the Cell Edited by: Hartman H, Matsuno K. Singapore: World Scientific Publishing; 1992:163-182.

290. Gogarten-Boekels M, Hilario E, Gogarten JP: The effects of heavy meteorite bombardment on the early evolution - the emergence of the three domains of life. Orig Life Evol Biosph 1995 25(I-3):25I-264

29l. Nisbet EG, Fowler CMR: Archaean metabolic evolution of microbial mate. Proc $R$ Soc Lond B Biol Sci 1999 266( I 436):2375-2382 
292. Doolittle WF: You are what you eat: a gene transfer ratchet could account for bacterial genes in eukaryotic nuclear genomes. Trends Genet 1998, I4(8):307-3I I

293. Margulis L: Symbiosis in Cell Evolution: Life and Its Environment on the Early Earth. San Francisco: W.H.Freeman; I98I.

294. Skulachev VP: Role of uncoupled and non-coupled oxidations in maintenance of safely low levels of oxygen and its one-electron reductants. $Q$ Rev Biophys 1996, 29(2): I69-202.

295. Vellai T, Takacs K, Vida G: A new aspect to the origin and evoIution of eukaryotes. J Mol Evol 1998, 46(5):499-507.

296. Embley TM, Martin W: Eukaryotic evolution, changes and challenges. Nature 2006, 440(7084):623-630.

297. Mulkidjanian AY, Koonin EV, Makarova KS, Mekhedov SL, Sorokin A, Wolf YI, Dufresne A, Partensky F, Burd H, Kaznadzey D, et al.: The cyanobacterial genome core and the origin of photosynthesis. Proc Natl Acad Sci USA 2006, I03(35): I3126-13131.

298. Tice MM, Lowe DR: Photosynthetic microbial mats in the 3,4 I 6-Myr-old ocean. Nature 2004, 43 I (7008):549-552.

299. Tice MM, Lowe DR: Hydrogen-based carbon fixation in the earliest known photosynthetic organisms. Geology 2006, 34(I):37-40

300. Schäfer G, Engelhard M, Müller V: Bioenergetics of the archaea. Microbiol Mol Biol Rev 1999, 63(3):570-620.

30I. Thauer RK, Kaster AK, Seedorf H, Buckel W, Hedderich R: Methanogenic archaea: ecologically relevant differences in energy conservation. Nat Rev Microbiol 2008, 6(8):579-59l.

302. Koga $\mathrm{Y}$, Morii $\mathrm{H}$ : Biosynthesis of ether-type polar lipids in archaea and evolutionary considerations. Microbiol Mol Biol Rev 2007, 7 I (I):97-I20.

303. Mulkidjanian AY, Galperin MY, Makarova KS, Wolf YI, Koonin EV: Evolutionary primacy of sodium bioenergetics. Biol Direct 2008, 3:13.

304. Jarrell KF, McBride MJ: The surprisingly diverse ways that prokaryotes move. Nat Rev Microbiol 2008, 6(6):466-476.

305. Makarova KS, Aravind L, Galperin MY, Grishin NV, Tatusov RL, Wolf YI, Koonin EV: Comparative genomics of the Archaea (Euryarchaeota): evolution of conserved protein families, the stable core, and the variable shell. Genome Res 1999, 9(7):608-628.

306. Koonin EV, Wolf Yl: Genomics of bacteria and archaea: the emerging dynamic view of the prokaryotic world. Nucleic Acids Res 2008, 36(2I):6688-6719.

307. Urakawa H, Dubilier N, Fujiwara Y, Cunningham DE, Kojima S, Stah DA: Hydrothermal vent gastropods from the same family (Provannidae) harbour epsilon- and gamma-proteobacterial endosymbionts. Environ Microbiol 2005, 7(5):750-754

308. Kouris A, Juniper SK, Frebourg G, Gaill F: Protozoan-bacterial symbiosis in a deep-sea hydrothermal vent folliculinid ciliate (Folliculinopsis sp.) from the Juan de Fuca Ridge. Marine Ecology 2007, 28(I):63-7I.

309. MacPherson S, Larochelle M, Turcotte B: A fungal family of transcriptional regulators: The zinc cluster proteins. Microbiol Mol Biol Rev 2006, 70(3):583-604.

310. Panina EM, Mironov AA, Gelfand MS: Comparative genomics of bacterial zinc regulons: Enhanced ion transport, pathogenesis, and rearrangement of ribosomal proteins. Proc Natl Acad Sci USA 2003, I00(17):9912-9917.

31I. Andreini C, Banci L, Bertini I, Rosato A: Occurrence of copper proteins through the three domains of life: $A$ bioinformatic approach. J Proteome Res 2008, 7(I):209-2I6.

312. Lill R, Mühlenhoff $U$ : Maturation of iron-sulfur proteins in eukaryotes: mechanisms, connected processes, and diseases. Annu Rev Biochem 2008, 77:669-700.

313. Panek $H$, O'Brian MR: A whole genome view of prokaryotic haem biosynthesis. Microbiology 2002, I 48:2273-2282.

314. Battistuzzi FU, Feijao A, Hedges SB: A genomic timescale of prokaryote evolution: insights into the origin of methanogenesis, phototrophy, and the colonization of land. BMC Evol Biol 2004, 4:44.

315. Niemeyer CM: Nanoparticles, proteins, and nucleic acids: Biotechnology meets materials science. Angew Chem Int Ed Engl 200I, 40(22):4I28-4I58.

316. Parak WJ, Gerion D, Pellegrino T, Zanchet D, Micheel C, Williams SC, Boudreau R, Le Gros MA, Larabell CA, Alivisatos AP: Biological applications of colloidal nanocrystals. Nanotechnology 2003 I4(7):RI5-R27.
317. Katz E, Willner I: Integrated nanoparticle-biomolecule hybrid systems: Synthesis, properties, and applications. Angew Chem Int Ed Engl 2004, 43(45):6042-6I08.

318. Alivisatos AP, Gu WW, Larabell C: Quantum dots as cellular probes. Annu Rev Biomed Eng 2005, 7:55-76.

319. Hoffmann N: Photochemical reactions as key steps in organic synthesis. Chem Rev 2008, I 08(3): I052-I 103.

320. Marinkovic S, Hoffmann N: Efficient radical addition of tertiary amines to electron-deficient alkenes using semiconductors as photochemical sensitisers. Chem Commun (Camb) 2001:1576-1577.

321. Marinkovic S, Hoffmann N: Semiconductors as sensitisers for the radical addition of tertiary amines to electron deficient alkenes. Int J Photoenergy 2003, 5(3): 175-182.

322. Marinkovic S, Hoffmann N: Diastereoselective radical tandem addition-cyclization reactions of aromatic tertiary amines by semiconductor-sensitized photochemical electron transfer. Eur J Org Chem 2004:3 102-3107.

323. Pratt AC: Photoreactions of compounds containing heteroatoms other than oxygen. In Photochemistry Volume 33. London: Royal Society of Chemistry; 2002:242-306.

324. Boucher Y, Douady CJ, Papke RT, Walsh DA, Boudreau MER, Nesbo CL, Case RJ, Doolittle WF: Lateral gene transfer and the origins of prokaryotic groups. Annu Rev Genet 2003, 37:283-328.

325. Schwartz AW: Phosphorus in prebiotic chemistry. Philos Trans $R$ Soc Lond B Biol Sci 2006, 36 I ( I 474): 1743-1749.

326. Skulachev VP: Biochemical mechanisms of evolution and the role of oxygen. Biochemistry (Moscow) 1998, 63( I I): I335-1343.

327. Raymond J, Segre D: The effect of oxygen on biochemical networks and the evolution of complex life. Science 2006, 3 I I(5768): I764-I767.

328. Vallee BL, Gibson JG: The zinc content of whole blood, plasma, leukocytes and erythrocytes in the anemias. Blood 1949 , 4(5):455-466.

329. Fosmire GJ: Zinc toxicity. Am J Clin Nutr 1990, 5 I (2):225-227.

330. Glasner ME, Bergman NH, Bartel DP: Metal ion requirements for structure and catalysis of an RNA ligase ribozyme. Biochemistry 2002, 4 I(25):8103-8II 2.

331. Lawrence MS, Bartel DP: New ligase-derived RNA polymerase ribozymes. RNA 2005, I I(8): I I73-I I80.

332. Zivarts M, Liu Y, Breaker RR: Engineered allosteric ribozymes that respond to specific divalent metal ions. Nucleic Acids Res 2005, 33(2):622-631

333. Forterre $P$, Philippe $H$ : Where is the root of the universal tree of life? Bioessays 1999, 2 I (1 0):87|-879.

334. Marguet E, Forterre P: Stability and manipulation of DNA at extreme temperatures. Meth Enzymol 200I, 334:205-2I5.

335. Butzow J, Eichhorn GL: Different susceptibility of DNA and RNA to cleavage by metal ions. Nature 1975 , 254(5498):358-359.

Publish with Biomed Central and every scientist can read your work free of charge

"BioMed Central will be the most significant development for disseminating the results of biomedical research in our lifetime. "

Sir Paul Nurse, Cancer Research UK

Your research papers will be:

- available free of charge to the entire biomedical community

- peer reviewed and published immediately upon acceptance

- cited in PubMed and archived on PubMed Centra

- yours - you keep the copyright 